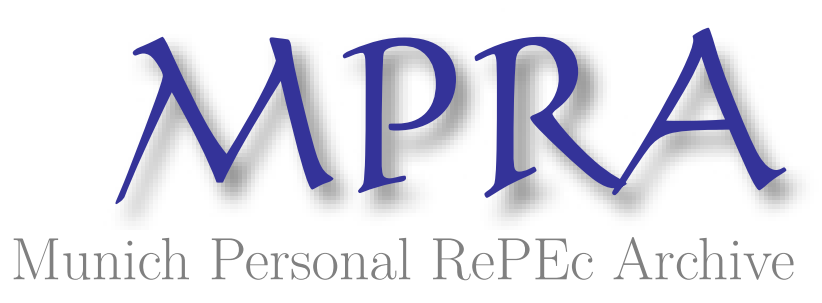

\title{
Essays on Experimental Investigation of Lottery Contests
}

Sheremeta, Roman

August 2009

Online at https://mpra.ub.uni-muenchen.de/49888/

MPRA Paper No. 49888, posted 18 Sep 2013 06:55 UTC 
ESSAYS ON EXPERIMENTAL INVESTIGATION OF LOTTERY CONTESTS

\author{
A Dissertation \\ Submitted to the Faculty \\ of \\ Purdue University \\ by \\ Roman M. Sheremeta \\ In Partial Fulfillment of the \\ Requirements for the Degree \\ of \\ Doctor of Philosophy
}

August 2009

Purdue University

West Lafayette, Indiana 
Для слави Христа.

Присвячується моїм батькам за їхню самовіддану підтримку і любов.

For the glory of Christ.

To my parents for their devotion, unconditional support and enduring love. 


\section{ACKNOWLEDGMENTS}

This dissertation is a result of perseverance, hard work and most importantly support from many generous and inspiring people.

I am greatly indebted to my advisor Professor Tim Cason who helped me to focus on the important parts of my work and guided me with his insights. Without his discernment, support and countless hours of advising, it would have been much more difficult, if not impossible, to complete this dissertation.

I also want to thank my committee members who were very generous with their time. In particular, I am grateful to Professor Dan Kovenock for helping me to write rigorous economic theory and design accurate economic experiments. Professors Jason Abrevaya, Jack Barron, and Marco Casari provided valuable research feedback and helped to do systematic econometric analysis.

During the time of writing my dissertation I received insightful comments and support from my colleagues. Jingjing Zhang has been a wonderful friend and coauthor. Her kind and heartwarming support is especially appreciated. Subhasish Modak Chowdhury, Levi Mielke, Curtis Price, and Anya Savikhin provided comments and valuable feedback to improve my research.

Finally, I would like to thank my parents and my brother who have been a constant source of spiritual support and enduring love. 
TABLE OF CONTENTS

Page

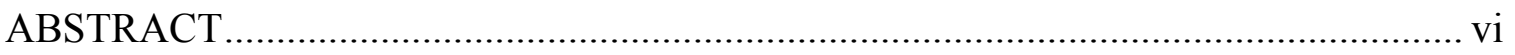

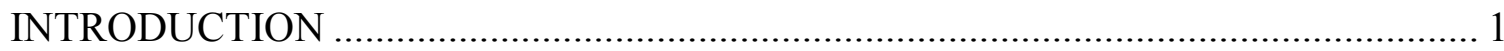

ESSAY 1: CONTEST DESIGN: AN EXPERIMENTAL INVESTIGATION ................ 8

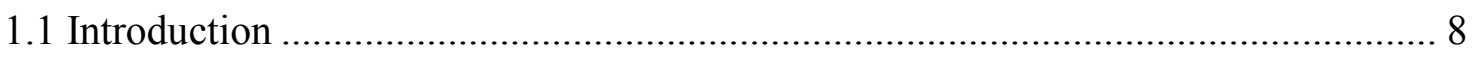

1.2 Theoretical Model ..................................................................................... 11

1.3 Experimental Design and Procedures............................................................. 13

A. Treatments and Hypothesis ..................................................................... 13

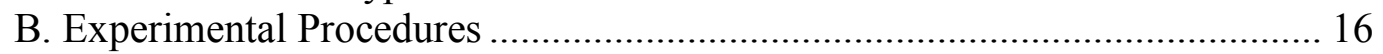

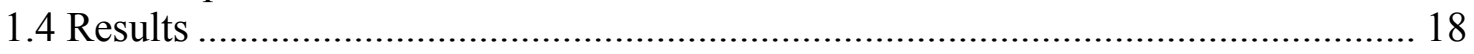

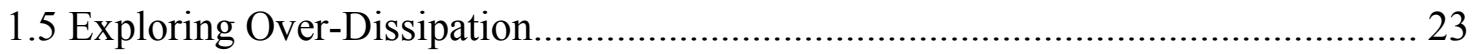

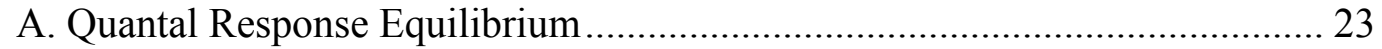

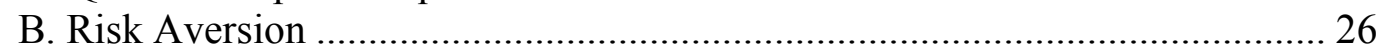

C. Lag Dependence and Assessment of the Random Draw ................................ 28

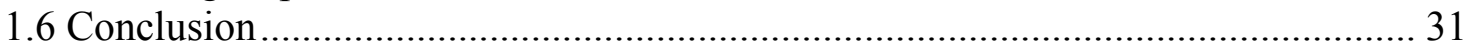

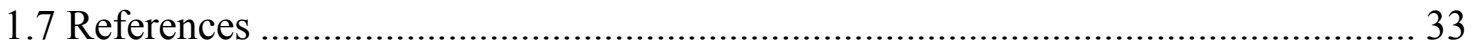

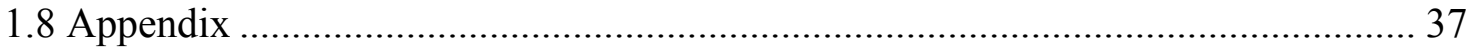

ESSAY 2: EXPERIMENTAL COMPARISON OF MULTI-STAGE AND ONE-STAGE

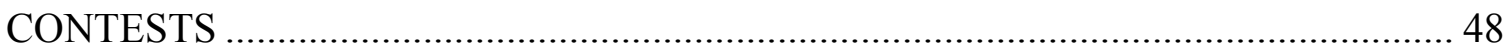

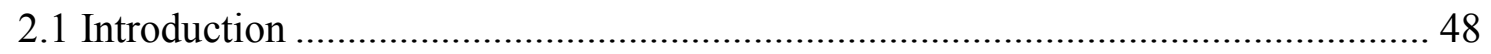

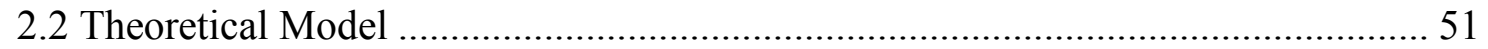

2.3 Experimental Design and Procedures.................................................................. 53

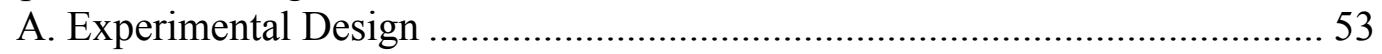

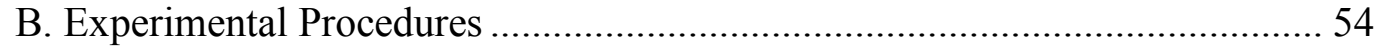

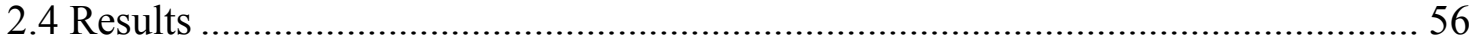

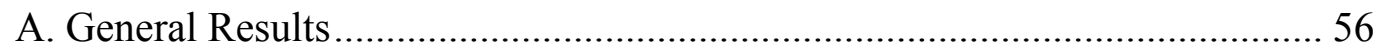

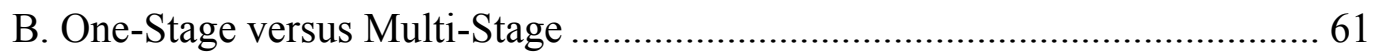

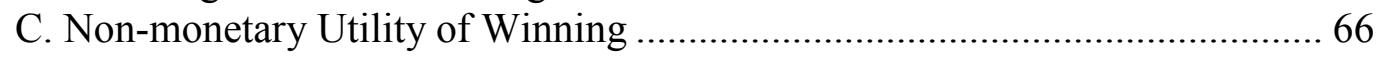

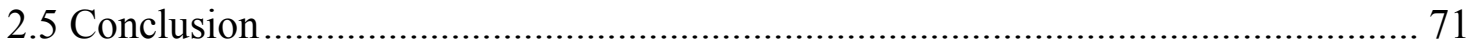

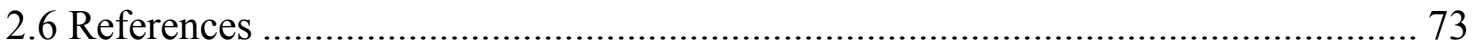

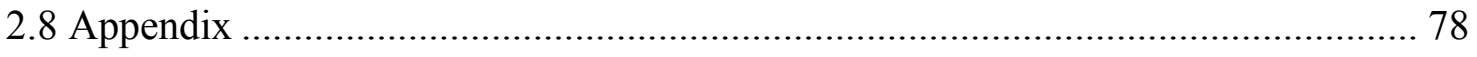


ESSAY 3: EFFORT CARRYOVER AND INFORMATION DISCLOSURE IN TWO

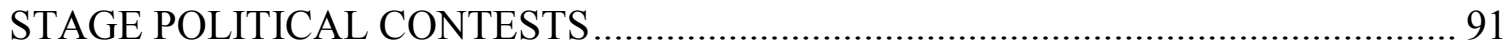

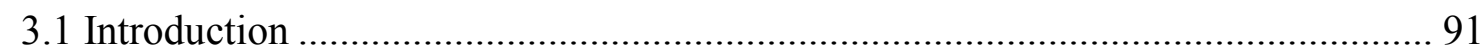

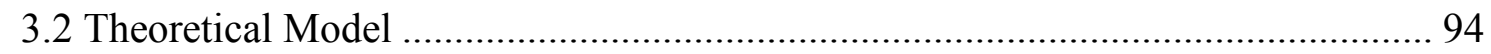

3.3 Experimental Design and Procedures.................................................................... 96

A. Experimental Design and Hypotheses ......................................................... 96

B. Experimental Procedures ....................................................................... 98

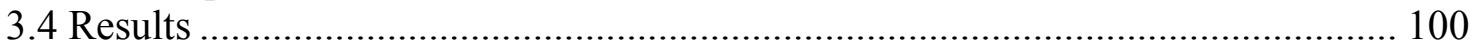

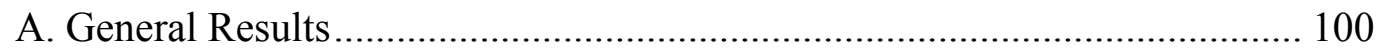

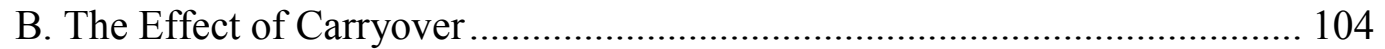

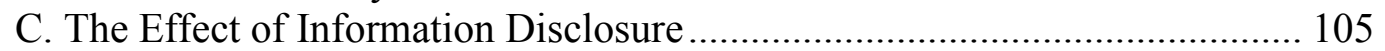

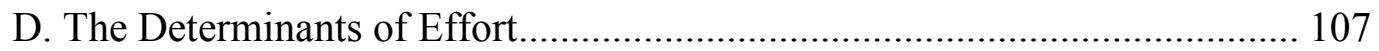

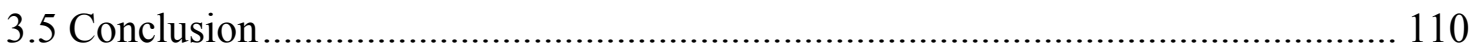

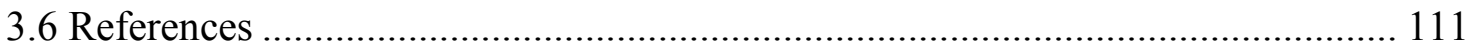

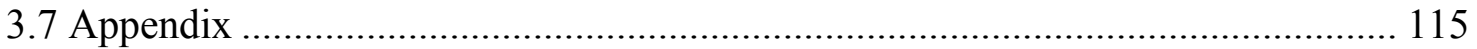

ESSAY 4: PERFECT-SUBSTITUTES, BEST-SHOT, AND WEAKEST-LINK

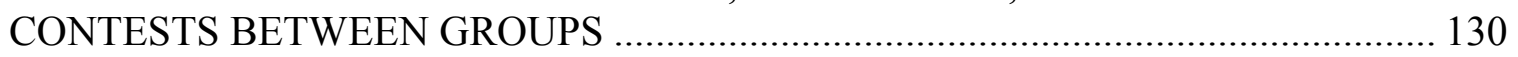

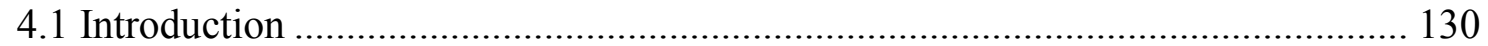

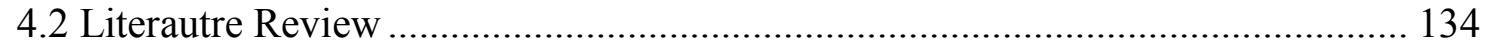

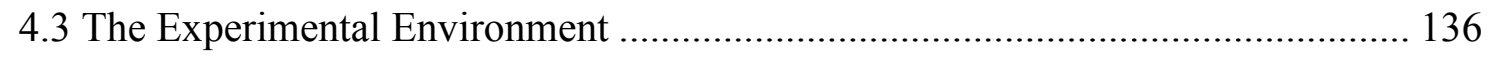

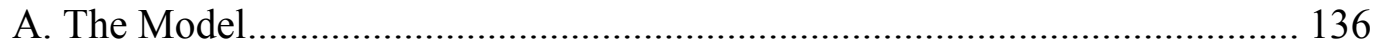

B. Experimental Design and Predictions........................................................... 140

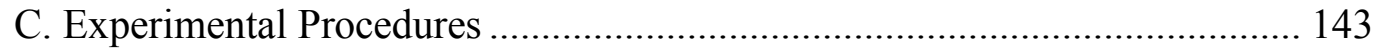

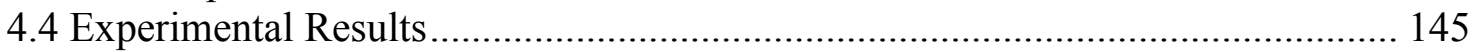

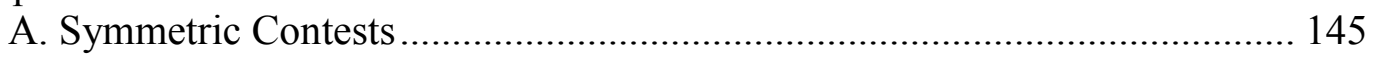

B. Asymmetric Contests ................................................................................ 153

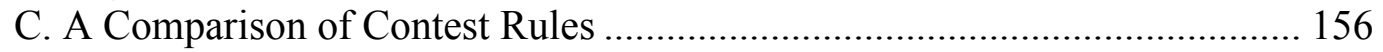

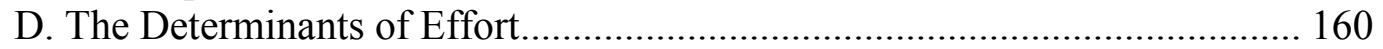

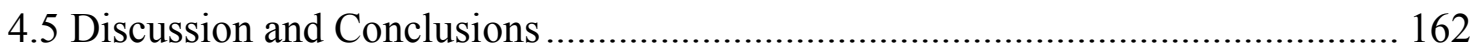

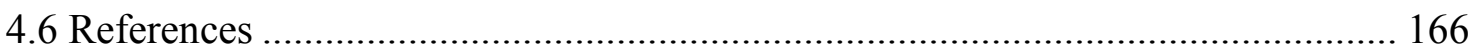

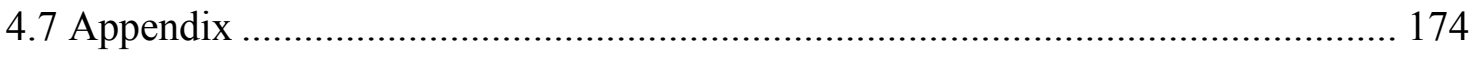

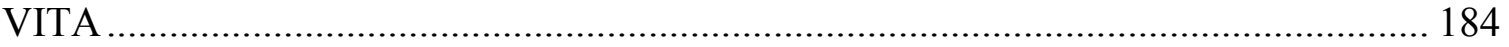




\begin{abstract}
Sheremeta, Roman M. Ph.D., Purdue University, August, 2009. Essays on Experimental Investigation of Lottery Contests. Major Professor: Timothy N. Cason.
\end{abstract}

A contest is a situation in which individuals or groups expend costly resources while competing to win a specific prize. The variety of economic situations that can be described as contests has attracted enormous attention from economic theorists. Despite the extensive theoretical research of contests, very little empirical research has been done to evaluate the theory. This dissertation uses experimental methods to provide empirical investigation of different aspects of contest theory. The dissertation consists of four independent essays.

The first essay experimentally compares the performance of four simultaneous lottery contests: a grand contest, two multiple prize settings (equal and unequal prizes), and a contest which consists of two sub-contests. Consistent with the theory, the grand contest generates the highest effort levels among all simultaneous contests. In multi-prize settings, equal prizes produce lower efforts than unequal prizes. The results also support the argument that joint contests generate higher efforts than an equivalent number of subcontests. The second essay experimentally studies a two-stage elimination contest and compares its performance with a one-stage contest. Contrary to the theory, the two-stage contest generates higher total effort expenditures than the equivalent one-stage contest. 
The third essay investigates the performance of a two-stage elimination contest with effort carryover. Experimental results support all major theoretical predictions: the first stage effort and the total effort expenditures increase in the carryover rate, and the second stage effort decreases in the carryover rate.

Consistent with other experimental studies, there is significant over-dissipation of efforts relative to the equilibrium prediction in all contests. The first essay argues that this over-dissipation can be partially explained by strong endowment size effects. Subjects who receive bigger endowments tend to over-dissipate, while subjects who receive smaller endowments tend to under-dissipate. This behavior is consistent with the predictions of a quantal response equilibrium. The second and third essays provide evidence that winning is a component in a subject's utility and that non-monetary utility of winning is an important factor to explain over-dissipation in contests.

The final essay investigates contests between groups. Each group has one strong player, with a higher valuation for the prize, and two weak players, with lower valuations. In contests where individual efforts are perfect substitutes, both strong and weak players expend significantly higher efforts than predicted by theory. In best-shot contests, where group performance depends on the best performer within the group, most of the effort is expended by strong players while weak players free-ride. In weakest-link contests, where group performance depends on the worst performer within the group, there is almost no free-riding and all players expend similar positive efforts. 


\section{INTRODUCTION}

Costly competitions between economic agents are often portrayed as contests. A contest is a situation in which individuals or groups expend resources while competing to win a specific prize. Examples range from college admissions and competition for promotions to global relationships in which different countries and political parties expend resources to lobby their own interests (Krueger, 1974). The variety of economic situations that can be described as contests has attracted enormous attention from economic theorists. The most popular theories investigating different aspects of contests

are based on the seminal model of rent-seeking introduced by Tullock (1980). The main focus of rent-seeking literature is the relationship between the extent of rent dissipation and underlying contest characteristics such as group size, number of prizes, number of inter-related stages, and rules that regulate interactions (Nitzan, 1994).

Despite the extensive theoretical research of contests, very little empirical research has been done to evaluate the theory (Szymanski, 2003). This is because in the field one can observe only the performance which is a function of effort, ability, and random noise (Ericsson and Charness, 1994). Therefore, it is difficult to measure individual efforts separately from other factors. This dissertation uses experimental methods to provide empirical investigation of different aspects of contest theory. The dissertation consists of four independent essays. 
The first essay contributes to the discussion on contest design. A number of theoretical papers have been devoted to the design of an optimal contest that generates the highest revenue - the total amount of effort expended by the contestants. A common motivation for such research is the objective of various agencies (political parties, lottery administrators, and economic groups) to maximize earnings by extracting the highest effort from the contestants. Overall, it is generally observed in the contest literature that pooling competition generates higher dissipation rates (Clark and Riis, 1998; Amegashie, 2000; Fu and Lu, 2008; Moldovanu and Sela, 2006). Clark and Riis (1998) show that the income maximizing contest administrator obtains the highest rent-seeking effort when, instead of many small prizes, a large prize is provided. Fu and $\mathrm{Lu}$ (2008) demonstrate that the rent dissipation rate increases when the number of contestants and prizes are scaled up. Therefore, the authors conclude that a grand contest generates higher revenue than any set of subcontests. Moldovanu and Sela (2006) investigate a similar problem under the structure of all-pay auctions where all players know their own abilities and the distribution of abilities in the population. The major finding of Moldovanu and Sela (2006) is that independently of the number of contestants and the distribution of abilities, a grand contest generates the highest revenue when the cost function is either linear or concave.

Despite the abundance of theoretical work on contest design, no experimental research has specifically compared alternative contest mechanisms. To begin to bridge this gap, the first essay investigates and compares the performance of four simultaneous contests: a grand contest, two multi-prize settings (equal and unequal prizes), and a contest which consists of two sub-contests. Consistent with the theory, the grand contest 
generates the highest revenue among all simultaneous contests. In multi-prize settings, equal prizes produce lower efforts than unequal prizes. The results also provide strong empirical support for the argument that joint contests generate higher efforts than an equivalent number of sub-contests. However, contrary to the theory, there is significant over-dissipation in all contests. This over-dissipation can be partially explained by strong endowment size effects. Subjects who receive bigger endowments tend to over-dissipate while subjects who receive smaller endowments tend to under-dissipate. This behavior is consistent with the predictions of a quantal response equilibrium. Finally, there is a strong heterogeneity between subjects and expenditures span the entire strategy space, which is clearly inconsistent with the pure strategy equilibrium. Most of these findings can be explained to some extent by differences in risk preference and probabilistic nature of lottery contests.

The majority of rent-seeking studies are based on the assumption that contests last for only one stage. Many contests in practice, however, last for multiple stages. In each stage contestants expend costly efforts in order to advance to the final stage and win the prize. The US presidential race and many other political competitions fall into the category of multi-stage elimination contests. At each stage, candidates use self-promotion and campaign advertisement in order to advance to the final stage and win the election. Another prominent example of multi-stage elimination contests is the international competition for hosting the Olympic Games. In this contest, countries are eliminated at each stage and the resources spent by each country in earlier stages affect the probability of winning the competition in later stages. 
Multi-stage elimination contests have been studied theoretically by Rosen (1986), Clark and Riis (1996), Gradstein (1998), Amegashie (1999), Gradstein and Konrad (1999), Baik and Lee (2000), and Stein and Rapoport (2005). Gradstein and Konrad (1999), for example, consider a multi-stage elimination contest in which a number of parallel contests take place at each stage and only winners are promoted to the next stage. They show that, depending on the contest success function, a multi-stage contest may induce higher effort by the participants than a one-stage contest. Under a lottery contest success function, however, the two structures are equivalent. In the same line of research, Baik and Lee (2000) study a two-stage elimination contest with effort carryovers. In such a contest, players in two groups compete non-cooperatively to win a prize. In the first stage, each group selects a finalist who competes for the prize in the second stage. Firststage efforts are partially (or fully) carried over to the second stage. Baik and Lee (2000) demonstrate that, in the case of player-specific carryovers, rent dissipation increases in the carryover rate and the rent is fully dissipated with full carryover.

The second essay compares the performance of a two-stage elimination contest with an equivalent one-stage contest. The experiment is based on the original model developed by Gradstein and Konrad (1999). The results of the experiment indicate that, contrary to the theory, the two-stage contest generates higher revenue and higher dissipation rates than the equivalent one-stage contest. Over-dissipation is observed in both stages of the two-stage contest and experience diminishes over-dissipation in the first stage but not in the second stage. Multivariate analysis reveals that the variation in individual behavior can be partially explained by the differences in risk preferences. The experiment also provides evidence that winning is a component in a subject's utility and 
that non-monetary utility of winning is an important factor to explain over-dissipation in contests.

The third essay explores the following questions: What is the effect of effort carryover on the behavior of contestants in a two-stage elimination contest? How does the information about the effort carried over by the opponent affect the behavior in different stages of the contest? To answer these questions we experimentally study a twostage elimination contest developed by Baik and Lee (2000). The findings of the experiment indicate that efforts expended in both stages of the competition exceed theoretical predictions, with experience diminishing effort expenditures in the first stage but not in the second stage. Experimental results support all major comparative statics predictions of the theory: the first stage effort and the total effort expenditures increase in the carryover rate, and the second stage effort decreases in the carryover rate. We also find that disclosing information about the opponent's carryover effort increases the second stage effort and decreases the first stage effort.

The final essay investigates contests between groups. Examples of contests between groups include competitions between firms for patents, R\&D competitions between consortia, or election campaigns by political parties. As these contests unfold, conflicts arise within each group and between groups. Members of the same group have incentives to cooperate with each other by contributing individual efforts in order to win a contest. Since effort is costly, each member also has an incentive to abstain from contributing any effort and instead free-ride on the efforts of other members. The amount of free-riding that occurs within a group depends on the composition of the group and the rules that regulate the competition. Members of the same group who have a lower interest 
in winning the competition are more likely to free-ride on the efforts of members who have a higher interest in winning. However, free-riding behavior is unlikely when the performance of the entire group depends crucially on the performance of each member of a group.

The purpose of the final essay is to examine, experimentally, how heterogeneity within and between groups affects group competition, and what impact different contest rules have on effort expended and the amount of free-riding. The experiment employs lottery contests between two groups. Each group has two types of players - one strong player and two weak players. The strong player values the prize more highly than the weak player and the valuations are common knowledge. The assumptions of the model allow us to interpret the heterogeneity in valuations as heterogeneity in abilities or heterogeneity in costs. All players within each group simultaneously and independently expend their efforts. In the "perfect-substitutes" contest, the performance of a group depends on the sum of individual efforts. In the "best-shot" contest, the performance of a group depends on the best performer. In the "weakest-link" contest, the performance of a group depends on the worst performer. The better performing group is more likely to win the prize. However, the worse performing group still has a chance to win, since the probability of winning is determined by a lottery contest success function.

The results of the experiment indicate that, contrary to theoretical predictions, there is significant over-contribution of efforts by both strong and weak players in contests where individual efforts are perfect substitutes. This over-contribution is not explained by quantal response equilibrium but it can be partially explained by social identity theory. Consistent with theoretical predictions, in best-shot contests most of the 
effort is expended by strong players while weak players free-ride. In weakest-link contests all players expend similar positive efforts conforming to the Pareto dominant equilibrium. When groups are asymmetric, the result of the competition depends on the rule that regulates the competition. The group with a stronger player is more likely to win the contest if the performance of both groups depends solely on the best performer within each group. On the contrary, the same group is less likely to win the weakest-link and the perfect-substitutes contests.

The rule that regulates the competition also determines the amount of total effort expended, amount of free-riding, and the relative performance of strong players. Perfectsubstitutes contests generate the highest total effort expended among all contests, followed by best-shot and then weakest-link contests. The most free-riding behavior occurs in best-shot contests while there is almost no free-riding in weakest-link contests. Strong players expend the highest relative effort in best-shot contests, followed by perfect-substitutes and then weakest-link contests. 


\section{ESSAY 1}

\section{CONTEST DESIGN: AN EXPERIMENTAL INVESTIGATION}

\subsection{Introduction}

Costly competitions between economic agents are often portrayed as contests. Examples range from college admissions and competition for promotions to global relationships in which different countries and political parties expend resources to lobby their own interests (Krueger, 1974; Tullock, 1980). The variety of economic situations that can be described as contests has attracted enormous attention from economic theorists. The main focus of this literature is the relationship between the setup of rentseeking contests and the strategic behavior of contestants. It is well recognized that strategic behavior is sensitive to different contest rules. Therefore, depending on the objective, a careful design of each contest is required.

Despite the abundance of theoretical work on contest design, no experimental research has specifically compared alternative contest mechanisms. ${ }^{1}$ To begin to bridge this gap, this study investigates and compares the performance of four simultaneous contests: a grand contest, two multi-prize settings (equal and unequal prizes), and a contest which consists of two subcontests.

\footnotetext{
${ }^{1}$ Several experimental studies looked at the design of rank order tournaments (Orrison et al., 2004; Harbring and Irlenbusch, 2003, 2005) and fund-raising lotteries (Morgan and Sefton, 2000; Lange, 2007). The most closely related work to ours is done by Müller and Schotter (2007) who analyze the influence of prizes in all-pay auction with heterogeneous agents following the theoretic work by Moldovanu and Sela (2001).
} 
Consistent with the theory, we find that the grand contest generates the highest revenue among all simultaneous contests. In multi-prize settings, equal prizes produce lower efforts than unequal prizes. Our results also provide strong empirical support for the argument that joint contests generate higher efforts than an equivalent number of subcontests. However, contrary to the theory, we find significant over-dissipation in all contests. This over-dissipation can be partially explained by strong endowment effects. Subjects who receive bigger endowments tend to over-dissipate while subjects who receive smaller endowments tend to under-dissipate in contests. This behavior is consistent with the predictions of a quantal response equilibrium. Finally, we find that there is a strong heterogeneity between the subjects and that, instead of playing the pure strategy equilibrium, subjects expend efforts that span the entire strategy space. Most of these findings can be explained to some extent by differences in risk preference and misperception of the random draw.

A number of theoretical papers have been devoted to the design of an optimal contest that generates the highest revenue - the total amount of effort expended by the contestants. A common motivation for such research is the objective of various agencies (political parties, lottery administrators, and economic groups) to maximize earnings by extracting the highest effort from the contestants. Gradstein and Konrad (1999), for example, provide a rationale for a multi-stage contest design by endogenizing the choice of contest structure. They show that, depending on a return to scale parameter of the contest success function, a multi-stage contest may induce higher effort by the participants than a one-stage contest. In the same line of research, Baik and Lee (2000) study a two-stage contest with effort carryovers. They demonstrate that, in the case of 
player-specific effort carryovers, the rent-dissipation rate (defined as the ratio of the expended total effort to the value of the prize) increases in the carryover rate and the rent is fully dissipated with carryover rate equal to one. Finally, Fu and $\mathrm{Lu}$ (2007) investigate the optimal structure of a multistage sequential-elimination contest with pooling competition in each stage. They demonstrate that the optimal contest eliminates one contestant at each stage until the finale in which a single winner takes the entire prize.

Overall, it is generally observed in the contest literature that pooling competition generates higher dissipation rates (Clark and Riis, 1998; Amegashie, 2000; Fu and Lu, 2009; Moldovanu and Sela, 2006). ${ }^{2}$ Clark and Riis (1998) show that the income maximizing contest administrator obtains the highest rent-seeking effort when, instead of many small prizes, a large prize is provided. Fu and Lu (2009) demonstrate that the rent dissipation rate increases when the number of contestants and prizes are scaled up. Therefore, the authors conclude that a grand contest generates higher revenue than any set of subcontests. Moldovanu and Sela (2006) investigate a similar problem under the structure of all-pay auctions where all players know their own abilities and the distribution of abilities in the population. The major finding of Moldovanu and Sela (2006) is that independently of the number of contestants and the distribution of abilities, a grand contest generates the highest revenue when the cost function is either linear or concave. However, it is not always the case that pooling competition generates the highest efforts. For example, if the contestants have convex costs several prizes may be optimal (Moldovanu and Sela, 2001; Kräkel, 2006). The non-optimality of a single large

\footnotetext{
${ }^{2}$ For more multiple prize contests see Glazer and Hassin (1988), Barut and Kovenock (1998), and Che and Gale (2003).
} 
prize can also occur in a contest where players have commonly known but different abilities (Szymanski and Valletti, 2005).

The empirical evidence for contest design theory is mixed (Szymanski, 2003). Maloney and McCormick (2000), for example, analyze responses of individual runners to prizes in foot races. They find a significant relation between the performance and the prize value. Consistent with Lazear and Rosen (1981), higher prize values cause higher effort levels. Similar to Maloney and McCormick (2000), Lynch and Zax (2000) examine data on road races in the United States. They find that the performance increases in response to larger prize spreads. However, when controlled for ability factor, the impact of the prize spread disappears. The authors thus conclude that the larger prize spreads produce better performance not because they encourage all runners to run faster but because they attract faster runners.

\subsection{Theoretical Model}

Denote by $C \equiv C\left(N,\left\langle V_{S}\right\rangle_{s=1}^{K}\right)$ a contest with $N>K$ identical risk-neutral players who are competing for $K \geq 1$ prizes of a common value $V_{s}, s=1, \ldots, K$. No player may win more than one prize. Each player $i$ chooses irreversible effort level of $e_{i}$ to influence the probability of winning. Let $\Omega_{s}$ be the set of remaining $(N-s+1)$ players who have not won one of the $(s-1)$ prizes. Then the conditional probability that a contestant $i$ wins the $s$-th prize is given by a lottery contest success function:

$$
p_{i}\left(e_{i}, e_{-i} ; \Omega_{S}\right)=\frac{e_{i}}{e_{i}+\sum_{j \in \Omega_{S}} e_{j}}, \quad i \neq j
$$


The efforts are often raised to an exponent term to indicate the sensitivity of a contest. Our reasons for choosing this specific contest success function is that it is simple enough for subjects to understand and it is also commonly used in most of the rentseeking contest literature, including virtually all of the experimental contest literature. It is important to emphasize, however, that the simplicity of (1) does not affect the comparative statics predictions of the theory (Clark and Riis, 1998; Fu and Lu, 2009).

We concentrate our analysis on the symmetric pure strategy Nash equilibrium of the game. The expected payoff of player $i, E\left(\pi_{i}\right)$, is derived by multiplying player $i$ 's probability of winning each prize, $p_{i}\left(e_{i}, e_{-i} ; \Omega_{s}\right)$, by its value, $V_{s}$. Since we are considering symmetric equilibrium the efforts made by other players $i \neq j$ can be denoted as $e$. Therefore, the probability that $i$ wins the first prize is $e_{i} /\left(e_{i}+(N-1) e\right)$. If $i$ does not win the first prize, his conditional probability of winning the second prize is the product of the probability that $i$ does not win the first prize and the probability that he does win the second prize. Applying this reasoning we can write player $i$ 's expected payoff as:

$$
\begin{aligned}
& E\left(\pi_{i}\right)=\frac{e_{i}}{e_{i}+(N-1) e} V_{1}+\frac{(N-1) e}{e_{i}+(N-1) e} \frac{e_{i}}{e_{i}+(N-2) e} V_{2}+ \\
& +\frac{(N-1) e}{e_{i}+(N-1) e} \frac{(N-2) e}{e_{i}+(N-2) e} \frac{e_{i}}{e_{i}+(N-3) e} V_{3}+\cdots+\prod_{h=1}^{K-1} \frac{(N-h) e}{e_{i}+(N-h) e} \frac{e_{i}}{e_{i}+(N-K) e} V_{K}-e_{i}
\end{aligned}
$$

The expected payoff (2) is based on the assumptions that players are risk-neutral and have linear costs. However, by relaxing the linearity of costs assumption the comparative statics predictions of the theory are not affected. In fact, in the derivation of the equilibrium, Clark and Riis (1998) use a nonlinear cost function $e_{i}^{1 / r}$ instead of $e_{i}$, 
where $r>(<) 1$. Differentiating (2) with respect to $e_{i}$ leads to the equilibrium effort level in the contest $C\left(N,\left\langle V_{s}\right\rangle_{s=1}^{K}\right):^{3}$

$$
e^{*}=\frac{1}{N} \sum_{S=1}^{K} V_{S}\left(1-\sum_{h=0}^{s-1} \frac{1}{N-h}\right)
$$

Formula (3) is the building block of the experimental design used in this study. It shows that the effort level of each contestant depends on the number of contestants, the number of prizes, the value of prizes, and the ordering of prizes. Especially interesting is the "placement effect": the contest administrator can increase the effort level (3) by reducing the value of an early prize $V_{s}$ and increasing the value of a later prize $V_{s-1}$ by the same amount. Taking into account that the revenue collected by the administrator is simply the summation of all individual efforts, the placement effect justifies the use of a large single prize to maximize the revenue collected in the contest.

\subsection{Experimental Design and Procedures}

\section{A. Treatments and Hypothesis}

Suppose there are $N$ players who are willing to participate in a contest. The administrator has a budget $V$ and he wants to maximize total revenue extracted from contestants. The administrator must choose how to organize this contest. The simplest way to do this is a simultaneous move grand contest, in which all players are pooled into one large group with only one large prize. This type of contest is the baseline treatment of this study.

\footnotetext{
${ }^{3}$ General conditions for existence of the equilibrium and detail derivations are shown in Clark and Riis (1998).
} 
Treatment GC: The first contest is a grand contest $C_{1}(N, V)$ in which all $N$ contestants are in the same group and they compete for a single prize of value $V$. Applying (3) and summing over all contestants' efforts, the total revenue collected in $C_{1}$ is

$$
T R_{G C}=V\left(1-\frac{1}{N}\right)
$$

If the prize $V$ is divisible the administrator must choose how to divide it. He can divide the prize into several unequal prizes or he can make all prizes equal. The next two treatments investigate these alternatives.

Treatment UC: In contest $C_{2}\left(N,\left\langle V_{1}, V_{2}\right\rangle\right)$ all contestants are competing for two unequal prizes $V_{1}=\frac{3}{4} V$ and $V_{2}=\frac{1}{2} V$. A 3 to 1 ratio of splitting the prize has been proposed by Galton (1902). Note, that the sum of $V_{1}$ and $V_{2}$ yields the combined prize of value $V$. The total revenue generated by this contest is

$$
T R_{U C}=V\left(1-\frac{1}{N}-\frac{1}{4(N-1)}\right)
$$

Treatment EC: In the third contest, $C_{3}\left(N,\left\langle V_{1}, V_{2}\right\rangle\right)$, all contestants compete for two prizes of the same value $V_{1}=V_{2}=\frac{1}{2} V$. The total revenue collected is derived from formula (3):

$$
T R_{S C}=V\left(1-\frac{1}{N}-\frac{1}{2(N-1)}\right)
$$

Frequently, instead of putting the contestants into one large group, they are split into several subgroups. In these cases the competition goes on within each group. As a result, the contest organizer collects the revenue from each subcontest separately. 
Treatment SC: This last simultaneous contest treatment consists of two separate and identical contests $C_{41}=C_{42}=C\left(\frac{1}{2} N, \frac{1}{2} V\right)$. The SC treatment resembles the EC treatment, but instead of competition within the same group, contestants are split into two equal size groups $\frac{1}{2} N$ and the winner of each group receives a prize value $\frac{1}{2} V$. The total revenue collected in both $C_{41}$ and $C_{42}$ is

$$
T R_{S C}=V\left(1-\frac{2}{N}\right)
$$

Based on the four treatments, we can formalize the following three hypotheses:

Hypothesis 1: Grand contest (GC) generates the highest revenue among all simultaneous contests.

This hypothesis follows directly from the four treatments listed above. It can also be derived from Clark and Riis (1998), who showed that an administrator who wishes to maximize the revenue should combine all of the prizes into one grand prize.

Hypothesis 2: In multi-prize settings, equal prizes (EC) produce lower efforts than unequal prizes (UC).

This hypothesis comes from the observation that increasing the value of the first prize, while decreasing the value of the second prize by the same amount, increases effort expenditures. Therefore, the UC treatment should generate higher revenue than the EC treatment, since in the UC treatment the first prize is $V_{1}=\frac{3}{4} V$ while in the EC treatment the first prize is $V_{2}=\frac{1}{2} V$. Our final hypothesis is based on a recent study by $\mathrm{Fu}$ and $\mathrm{Lu}$ (2009), who showed that the joint contest generates higher revenue than any set of subcontests. 
Hypothesis 3: Joint contest (EC) generates higher efforts than equivalent number of subcontests (SC).

In summary, the four contests can be ranked by the total revenue collected: $T R_{G C}>T R_{U C}>T R_{E C}>T R_{S C}$. If revenue maximization is the objective of the administrator then the grand contest should be preferred over all other contests, unequal prize splitting should be preferred over equal prize splitting, and a joint contest should be preferred over two equivalent subcontests.

\section{B. Experimental Procedures}

The experiment consists of four different contests. Table 1.3.1 shows the equilibrium effort levels, revenue generated by each contest, and dissipation rates, defined as the total expenditures divided by the total value of the prize, for $N=4$ and $V=120$.

Table 1.3.1 - Experimental Design and Nash Equilibrium Predictions

\begin{tabular}{|c|c|c|c|c|c|c|c|}
\hline \multirow{2}{*}{ Treatment } & \multicolumn{2}{|c|}{ Number of Players per } & \multirow{2}{*}{$\begin{array}{l}\text { Prizes per } \\
\text { Group, } s\end{array}$} & \multirow{2}{*}{$\begin{array}{c}\text { Value of the } \\
\text { Prize, } V\end{array}$} & \multicolumn{2}{|c|}{ Equilibrium } & \multirow{2}{*}{$\begin{array}{c}\text { Dissipation } \\
\text { Rate }\end{array}$} \\
\hline & Groups & Group, $N$ & & & Effort, $e$ & Revenue, $T R$ & \\
\hline GC & 1 & 4 & 1 & 120 & 22.5 & 90 & 0.75 \\
\hline UC & 1 & 4 & 2 & 90,30 & 20.0 & 80 & 0.67 \\
\hline $\mathrm{EC}$ & 1 & 4 & 2 & 60,60 & 17.5 & 70 & 0.58 \\
\hline $\mathrm{SC}$ & 2 & 2 & 1 & 60 & 15.0 & 60 & 0.50 \\
\hline
\end{tabular}

The experiment used 132 subjects drawn from the population of undergraduate students at Purdue University. Computerized experimental sessions were run using zTree (Fischbacher, 2007) at the Vernon Smith Experimental Economics Laboratory. We ran eleven experimental sessions with two treatments in each session as in Table 1.3.2. There were 12 subjects in the lab during each session. Each experimental session proceeded in three parts. Subjects were given instructions, available in the Appendix, at 
the beginning of each part and the experimenter read the instructions aloud. In the first part subjects made a series of choices in simple lotteries, similar to Holt and Laury (2002). The second and the third parts of the experiment corresponded to two out of four treatments. For example, in GC-UC, each subject played in a grand contest for 30 periods, then played for 30 periods in an unequal prize contest. In each period, subjects were randomly and anonymously placed into a group of 4 players in GC, UC, and EC treatments or into a group of 2 players in SC treatment.

Table 1.3.2 - Summary of Treatments and Sessions

\begin{tabular}{lccccc}
\hline \hline \multirow{2}{*}{ Design } & $\begin{array}{c}\text { Number of } \\
\text { Sessions }\end{array}$ & $\begin{array}{c}\text { Total } \\
\text { Participants }\end{array}$ & $\begin{array}{c}\text { Number of } \\
\text { Decisions }\end{array}$ & $\begin{array}{c}\text { Number of } \\
\text { Periods }\end{array}$ & Endowment \\
\hline GC-UC & 2 & 24 & 1440 & 30 & 60 \\
UC-GC & 2 & 24 & 1440 & 30 & 60 \\
EC-SC & 2 & 24 & 1440 & 30 & 60 \\
SC-EC & 2 & 24 & 1440 & 30 & 60 \\
GC-UC (40) & 1 & 12 & 720 & 30 & 40 \\
Pilot Sessions & 2 & 24 & 960 & 20 & 60 \\
\hline
\end{tabular}

At the beginning of each period, each subject received an endowment of 60 experimental francs. Subjects could use their endowments to expend efforts (place bids) in order to win a prize. Subjects were informed that by increasing their efforts, they would increase their chance of winning the prize and that, regardless of who wins the prize, all subjects would have to pay for their efforts. After all subjects submitted their efforts the computer assigned the winner via a random draw. A simple lottery was used to explain how the computer chose the winner. At the end of each period, the sum of all efforts in the group, the result of the random draw, and personal period earnings were reported to all subjects. After completing all 60 decision periods, 10 periods were randomly selected for payment (5 periods for each treatment). The earnings were 
converted into US dollars at the rate of 50 francs to $\$ 1$. On average, subjects earned $\$ 18$ each and this was paid in cash. The experimental sessions lasted for about 70 minutes.

\subsection{Results}

Table 1.4.1 summarizes average efforts and payoffs over all treatments, and shows that subjects over-expend effort relative to the risk-neutral Nash prediction. As a result, payoffs are lower than expected. Note that on average players competing in the grand contest do not earn any positive payoffs.

Table 1.4.1 - Average Statistics ${ }^{4}$

\begin{tabular}{|c|c|c|c|c|c|c|c|}
\hline \multirow{2}{*}{ Treatment } & \multicolumn{2}{|c|}{ Effort, $e$} & \multirow{2}{*}{$\begin{array}{c}\text { Revenue, } \\
T R \\
\end{array}$} & \multicolumn{2}{|c|}{ Payoff, $\pi$} & \multicolumn{2}{|c|}{ Dissipation Rate } \\
\hline & Equilibrium & Actual & & Equilibrium & Actual & Equilibrium & Actual \\
\hline GC & 22.5 & $30.0(0.5)$ & 120.1 & 7.5 & $0.0 \quad(1.3)$ & 0.75 & 1.00 \\
\hline UC & 20.0 & $29.3(0.5)$ & 117.4 & 10.0 & $0.7 \quad(0.9)$ & 0.67 & 0.98 \\
\hline $\mathrm{EC}$ & 17.5 & $21.6(0.3)$ & 86.4 & 12.5 & $8.4 \quad(0.7)$ & 0.58 & 0.72 \\
\hline $\mathrm{SC}$ & 15.0 & $19.7(0.3)$ & 78.6 & 15.0 & $10.3(0.8)$ & 0.50 & 0.66 \\
\hline
\end{tabular}

Standard error of the mean in parentheses

The dissipation rate is defined as the ratio of the expended total effort (revenue) to the value of the prize. In the grand contest $100 \%$ of the rent is dissipated by 4 players, while only $66 \%$ of the rent is dissipated by 4 players in the two subcontests. Actual dissipation rates are significantly higher than what is predicted by the theory. ${ }^{5}$

Result 1: Significant over-dissipation is observed in all treatments.

\footnotetext{
${ }^{4} \mathrm{We}$ also checked for a possible order effect since subjects consecutively played in two of the four possible contests. No significant difference was found. In fact, the averages presented in Table 1.4.1 are almost identical to the averages when we consider only the first treatment in each session. In GC, UC, EC and SC the average efforts without the order effect are 30.2, 29.9, 21.5, and 18.5.

${ }^{5}$ To support this conclusion we estimated a simple panel regression for each treatment, where the dependent variable is effort and independent variables are a constant and session dummy-variables. The model included a random effects error structure, with the individual subject as the random effect, to account for the multiple decisions made by individual subjects. Based on a standard Wald test, conducted on estimates of a model, we found that for all treatments the constant coefficients are significantly higher than the predicted theoretical values in Table 1.4.1 ( $p$-value $<0.05)$. The same conclusion also stands after clustering standard errors at the session level $(p$-value $<0.05)$.
} 
Table 1.4.1 also reports the total revenue collected in each contest. This revenue can be calculated by summing up all efforts within a given contest or by multiplying dissipation rate by the prize value. The data indicates that all four revenues are ranked consistently with the theory. The revenue collected in the EC treatment is higher than the revenue collected in the SC treatment. A random effect regression of effort on the treatment dummy-variable indicates that the difference is significant $(p$-value $<0.01) .^{6}$ This finding is consistent with Hypothesis 3. The actual difference between the revenue collected in the EC and SC treatments is about 8 , which is very close to the theoretical prediction of 10 .

Result 2: The equal-prize joint contest generates significantly greater effort and revenue than the two equivalent subcontests.

The next result, which supports Hypothesis 2, is that the revenue collected in the UC treatment exceeds the revenue collected in the EC treatment. Based on the estimation of a random-effect model with standard errors clustered at the session level, the difference in revenues is significant $(p$-value $<0.05)$. Although this finding supports Hypothesis 2, the difference in revenues of $31(=117-86)$ is much higher than the theoretical difference of $10(=80-70)$.

Result 3: The unequal-prize contest generates significantly greater effort and revenue than the equal-prize contest.

The grand contest is designed to produce the highest competition from the contestants and therefore generates the highest revenue for the administrator. Table 1.4.1

\footnotetext{
${ }^{6}$ When clustering standard errors at the session level, the difference is significant only for the last 15 periods of the experiment $(p$-value $<0.05)$.
} 
shows that the grand contest indeed generates the highest effort level, the highest revenue, and the highest dissipation rate. This provides support for Hypothesis 1. Based on the estimation of a random-effect model with standard errors clustered at the session level, the effort expended in the GC treatment is significantly higher than the effort expended in the EC treatment $(p$-value $<0.05)$ and the SC treatment $(p$-value $<0.05)$. The difference in effort between the GC and UC treatments is significant only for the last 15 periods of the experiment $(p$-value $<0.05){ }^{7}$

Result 4: The grand contest generates somewhat higher efforts and revenue than unequal-prize contest and considerably higher efforts and revenue than either equal-prize contest or two equivalent subcontests.

Overall, Results 2, 3, and 4 provide strong empirical support for the theoretical findings of contest design: the most rent-seeking efforts are obtained when a large prize is provided instead of several small prizes and the joint contest generates higher revenue than a set of subcontests. The support for the theory comes from aggregate rather than individual analysis of the data. Figure 1.4.1a displays the full distribution of efforts made in first 15 periods of the experiment. Instead of following a unique pure strategy Nash equilibrium, subjects' efforts are distributed on the entire strategy space. In the SC treatment, for example, all efforts should be concentrated at 15 , but instead they range from 0 to 60. Similar behavior is observed in GC, UC, and EC treatments.

Result 5: The actual efforts are distributed on the entire strategy space.

\footnotetext{
${ }^{7}$ It is important to emphasize that although the average efforts are similar in both GC and UC treatments, the strategic behavior of individual subjects is very different. By analyzing individual efforts, we find that in the GC treatment subjects choose 0 and 60 more often than in the UC treatment (right panel of Figure 4.1b). As a result, there are more subjects who compete too much and at the same time more subjects who drop out of the competition in the GC treatment than in the UC treatment.
} 

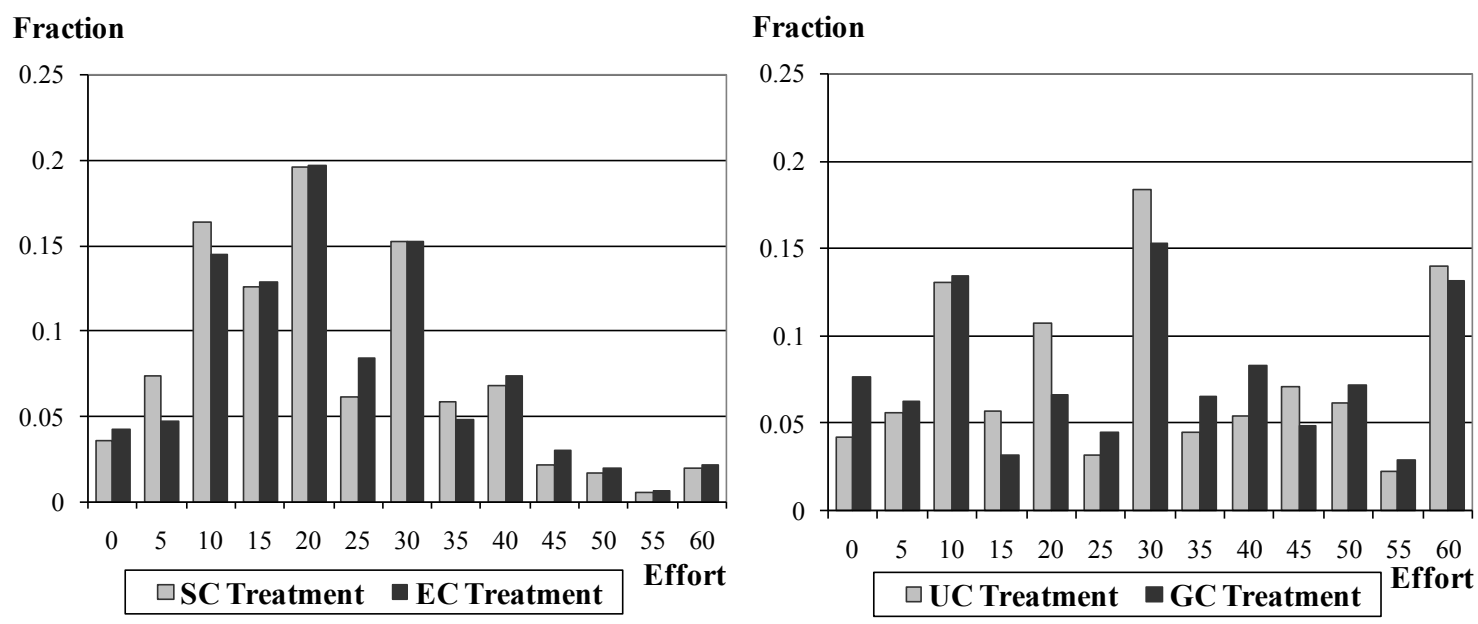

Figure 1.4.1a - Distribution of Efforts in Periods 1-15
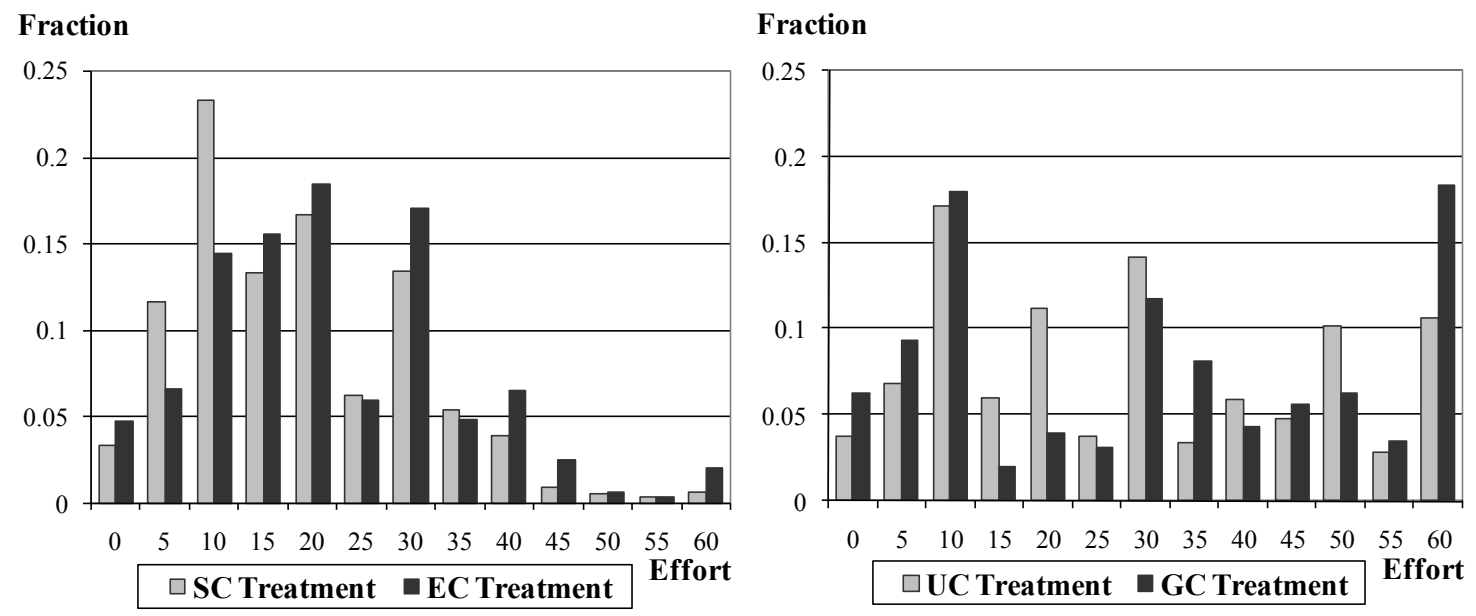

Figure 1.4.1b - Distribution of Efforts in Periods 16-30

It is often argued that subjects need to get some experience in order to learn how to play the equilibrium (Camerer, 2003). For that reason, Figure 1.4.1b displays the distribution of efforts in final 15 periods of the experiment. The fraction of the equilibrium efforts in SC and EC treatments is around $13-16 \%$ and the fraction of equilibrium efforts in $\mathrm{GC}$ and $\mathrm{UC}$ treatments is around $4-11 \%$. There is a minor difference between the distribution of efforts in periods 1-15 and periods 16-30. Nevertheless, some learning takes place. The fraction of efforts which are higher than the 
equilibrium decreases and the fraction of efforts which are lower than the equilibrium increases with the periods played. This can be seen by the leftward shift of the distribution (Figure 1.4.1a versus Figure 1.4.1b). In Section 1.5 we provide more formal analysis of the learning trends that occur in our experiment.
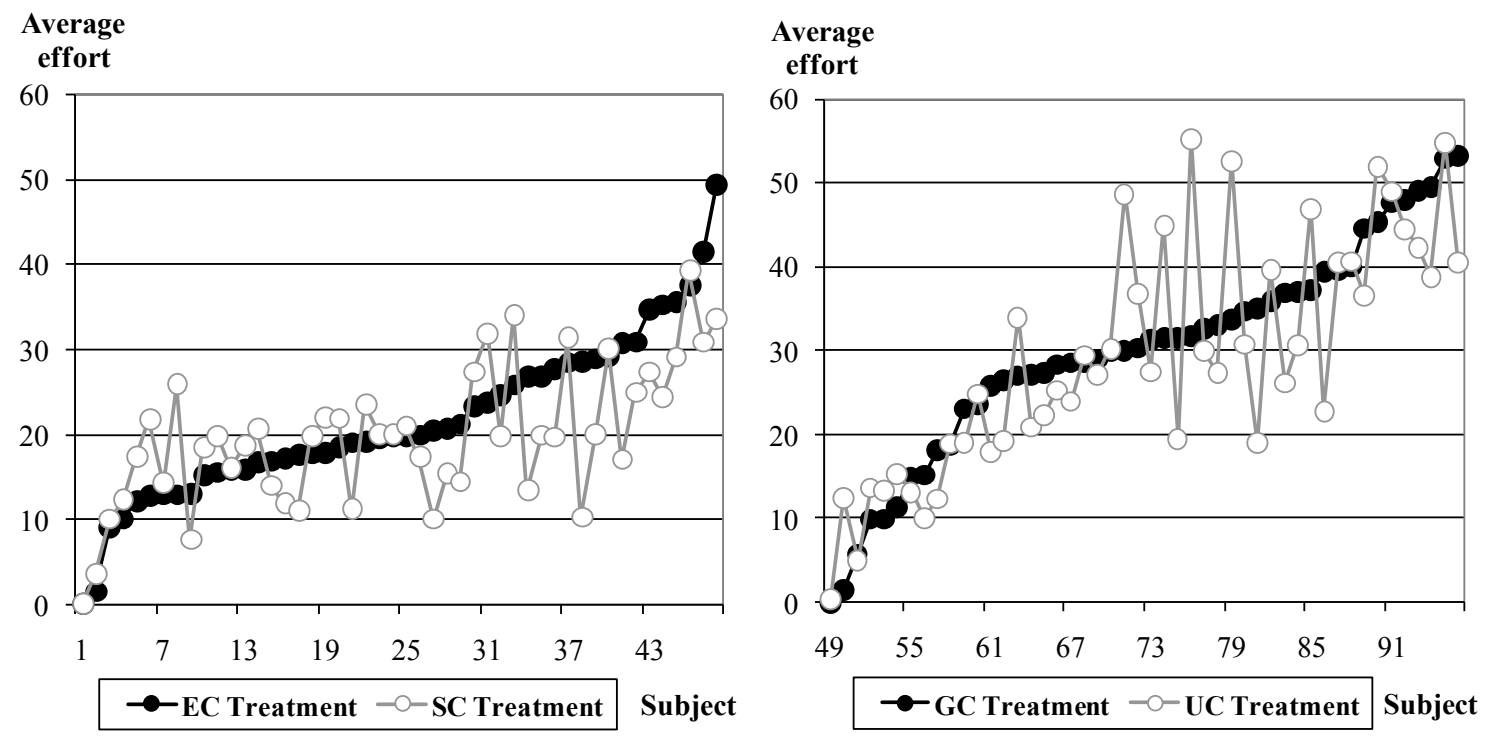

Figure 1.4.2 - Average Effort by Subjects in EC-SC and GC-UC Treatments

Another argument that is commonly made in the experimental and theoretical literature is that players may play an asymmetric equilibrium instead of a symmetric equilibrium (Dechenaux et al., 2006). Although Clark and Riis (1998) do not prove the uniqueness of the pure strategy equilibrium (3), in our specific case the equilibrium is indeed unique (Szidarovszky and Okuguchi, 1997; Cornes and Hartley, 2005). ${ }^{8}$

\footnotetext{
${ }^{8}$ Because of experimental design all players are restricted to choose integer effort levels from 0 to 60 . Therefore, one can look at the 4-player contest as 4-dimensional normal form game with nearly $1.4 \mathrm{E}+07$ possible outcomes. We ran computer simulation to check for all possible pure strategy equlibria and the only one that was found is unique and symmetric. Because of the restriction on the strategy space, in the equilibrium of the GC (EC) treatment two players expend 23 (18) francs and two players expend 22 (17) francs. It is also important to emphasize that because of the concavity of payoff functions the pure strategy equilibrium is also the unique mixed strategy equilibrium. We performed computer simulation for the SC treatment to confirm this.
} 
Figure 1.4.2 displays the average efforts by all subjects who participated in the experiment. On the left side each subject is ranked by the average effort he expended in the EC treatment and on the right side each subject is ranked by the average effort he expended in the GC treatment. Some subjects never enter the competition and expend zero effort in all periods, while others expend substantial effort, averaging about $50 .^{9}$

Result 6: There is a strong heterogeneity in efforts between the subjects.

Uniqueness of the pure strategy equilibrium and findings in Results 1, 5, and 6 produce a challenge for contest theory. Nevertheless, Results 2, 3, and 4 support the major comparative static predictions. Why individual behavior is different across subjects is a separate question. There are many behavioral and demographic factors that may cause these differences. The next section explores in more detail the possible behavioral and demographic factors that cause subjects to deviate from the theoretical predictions.

\subsection{Exploring Over-Dissipation}

\section{A. Quantal Response Equilibrium}

Although the comparative statics predictions hold in the experiment, there is a significant over-dissipation in all treatments (Result 1) which is not captured by the theory. Potters et al. (1998) conjectured that most subjects are likely to make mistakes. These mistakes add noise to the Nash equilibrium solution and thus may cause overdissipation in contest games. We check this hypothesis by applying a quantal response

\footnotetext{
${ }^{9}$ Evidently, the participants who bid more in EC treatment are also more likely to bid more in SC treatment. We can track this correlation since each subject participated in two different treatments in each session. The Spearman's rank correlation coefficient, $\rho$, is 0.58 and it is significantly greater than zero ( $p$ value $<0.01)$. The correlation between GC and UC treatment is even higher, $\rho=0.81(p$-value $<0.01)$. This important observation shows the consistency of each subject's behavior across different experimental contests. Therefore, it strongly confirms the presence of heterogeneity between the subjects.
} 
equilibrium (QRE) developed by McKelvey and Palfrey (1995). The crucial parameter of this model is the error parameter, $\mu$, which determines the sensitivity of the choice probabilities with respect to payoffs. The maximum likelihood estimates of $\mu$ for each treatment are shown in the Table 1.5.1. ${ }^{10}$ The table also reports the corresponding value of the likelihood function. The level of mistakes made in GC and UC treatments is very high. We cannot reject the random play hypothesis for either of the treatments. This conclusion stands even when we estimate the model based on the data from the last 15 periods of the experiment. On the other hand, the behavior in EC and SC treatments can be captured by the QRE with a reasonable level of mistakes.

Table 1.5.1 - QRE Computation Based on All Periods

\begin{tabular}{ccccc}
\hline \hline Treatment & $\mu$, error & LL & $\begin{array}{c}\text { LR test } \\
\text { (Random) }\end{array}$ & $\begin{array}{c}\text { LR test } \\
\text { (Equilibrium) }\end{array}$ \\
\hline GC & $1.21 \mathrm{E}+07$ & -5919.7 & $p=0.99$ & $p<0.01$ \\
$\mathrm{UC}$ & 729.4 & -5919.7 & $p=0.77$ & $p<0.01$ \\
$\mathrm{EC}$ & 9.3 & -5654.6 & $p<0.01$ & $p<0.01$ \\
$\mathrm{SC}$ & 9.3 & -5557.9 & $p<0.01$ & $p<0.01$ \\
$\mathrm{GC}(40)$ & 113.4 & -1336.7 & $p=0.56$ & $p<0.01$ \\
$\mathrm{UC}(40)$ & 3.2 & -1274.5 & $p<0.01$ & $p<0.01$ \\
\hline
\end{tabular}

Figure 1.5.1 illustrates the average effort at the QRE as a function of $\mu$ for each treatment. On the vertical axis we find the average effort for each player. When $\mu$ is zero, the behavior is consistent with the Nash equilibrium. With increasing level of mistakes, all players over-expend average effort relative to the Nash equilibrium. As players move closer to random play, i.e., putting equal weights on each strategy, the average effort approaches 30 (one half of the endowment). Even without additional computation one can see how the QRE can account for the over-dissipation in all treatments of the

\footnotetext{
${ }^{10}$ The estimation procedure followed Goeree et al. (2002). A more detail description of the estimation procedure is available from the author upon a request.
} 
experiment. For example, the average effort of 19.6 in SC treatment falls perfectly on the bottom curve around $\mu \approx 9$ (left panel of Figure 1.5.1).
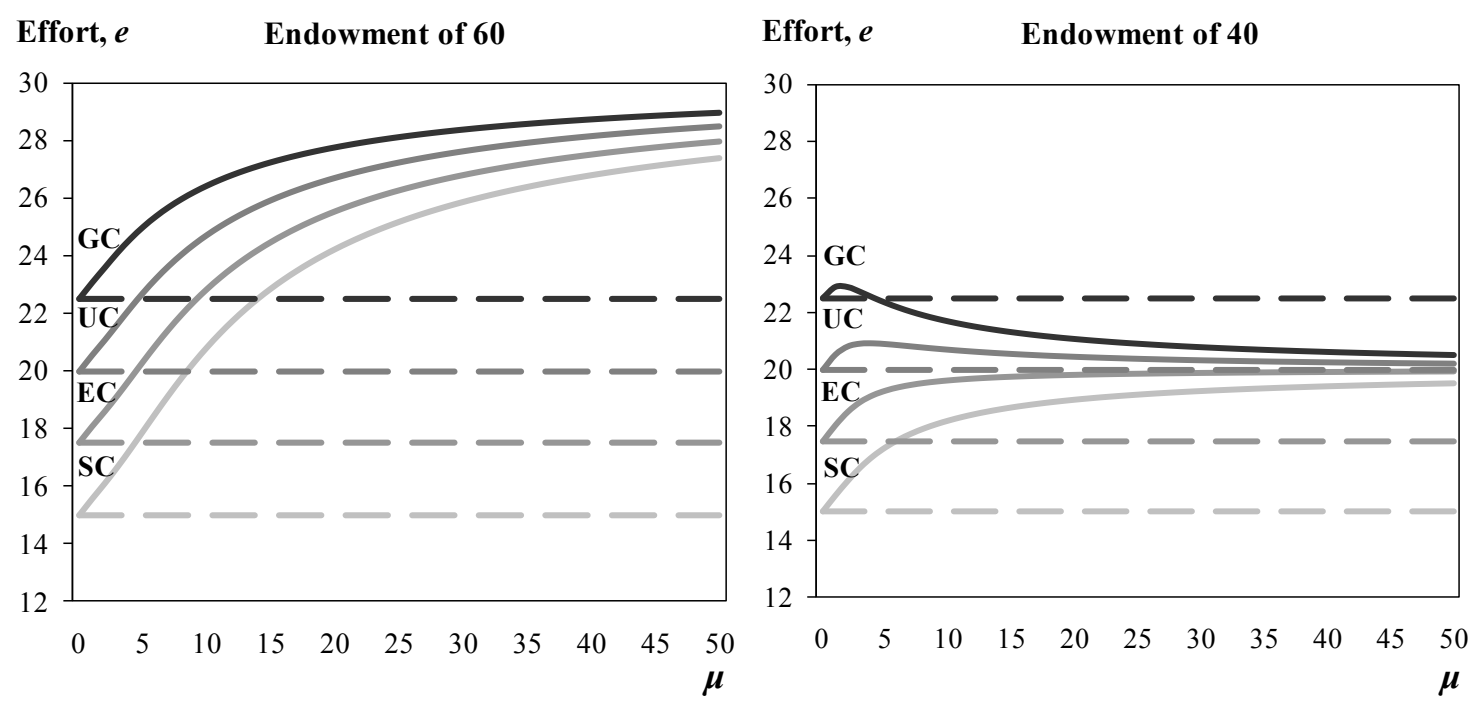

Figure 1.5.1 - Average Effort at the QRE

It is important to emphasize that computation of QRE is heavily dependent on the initial endowment which subjects receive to play the contest game. In our experiment, each period all subjects receive an endowment of 60 . Given this endowment, according to the QRE, at each level of mistakes subjects can only expend effort which is higher than the Nash equilibrium (left panel of Figure 1.5.1). Therefore, one may argue that the overdissipation in contests can always be explained by the QRE. ${ }^{11}$ However, this argument is not necessarily true because lower endowments may lead to under-dissipation relative to the Nash equilibrium prediction. For example, when the endowment is 40 , the QRE predicts that higher level of mistakes in the GC treatment should result in under-

\footnotetext{
${ }^{11}$ Bullock and Rutstrom (2007) find that observed behavior in the Tullock-type model of political competition is fully captured by QRE predictions. Anderson et al. (1998) develop a theoretical model of the all-pay auction based on the QRE. The model predicts that overbidding in the all-pay auction occurs due to the mistakes and that overbidding should increase with the size of the bidders' group. Nevertheless, Gneezy and Smorodinsky (2006) found that the over-dissipation in the all-pay auction is independent of the group size in later periods.
} 
dissipation (right panel of Figure 1.5.1). The intuition behind this prediction is straightforward: when subjects have large endowments then their mistakes are more likely to result in over-dissipation, while small endowments are more likely to result in under-dissipation.

To make a definite conclusion, we conducted one more session with GC (40) and UC (40) treatments. This time each subject was given an endowment of 40 instead of 60 . We were very surprised to discover that the average effort in GC (40) treatment indeed fell from 30.0 to 21.6 which is below the Nash equilibrium prediction of 22.5. In the UC (40) treatment, average effort fell from 29.3 to 21 . This finding is a strong support for QRE. ${ }^{12}$ It is also consistent with Sheremeta (2009), who conducted one treatment equivalent to the GC treatment. In that study subjects were given the endowment of 120 francs instead of 60 and as a result the average effort was 34.1 instead of 30 . A strong effect of the endowment on subjects' behavior can explain why some experimental studies (Schmidt et al., 2005; Shupp, 2004) find less rent-seeking expenditures than what is predicted by the equilibrium. ${ }^{13}$

\section{B. Risk Aversion}

The QRE model can account for the general trend of over-dissipation in the experiment. However, it cannot explain the heterogeneity in efforts between the subjects

\footnotetext{
${ }^{12}$ With the restriction on the endowment, the estimated level of mistakes, $\mu$, also decreased in both treatments (Table 1.5.1). However, in the GC (40) treatment we still cannot reject the random play hypothesis.

${ }^{13}$ In Schmidt et al. (2005) and Shupp (2004) subjects were given a budget which allowed them to bid up to $\$ 20$ while $\$ 13.5$ was the Nash equilibrium prediction. Assuming a substantial level of mistakes made by subjects, the QRE approaches $\$ 10$ and is below the Nash equilibrium. Therefore, taking into account our findings about the effect of the endowment on the behavior of the rent-seekers, we can explain why these authors find significant under dissipation in their experiments.
} 
(Result 6). In the experimental literature it is believed that this heterogeneity is mainly caused by heterogeneity of risk preferences. Previous experimental studies found a significant effect of risk aversion on the dissipation rate (Miller and Pratt, 1991). In our experiment, rather than estimating risk aversion from the observed choices in contest games (Goeree et al., 2002; Schmidt et al., 2005), in the first stage we used a simple lottery to elicit risk aversion from the subjects.

Table 1.5.2 - Classification of Subjects by Risk Aversion (All Treatments)

\begin{tabular}{cccc}
\hline \hline $\begin{array}{c}\text { Number of } \\
\text { A choices }\end{array}$ & $\begin{array}{c}\text { Number of } \\
\text { Subjects }\end{array}$ & $\begin{array}{c}\text { Relative Risk } \\
\text { Aversion, } r\end{array}$ & $\begin{array}{c}\text { Average } \\
\text { Effort, } e\end{array}$ \\
\hline 4 & 1 & 1.73 & 30.07 \\
5 & 2 & 1.46 & 33.03 \\
6 & 4 & 1.26 & 34.94 \\
7 & 18 & 1.10 & 25.68 \\
8 & 12 & 0.96 & 24.74 \\
9 & 10 & 0.83 & 27.06 \\
10 & 19 & 0.73 & 21.86 \\
11 & 14 & 0.63 & 26.59 \\
12 & 8 & 0.54 & 22.93 \\
13 & 5 & 0.46 & 25.11 \\
14 & 1 & 0.39 & 9.55 \\
15 & 2 & 0.32 & 10.07 \\
\hline
\end{tabular}

Following Holt and Laury (2002), subjects were asked to state whether they preferred safe option A or risky option B. In the experiment, the majority of subjects chose the safe option A when the probability of the high payoff in option B was small, and then crossed over to option B. ${ }^{14}$ Table 1.5.2 presents a summary of A choices made by all subjects in the experiment. Risk neutrality corresponds to the switching point of either 7 or 8 safe choices A. The majority of subjects show a tendency toward risk-averse

\footnotetext{
${ }^{14}$ Option A yielded $\$ 1$ payoff with certainty, while option B yielded a payoff of either $\$ 3$ or $\$ 0$. The probability of receiving $\$ 3$ or $\$ 0$ varied across all 15 lotteries. The first lottery offered a $5 \%$ chance of winning $\$ 3$ and a $95 \%$ chance of winning $\$ 0$, while the last lottery offered a $70 \%$ chance of winning $\$ 3$ and a $30 \%$ chance of winning $\$ 0$.
} 
or risk-neutral behavior. Based on the observed switching point for each subject, we can estimate their degree of risk aversion. ${ }^{15}$ To be consistent with other studies we calculate risk aversion parameters, $r$, based on the assumption that all subjects have constant relative risk aversion. The estimates are shown in Table 1.5.2. Higher $r$ corresponds to lower number of safe choices A. Conventionally, subjects are considered to be riskseeking when $r>1$. Risk neutrality corresponds to the case when $r=1$. As $r$ decreases, subjects become more risk-averse and prefer more safe options A.

Theoretical work by Hillman and Katz (1984) showed that risk-averse players should exert lower efforts than the prediction for risk-neutral players and risk-seeking players should exert higher efforts. Thus, if risk aversion is a crucial factor for explaining heterogeneity between the subjects then the efforts expended in the contest should be negatively correlated with the number of safe choices made. The last column of Table 1.5.2 displays an average effort corresponding to the number of safe choices A made by all subjects. Consistent with the theory, there is significant negative correlation between these two variables. The Spearman's rank correlation coefficient, $\rho$, is -0.81 and it is significantly different from zero $(p$-value $<0.01)$.

\section{Lag Dependence and Assessment of the Random Draw}

So far, we have discussed several explanations for over-dissipation (Result 1) and heterogeneity between the subjects (Result 6). Another question that needs to be addressed is why actual efforts are distributed on the entire strategy space (Result 5). One

\footnotetext{
${ }^{15}$ Note that switching from A to B only gives us an interval of risk aversion coefficient. However, for statistical computations we will use a mid-point approximation.
} 
explanation may come from the probabilistic nature of a contest. The random draw made by the computer in period $t-1$ may affect the individual behavior in period $t$. To capture this dynamic we estimated several random-effects (RE) models (Table 1.5.3).

Table 1.5.3 - Random-Effect Models

\begin{tabular}{|c|c|c|c|}
\hline \multirow{2}{*}{ Dependent variable, Effort } & (1) & (2) & (3) \\
\hline & RE & RE & $\mathrm{RE}$ \\
\hline \multirow{2}{*}{$\begin{array}{l}\text { \# of safe options A } \\
\text { [degree of risk aversion] }\end{array}$} & $-1.01 * * *$ & $-0.97 * * *$ & $-0.67^{* * *}$ \\
\hline & $(0.26)$ & $(0.20)$ & $(0.08)$ \\
\hline inconsistency & 1.92 & 1.7 & 0.81 \\
\hline [ 1 if subject is inconsistent in the lottery choices] & $(1.93)$ & $(1.43)$ & $(0.61)$ \\
\hline bidding time & $0.09 * *$ & $0.10 * *$ & $0.15^{* * *}$ \\
\hline [time spent to make a decision] & $(0.04)$ & $(0.04)$ & $(0.04)$ \\
\hline $1 / \mathrm{t}$ & $4.26^{* * *}$ & $4.16^{* * *}$ & $3.92 * *$ \\
\hline [inverse of a time trend] & $(1.46)$ & $(1.46)$ & $(1.55)$ \\
\hline \# quiz & -0.22 & -0.17 & $-0.31 * *$ \\
\hline [correct quiz answers] & $(0.49)$ & $(0.36)$ & $(0.15)$ \\
\hline win-lag & $2.05 * * *$ & & \\
\hline [1 if subject won in $t-1]$ & $(0.32)$ & & \\
\hline \multicolumn{2}{|l|}{ fairwin-lag } & $5.16^{* * *}$ & $1.79^{* * *}$ \\
\hline \multicolumn{2}{|l|}{ [ 1 if subject wins in period $t-1$ and the draw is fair] } & $(0.37)$ & $(0.44)$ \\
\hline \multicolumn{2}{|l|}{ unfairwin-lag } & $-3.00 * * *$ & $-2.44 * * *$ \\
\hline \multirow{2}{*}{\multicolumn{2}{|c|}{$\begin{array}{l}\text { [1 if subject wins in period } t \text {-1 and the draw is unfair] } \\
\text { daverage-lag }\end{array}$}} & $(0.49)$ & $(0.51)$ \\
\hline & & & $0.51 * * *$ \\
\hline \multicolumn{2}{|l|}{ [deviation from average effort in $t-1$ ] } & & $(0.01)$ \\
\hline treatment-GC & $9.48 * * *$ & $9.58 * * *$ & $9.07 * * *$ \\
\hline [1 if treatment is GC] & $(0.84)$ & $(0.84)$ & $(0.89)$ \\
\hline $\begin{array}{l}\text { treatment-UC } \\
{[1 \text { if treatment is } \mathrm{UC}]}\end{array}$ & $8.22 * * *$ & $8.36^{* * *}$ & $8.27^{* * *}$ \\
\hline \multirow{2}{*}{$\begin{array}{l}{[1 \text { if treatment is UC] }} \\
\text { treatment-EC }\end{array}$} & $(0.94)$ & $(0.94)$ & $(1.00)$ \\
\hline & $2.06 * * *$ & $2.05 * * *$ & $2.07 * * *$ \\
\hline [1 if treatment is EC] & $(0.48)$ & $(0.48)$ & $(0.51)$ \\
\hline \multirow[t]{2}{*}{ constant } & $22.35^{* * *}$ & $25.72 * * *$ & $24.69^{* * *}$ \\
\hline & $(5.16)$ & (3.79) & $(1.62)$ \\
\hline
\end{tabular}

Standard errors in parentheses

* significant at $10 \%$; $* *$ significant at $5 \%$; $* *$ significant at $1 \%$

In each regression we also control for session effects

Specification (1) is a simple RE regression of individual efforts made in all periods of the experiment on experimentally relevant explanatory variables. The coefficient capturing risk aversion is significant and has the expected sign. The variable inconsistency is intended to capture the subjects who demonstrated inconsistency in their risk preferences. Time spent on making a decision has a positive effect on over- 
dissipation. One explanation for this may be that subjects who take more time to make their decisions are actually confused about what they should do and therefore they make more mistakes (from Section 1.5, more mistakes corresponds to higher over-dissipation).

We also find that the inverse of a time trend is positive and significant in all specifications, which suggests that individual learning is taking place and, that with the repetition of the game, subjects expend lower efforts. The quiz variable is measured by the number of correct quiz answers (a measure of how well subjects understand the instructions) and is designed to capture the ability factor. ${ }^{16}$ However, we found this variable is not significantly different from zero.

To capture the dynamics of the game we include a win-lag variable. This is a dummy-variable which takes on the value of 1 if the player won the prize in period $t-1$ and is 0 otherwise. In Specification (1), this variable has a significant positive effect on effort. One explanation for this finding is due to the income effect: subjects who won in period $t-1$ have higher income in period $t$ and therefore expend higher efforts. ${ }^{17}$ In Specification (2), instead of using win-lag variable, we use fairwin-lag and unfairwin-lag variables. The fairwin-lag (unfairwin-lag) variable takes on the value of 1 if subject wins the prize in period $t-1$ and the random draw in period $t-1$ is fair (unfair). The fair draw is defined as a random draw that favors the player whose effort is higher than the average effort in the group. On the other hand, the unfair draw favors a player with a low effort. From the estimation, we find that the subjects who expend high efforts and win raise their

\footnotetext{
${ }^{16}$ Before the actual experiment, subjects completed the quiz on the computer to verify their understanding of the instructions. If a subject's answer was incorrect, the computer provided the correct answer. The experiment started only after all participants had answered all quiz questions.

${ }^{17}$ It is rather surprising since we tried to avoid this effect by using random payment. It is also possible that subjects derive utility from winning (Goeree et al., 2002; Sheremeta, 2009). Thus, subjects who win the prize in period $t-1$ expend higher efforts to ensure that they win the prize in period $t$.
} 
efforts in the consecutive period, while the subjects who expend low efforts and win reduce their efforts in the consecutive period. One may argue that this is simply due to the fact that subjects who expend higher (lower) efforts in one period are also more likely to expend higher (lower) efforts in the next period. To address this argument we run Specification (3) in which we include daverage-lag variable. This variable is equal to the difference between player $i$ 's effort and the average effort in the group in period $t-1$. From the estimation we find that this variable is indeed significant, i.e., subjects whose efforts are above the average in the past exert higher efforts in the current period. Even though the magnitudes of fairwin-lag and unfairwin-lag variables dropped, both variables are still significant. The response to fair and unfair draw by the subjects is intuitive but it is not rational. Since the nature of winning the contest is probabilistic, the perception of fair and unfair draw is important in explaining why subjects vary their efforts across periods and why actual efforts are distributed on the entire strategy space.

\subsection{Conclusion}

In this study we use experimental methods to test several theoretical predictions of contest design literature. We investigate and compare the performance of four simultaneous contests: a grand contest, two multi-prize settings (equal and unequal prizes), and a contest which consists of two subcontests. Consistent with the theory, we find that the grand contest generates the highest revenue among all simultaneous contests. We also find that in multi-prize settings, equal prizes produce lower efforts than unequal prizes. Finally, our experiment supports the argument that joint contests generate higher efforts than the equivalent number of subcontests. 
Although the comparative statics predictions hold in our experiment, consistent with the other experimental studies, there is a strong heterogeneity between the subjects and significant over-dissipation of rent (Millner and Pratt, 1989, 1991; Davis and Reilly, 1998; Potters et al., 1998). Subjects' heterogeneity can be partially captured by differences in risk preferences. Significant over-dissipation can be possibly explained by strong endowment effects. Subjects who receive big endowments tend to over-dissipate, while subjects who receive smaller endowments tend to under-dissipate in contests. This behavior is consistent with the predictions of a quantal response equilibrium.

We argue that because of the probabilistic nature of contests it is important to control for lag of winning and misperception of the random draw. Subjects who expend high efforts and win the prize in period $t$-1 raise their efforts in the consecutive period, while subjects who expend low efforts and win in period $t$-1 substantially decreased their efforts in period $t$. These findings are attributed to the misperception of the random draw and they can partly explain why actual efforts in contests are distributed on the entire strategy space. 


\subsection{References}

Amegashie, J.A. (2000). Some Results on Rent-Seeking Contests with Shortlisting. Public Choice, 105, 245-253.

Anderson, S.P., Goeree, J.K., \& Holt, C.A. (1998). Rent Seeking with Bounded Rationality: An Analysis of the All-Pay Auction, Journal of Political Economy, 106, $828-853$.

Baik, K.H., \& Lee, S. (2000). Two-stage rent-seeking contests with carryovers. Public Choice, 103, 285-296.

Barut, Y., \& Kovenock, D. (1998). The Symmetric Multiple Prize All-Pay Auction with Complete Information. European Journal of Political Economy, 14, 627-644.

Bullock, D., \& Rutström, E. (2007). Policy making and rent-dissipation: An experimental test, Experimental Economics, 10, 21-36.

Che, Y.K., \& Gale, I. (2003). Optimal Design of Research Contests. American Economic Review, 93, 646-671.

Clark, D.J., \& Riis, C. (1998). Influence and the Discretionary Allocation of Several Prizes. European Journal of Political Economy, 14, 605-625.

Davis, D., \& Reilly, R. (1998). Do many cooks always spoil the stew? An experimental analysis of rent seeking and the role of a strategic buyer. Public Choice, 95, 89-115.

Dechenaux, E., Kovenock, D., \& Lugovskyy, V. (2006). Caps on Bidding in All-Pay Auctions: Comments on the Experiments of A. Rapoport and W. Amaldoss. Journal of Economic Behavior and Organization, 61, 276-283.

Fischbacher, U. (2007). z-Tree: Zurich Toolbox for Ready-made Economic experiments, Experimental Economics, 10, 171-178. 
Fu, Q., \& Lu, J. (2007). The optimal multi-stage contest. University of Munich, Working Paper.

Fu, Q., \& Lu, J. (2009). The beauty of "bigness": On optimal design of multi-winner contests. Games and Economic Behavior, 66, 146-161.

Galton, F. (1902). The Most Suitable Proportion Between The Values Of First And Second Prizes, Biometrika, 1(4), 385-390.

Glazer, A., \& Hassin, R. (1988). Optimal contests. Economic Inquiry, 26, 133-143.

Gneezy, U., \& Smorodinsky, R. (2006). All-Pay Auctions - An Experimental Study, Journal of Economic Behavior and Organization, 61, 255-275.

Goeree, J., Holt, C., \& Palfrey, T. (2002). Quantal Response Equilibrium and Overbidding in Private-Value Auctions. Journal of Economic Theory, 247-272.

Gradstein, M., \& Konrad, K.A. (1999). Orchestrating Rent Seeking Contests. Economic Journal, 109, 536-45.

Harbring, C., \& Irlenbusch, B., (2003). An experimental study on tournament design, Labour Economics, 10, 443-464.

Harbring, C., \& Irlenbusch, B., (2005). Incentives in Tournaments with Endogenous Prize Selection, Journal of Institutional and Theoretical Economics, 127, 636-663.

Hillman, A.L., \& Katz, E. (1984). Risk-averse rent seekers and the social cost of monopoly power. Economic Journal, 94, 104-110.

Holt, C.A., \& Laury, S.K. (2002). Risk Aversion and Incentive Effects. American Economic Review, 92, 1644-55.

Kräkel, M. (2006). Splitting Leagues, Journal of Economics, 88, 21-48. 
Krueger, A.O. (1974). The Political Economy of the Rent-Seeking Society. American Economic Review, 64, 291-303.

Lazear, E.P., \& Rosen, S. (1981). Rank-order tournaments as optimum labor contracts. Journal of Political Economy, 89, 841-864.

Lynch, J., \& Zax, J. (2000). The Rewards to Running: Prize Structure and Performance in Professional Road Racing, Journal of Sports Economics, 1, 323-340.

Maloney, M.T., \& McCormick, R.E. (2000). The Response of Workers to Wages in Tournaments: Evidence From Foot Races, Journal of Sports Economics, 1, 99-123

McKelvey, R., \& Palfrey, T. (1995). Quantal Response Equilibria for Normal Form Games. Games and Economic Behavior, 10, 6-38.

Millner, E.L., \& Pratt, M.D. (1989). An experimental investigation of efficient rentseeking. Public Choice, 62, 139-151.

Millner, E.L., \& Pratt, M.D. (1991). Risk Aversion and Rent-Seeking: An Extension and Some Experimental Evidence, Public Choice, 69, 81-92.

Moldovanu, B., \& Sela, A. (2001). The Optimal Allocation of Prizes in Contests. American Economic Review, 91, 542-558.

Moldovanu, B., \& Sela, A. (2006). Contest architecture. Journal of Economic Theory, $126,70-96$.

Müller, W., \& Schotter, A., (2007). Workaholics and Drop outs in Optimal Organizations. Working Paper, New York University.

Orrison, A., Schotter, A., \& Weigelt, K. (2004). Multiperson Tournaments: An Experimental Examination. Management Science, 50, 268-79. 
Potters, J.C., De Vries, C.G., \& Van Linden, F. (1998). An experimental examination of rational rent seeking. European Journal of Political Economy, 14, 783-800.

Schmidt, D., Shupp, R., \& Walker, J. (2005). Resource allocation contests: Experimental evidence. Indiana University, Working Paper.

Sheremeta, R.M. (2009). Experimental Comparison of Multi-Stage and One-Stage Contests, Purdue University, Working Paper.

Shupp, R. (2000). Single versus Multiple Winner Probabilistic Contests: An Experimental Investigation, Working Paper, Ball State University.

Szidarovszky, F., \& Okuguchi, K. (1997). On the Existence and Uniqueness of Pure Nash Equilibrium in Rent-Seeking Games. Games and Economic Behavior, 18, 135-140.

Szymanski, S. (2003). The economic design of sporting contests, Journal of Economic Literature, 41, 1137-1187.

Szymanski, S., \& Valletti, T.M. (2005). Incentive effects of second prizes, European Journal of Political Economy, 21, 467-481.

Tullock, G. (1980). Efficient Rent Seeking. In James M. Buchanan, Robert D. Tollison, Gordon Tullock, (Eds.), Toward a theory of the rent-seeking society. College Station, TX: Texas A\&M University Press, pp. 97-112. 


\subsection{Appendix}

\section{GENERAL INSTRUCTIONS}

This is an experiment in the economics of strategic decision making. Various research agencies have provided funds for this research. The instructions are simple. If you follow them closely and make appropriate decisions, you can earn an appreciable amount of money.

The experiment will proceed in three parts. Each part contains decision problems that require you to make a series of economic choices which determine your total earnings. The currency used in Part 1 of the experiment is U.S. Dollars. The currency used in Part 2 and 3 of the experiment is francs. Francs will be converted to U.S. Dollars at a rate of $\_0$ francs to _ 1 dollar. At the end of today's experiment, you will be paid in private and in cash. 12 participants are in today's experiment.

It is very important that you remain silent and do not look at other people's work. If you have any questions, or need assistance of any kind, please raise your hand and an experimenter will come to you. If you talk, laugh, exclaim out loud, etc., you will be asked to leave and you will not be paid. We expect and appreciate your cooperation.

At this time we proceed to Part 1 of the experiment.

\section{INSTRUCTIONS FOR PART 1}

\section{YOUR DECISION}

In this part of the experiment you will be asked to make a series of choices in decision problems. How much you receive will depend partly on chance and partly on the choices you make. The decision problems are not designed to test you. What we want to 
know is what choices you would make in them. The only right answer is what you really would choose.

For each line in the table in the next page, please state whether you prefer option A or option B. Notice that there are a total of 15 lines in the table but just one line will be randomly selected for payment. You ignore which line will be paid when you make your choices. Hence you should pay attention to the choice you make in every line. After you have completed all your choices a token will be randomly drawn out of a bingo cage containing tokens numbered from 1 to 15 . The token number determines which line is going to be paid.

Your earnings for the selected line depend on which option you chose: If you chose option $\mathrm{A}$ in that line, you will receive $\$ 1$. If you chose option B in that line, you will receive either $\$ 3$ or $\$ 0$. To determine your earnings in the case you chose option B there will be second random draw. A token will be randomly drawn out of the bingo cage now containing twenty tokens numbered from 1 to 20 . The token number is then compared with the numbers in the line selected (see the table). If the token number shows up in the left column you earn $\$ 3$. If the token number shows up in the right column you earn $\$ 0$.

Are there any questions? 


\section{Participant ID}

\begin{tabular}{|c|c|c|c|c|}
\hline $\begin{array}{l}\text { Decis } \\
\text { ion } \\
\text { no. }\end{array}$ & $\begin{array}{l}\text { Optio } \\
\text { n A }\end{array}$ & & $\begin{array}{l}\text { Option } \\
\text { B }\end{array}$ & $\begin{array}{l}\text { Please } \\
\text { choose } \\
\text { A or B }\end{array}$ \\
\hline 1 & $\$ 1$ & $\$ 3$ never & $\begin{array}{l}\$ 0 \text { if } 1,2,3,4,5,6,7,8,9,10,11,12,13 \\
\quad 14,15,16,17,18,19,20\end{array}$ & \\
\hline 2 & $\$ 1$ & $\$ 3$ if 1 comes out & $\begin{array}{l}\$ 0 \text { if } 2,3,4,5,6,7,8,9,10,11,12,13 \\
\quad 14,15,16,17,18,19,20\end{array}$ & \\
\hline 3 & $\$ 1$ & $\$ 3$ if 1 or 2 comes out & $\begin{aligned} \$ 0 & \text { if } 3,4,5,6,7,8,9,10,11,12,13,14,15 \\
& 16,17,18,19,20\end{aligned}$ & \\
\hline 4 & $\$ 1$ & $\$ 3$ if 1,2 or 3 & $\begin{aligned} \$ 0 & \text { if } 4,5,6,7,8,9,10,11,12,13,14,15 \\
& 16,17,18,19,20\end{aligned}$ & \\
\hline 5 & $\$ 1$ & $\$ 3$ if $1,2,3,4$ & $\begin{aligned} \$ 0 & \text { if } 5,6,7,8,9,10,11,12,13,14,15 \\
& 16,17,18,19,20\end{aligned}$ & \\
\hline 6 & $\$ 1$ & $\$ 3$ if $1,2,3,4,5$ & $\begin{aligned} \$ 0 & \text { if } 6,7,8,9,10,11,12,13,14,15 \\
& 16,17,18,19,20\end{aligned}$ & \\
\hline 7 & $\$ 1$ & $\$ 3$ if $1,2,3,4,5,6$ & $\begin{aligned} \$ 0 & \text { if } 7,8,9,10,11,12,13,14,15 \\
& 16,17,18,19,20\end{aligned}$ & \\
\hline 8 & $\$ 1$ & $\$ 3$ if $1,2,3,4,5,6,7$ & $\begin{array}{l}\$ 0 \text { if } 8,9,10,11,12,13,14,15 \\
16,17,18,19,20\end{array}$ & \\
\hline 9 & $\$ 1$ & $\$ 3$ if $1,2,3,4,5,6,7,8$ & $\begin{array}{l}\$ 0 \text { if } 9,10,11,12,13,14,15 \\
\quad 16,17,18,19,20\end{array}$ & \\
\hline 10 & $\$ 1$ & $\$ 3$ if $1,2,3,4,5,6,7,8,9$ & $\begin{array}{ll}\$ 0 & \text { if } 10,11,12,13,14,15 \\
& 16,17,18,19,20\end{array}$ & \\
\hline 11 & $\$ 1$ & $\$ 3$ if $1,2,3,4,5,6,7,8,9,10$ & $\$ 0$ if $11,12,13,14,15,16,17,18,19,20$ & \\
\hline 12 & $\$ 1$ & $\$ 3$ if $1,2,3,4,5,6,7,8,9,10,11$ & $\$ 0$ if $12,13,14,15,16,17,18,19,20$ & \\
\hline 13 & $\$ 1$ & $\$ 3$ if $1,2,3,4,5,6,7,8,9,10,11,12$ & $\$ 0$ if $13,14,15,16,17,18,19,20$ & \\
\hline 14 & $\$ 1$ & $\begin{array}{l}\$ 3 \text { if } 1,2,3,4,5,6,7,8,9,10 \\
11,12,13\end{array}$ & $\$ 0$ if $14,15,16,17,18,19,20$ & \\
\hline 15 & $\$ 1$ & $\begin{array}{l}\$ 3 \text { if } 1,2,3,4,5,6,7,8,9,10 \\
11,12,13,14\end{array}$ & $\$ 0$ if $15,16,17,18,19,20$ & \\
\hline
\end{tabular}




\section{INSTRUCTIONS FOR PART 2}

\section{YOUR DECISION}

The second part of the experiment consists of 30 decision-making periods. At the beginning of each period, you will be randomly and anonymously placed into a group of 4 participants. The composition of your group will be changed randomly every period. Each period, you and all other participants will be given an initial endowment of 60 francs. You will use this endowment to bid for a reward. The reward is worth 120 francs to you and the other three participants in your group. You may bid any integer number of francs between 0 and 60. An example of your decision screen is shown below.

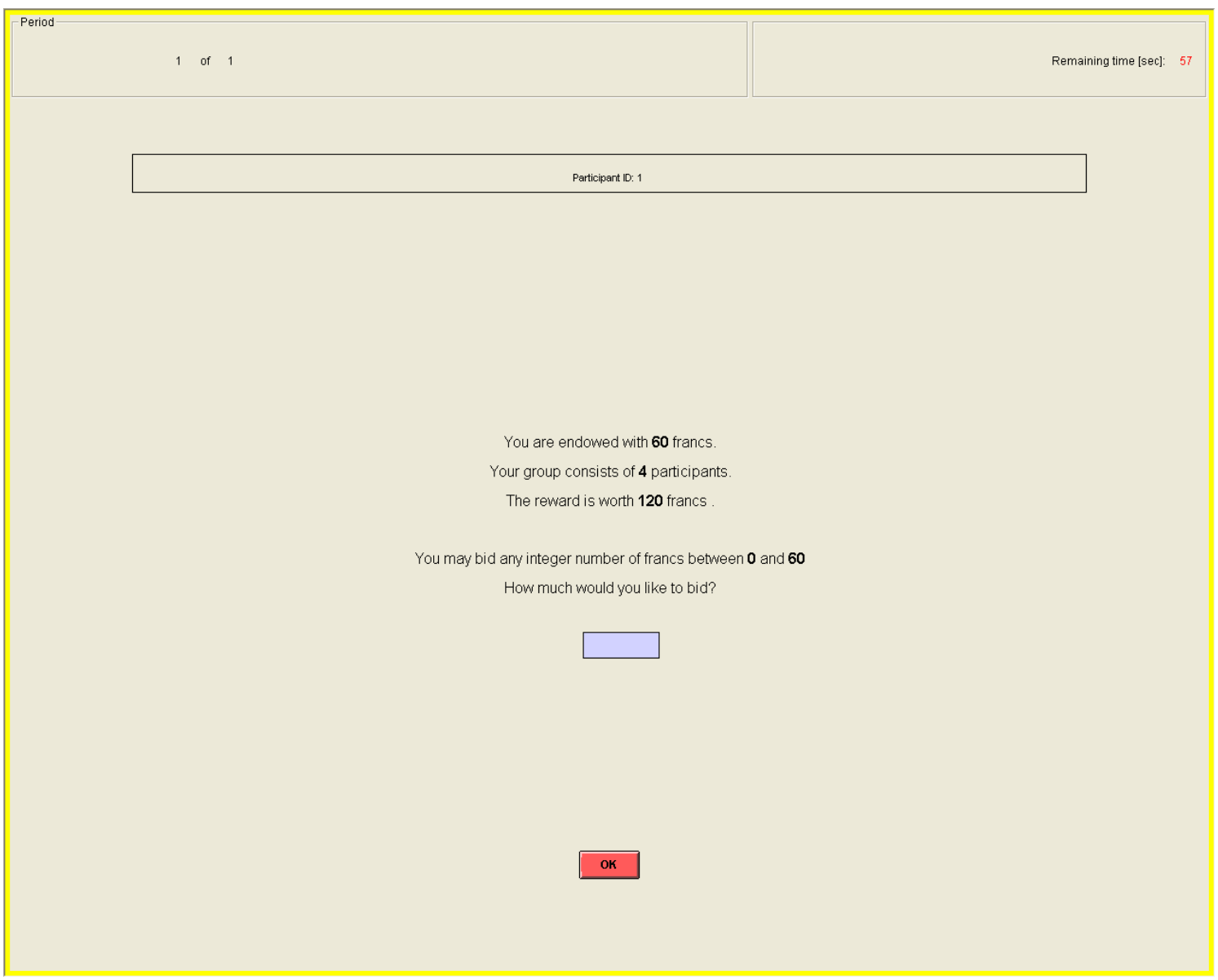

Decision Screen 


\section{YOUR EARNINGS}

After all participants have made their decisions, your earnings for the period are calculated. These earnings will be converted to cash and paid at the end of the experiment if the current period is one of the five periods that is randomly chosen for payment. If you receive the reward your period earnings are equal to your endowment plus the reward minus your bid. If you do not receive the reward your period earnings are equal to your endowment minus your bid.

If you receive the reward:

Earnings $=$ Endowment + Reward - Your Bid $=60+120-$ Your Bid

If you do not receive the reward:

Earnings $=$ Endowment - Your Bid $=60-$ Your Bid

The more you bid, the more likely you are to receive the reward. The more the other participants in your group bid, the less likely you are to receive the reward. Specifically, for each franc you bid you will receive one lottery ticket. At the end of each period the computer draws randomly one ticket among all the tickets purchased by 4 participants in the group, including you. The owner of the drawn ticket receives the reward of 120 francs. Thus, your chance of receiving the reward is given by the number of francs you bid divided by the total number of francs all 4 participants in your group bid.

Chance of receiving $=\frac{\text { Your Bid }}{\text { the reward }}=\frac{\text { Sum of all } 4 \text { Bids in your group }}{}$

In case all participants bid zero, the reward is randomly assigned to one of the four participants in the group. 


\section{Example of the Random Draw}

This is a hypothetical example used to illustrate how the computer is making a random draw. Let's say participant 1 bids 10 francs, participant 2 bids 15 francs, participant 3 bids 0 francs, and participant 4 bids 40 francs. Therefore, the computer assigns 10 lottery tickets to participant 1,15 lottery tickets to participant 2, 0 lottery tickets to participant 3 , and 40 lottery tickets for participant 4 . Then the computer randomly draws one lottery ticket out of $65(10+15+0+40)$. As you can see, participant 4 has the highest chance of receiving the reward: $0.62=40 / 65$. Participant 2 has $0.23=15 / 65$ chance, participant 1 has $0.15=10 / 65$ chance, and participant 3 has $0=$ 0/65 chance of receiving the reward.

After all participants make their bids, the computer will make a random draw which will decide who receives the reward. Then the computer will calculate your period earnings based on your bid and whether you received the reward or not.

At the end of each period, your bid, the sum of all bids in your group, whether you received the reward or not, and the earnings for the period are reported on the outcome screen as shown below. Once the outcome screen is displayed you should record your results for the period on your Personal Record Sheet under the appropriate heading. 


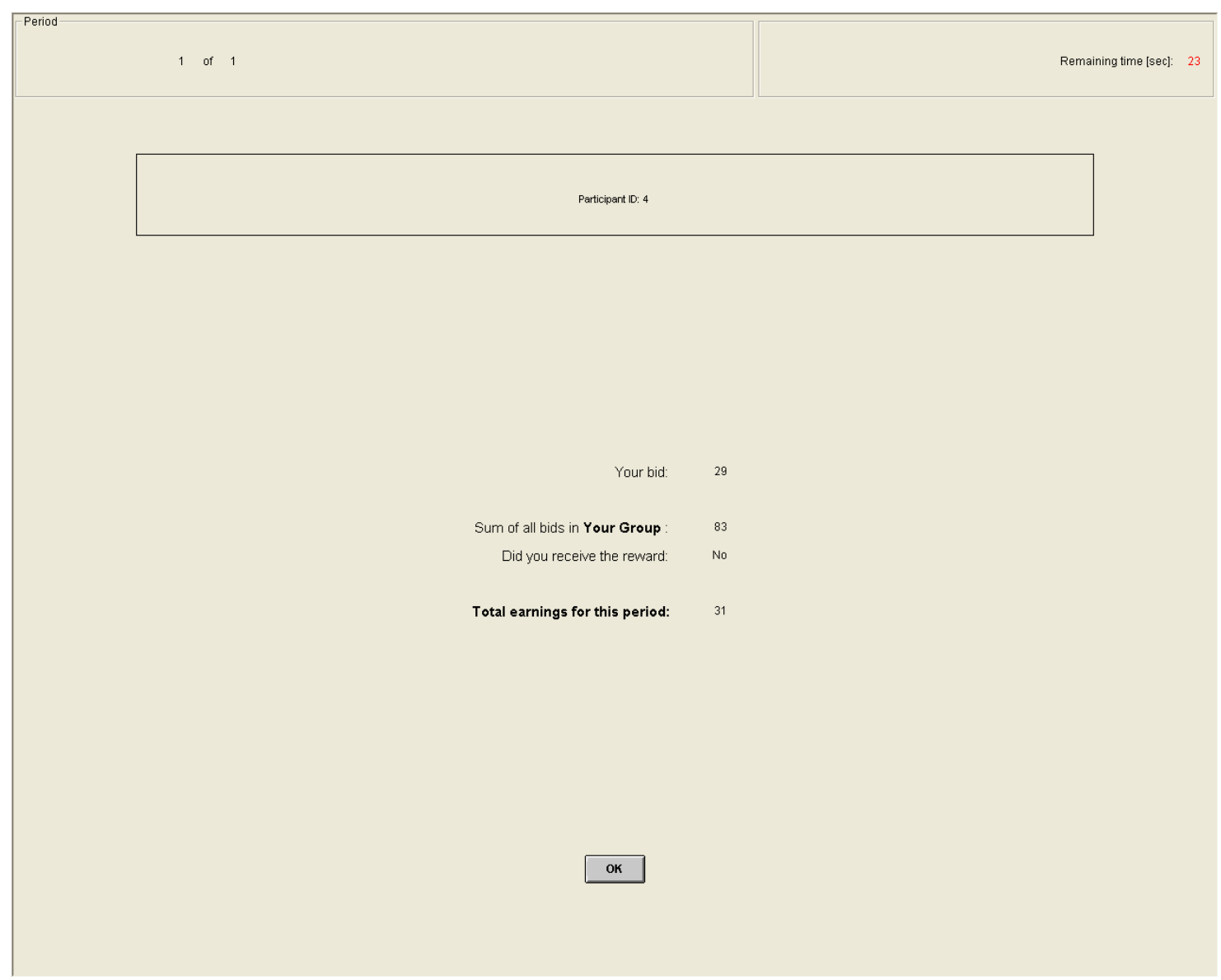

Outcome Screen

\section{IMPORTANT NOTES}

You will not be told which of the participants in this room are assigned to which group. At the beginning of each period you will be randomly re-grouped with three other participants to form a four person group. You can never guarantee yourself the reward. However, by increasing your contribution, you can increase your chance of receiving the reward. Regardless of who receives the reward, all participants will have to pay their bids. 
At the end of the experiment we will randomly choose 5 of the 30 periods for actual payment in Part 2 using a bingo cage. You will sum the total earnings for these 5 periods and convert them to a U.S. dollar payment, as shown on the last page of your record sheet.

Are there any questions?

\section{INSTRUCTIONS FOR PART 3}

The third part of the experiment consists of 30 decision-making periods. The rules for part 3 are almost the same as the rules for part 2. At the beginning of each period, you will be randomly and anonymously placed into a group of 4 participants. The composition of your group will be changed randomly every period. Each period you will be given an initial endowment of 60 francs. The only difference is that in part 3, you will use this endowment to bid for two rewards (instead of one reward). The first reward is worth 90 francs and the second reward is worth 30 francs to you and the other three participants in your group. You may bid any integer number of francs between 0 and 60 . After all participants have made their decisions, your earnings for the period are calculated in the similar way as in part 2.

If you receive the first reward:

Earnings $=$ Endowment + First Reward - Your Bid $=60+90-$ Your Bid

If you receive the second reward:

Earnings $=$ Endowment + Second Reward - Your Bid $=60+30-$ Your Bid

If you do not receive either reward:

Earnings $=$ Endowment - Your Bid $=60-$ Your Bid 
The more you bid, the more likely you are to receive either first or second reward. The more the other participants in your group bid, the less likely you are to receive any reward. Specifically, for each franc you bid you will receive one lottery ticket. At the end of each period the computer draws randomly one ticket among all the tickets purchased by 4 participants in the group, including you. The owner of the drawn ticket receives the first reward of 90 francs. Thus, your chance of receiving the first reward is given by the number of francs you bid divided by the total number of francs all 4 participants in your group bid.

$\begin{aligned} & \text { Chance of receiving } \\ & \text { the reward }\end{aligned}=\frac{\text { Your Bid }}{\text { Sum of all } 4 \text { Bids in your group }}$

In case you do not receive the first reward there is a second draw for the second reward. For the second draw computer draws randomly one ticket among all the tickets purchased by 3 participants in the group who did not receive the first reward (the participant who received the first reward is excluded from the second draw). The owner of the drawn ticket receives the second reward of 30 francs. Your chance of receiving the second reward is given by the number of francs you bid divided by sum of 3 bids made by the participants who did not receive the first reward.

$\begin{aligned} & \text { Chance of receiving } \\ & \text { the second reward }\end{aligned}=\begin{gathered}\text { Sum of all } 3 \text { Bids made by participants } \\ \text { who did not receive the first reward }\end{gathered}$

Each participant can win at most one reward. In case all participants bid zero, the first and the second reward is randomly assigned to two of the four participants in the group. 


\section{Example of the Random Draw}

This is a hypothetical example used to illustrate how the computer is making a random draw. Let's say participant 1 bids 10 francs, participant 2 bids 15 francs, participant 3 bids 0 francs, and participant 4 bids 40 francs. Therefore, the computer assigns 10 lottery tickets to participant 1,15 lottery tickets to participant 2, 0 lottery tickets to participant 3, and 40 lottery tickets for participant 4 . Then, for the first random draw, the computer randomly draws one lottery ticket out of $65(10+15+0+40)$. As you can see, participant 4 has the highest chance of receiving the first reward: $0.62=$ 40/65. Participant 2 has $0.23=15 / 65$ chance, participant 1 has $0.15=10 / 65$ chance, and participant 3 has $0=0 / 65$ chance of receiving the first reward.

After all participants make their bids, the computer makes a first random draw which decides who receives the first reward. Let's say that participant 4 has received the first reward. Then, for the second random draw, the computer randomly draws one lottery ticket out of $25(10+15+0)$. Since participant 4 has already received first reward he is excluded from the second draw. Now, as you can see, participant 2 has the highest chance of receiving the second reward: $0.6=15 / 25$. Participant 1 has $0.4=15 / 25$ chance and participant 3 has $0=0 / 25$ chance of receiving the second reward.

To summarize, all participants will make only one bid. After all participants have made their decisions, the computer will make two consecutive draws which will decide who receives the first and the second reward. Regardless of who receives the first and the second reward, all participants will have to pay their bids. Then the computer will calculate your period earnings based on your bid and whether you received either reward. 
At the end of each period, your bid, the sum of all bids in your group, whether you received the first reward or not, whether you received the second reward or not, and the earnings for the period are reported on the outcome screen. Once the outcome screen is displayed you should record your results for the period on your Personal Record Sheet under the appropriate heading.

At the end of the experiment we will randomly choose 5 of the 30 periods for actual payment in Part 3 using a bingo cage. You will sum the total earnings for these 5 periods and convert them to a U.S. dollar payment, as shown on the last page of your record sheet.

Are there any questions? 


\section{ESSAY 2 \\ EXPERIMENTAL COMPARISON OF MULTI-STAGE AND ONE-STAGE CONTESTS}

\subsection{Introduction}

Contests are economic, political, or social interactive situations in which agents expend resources to receive a certain prize. Examples include marketing and advertising by firms, patent races, and rent-seeking activities. All these contests differ from one another on multiple dimensions including group size, number of prizes, number of interrelated stages, and rules that regulate interactions. The most popular theories investigating different aspects of contests are based on the seminal model of rent-seeking introduced by Tullock (1980). The main focus of rent-seeking literature is the relationship between the extent of rent dissipation and underlying contest characteristics (Nitzan, 1994).

The majority of rent-seeking studies are based on the assumption that contests last for only one stage. Many contests in practice, however, last for multiple stages. In each stage contestants expend costly efforts in order to advance to the final stage and win the prize. Two major purposes of our study are to compare the performance of a one-stage contest versus a two-stage elimination contest and to examine whether over-dissipation is observed in both stages of the two-stage contest. 
We find that, contrary to the theory, the two-stage contest generates higher revenue and higher dissipation rates than the equivalent one-stage contest. Overdissipation is observed in both stages of the two-stage contest and experience diminishes over-dissipation in the first stage but not in the second stage. Our experiment also provides evidence that winning is a component in a subject's utility. A simple behavioral model that accounts for a non-monetary utility of winning can explain significant overdissipation in both contests. It can also explain why the two-stage contest generates higher revenue than the equivalent one-stage contest.

Recent theoretical models of multi-stage elimination contests reveal interesting dynamic aspects. Gradstein and Konrad (1999) consider a multi-stage elimination contest in which a number of parallel contests take place at each stage and only winners are promoted to the next stage. The authors show that, depending on the contest success function, a multi-stage contest may induce higher effort by the participants than a onestage contest. Under a lottery contest success function, however, the two structures are equivalent. In the same line of research, Baik and Lee (2000) study a two-stage elimination contest with effort carryovers. In this contest, players in two groups compete non-cooperatively to win a prize. In the first stage, each group selects a finalist who competes for the prize in the second stage. First-stage efforts are partially (or fully) carried over to the second stage. Baik and Lee (2000) demonstrate that, in the case of player-specific carryovers, the rent-dissipation rate (defined as the ratio of the expended total effort to the value of the prize) increases in the carryover rate and the rent is fully dissipated with full carryover. Other theoretical studies of multi-stage elimination contests have been conducted by Rosen (1986), Clark and Riis (1996), Gradstein (1998), 
Amegashie (1999), Stein and Rapoport (2005), Fu and $\mathrm{Lu}$ (2009), and Groh et al. (2009). ${ }^{18}$ All these studies investigate different aspects of multi-stage contests such as elimination procedures, interdependency between the stages, asymmetry between contestants, and resource constraints.

Since rent-seeking behavior in the field is difficult to measure, researchers have turned to experimental testing of the theory, with almost all studies focused on one-stage contests (Millner and Pratt, 1989, 1991; Shogren and Baik, 1991; Davis and Reilly, 1998; Potters et al., 1998; Anderson and Stafford, 2003). ${ }^{19}$ Despite considerable differences in experimental design among these studies, most share the major finding that aggregate rent-seeking behavior exceeds the equilibrium predictions. ${ }^{20}$ Several researchers have offered explanations for such behavior based on non-monetary utility of winning (Parco et al., 2005), misperception of probabilities (Baharad and Nitzan, 2008), quantal response equilibrium, and heterogeneous risk preferences (Goeree et al., 2002; Sheremeta, 2009).

There are currently only a few experimental studies that investigate the performance of multi-stage contests. ${ }^{21}$ Schmitt et al. (2004) develop and experimentally test a model in which rent-seeking expenditures in the current stage affect the probability of winning a contest in both current and future stages. Two other experimental studies are based on a two-stage rent-seeking model developed by Stein and Rapoport (2005). In this model all players have budget constraints. In the first stage, players compete within their

\footnotetext{
${ }^{18}$ Another type of multi-stage contests is the multi-battle contests. In a multi-battle contest, players compete in a sequence of simultaneous move contests to win a prize and the player whose number of victories reaches some given minimum number wins the prize. Such contests have been studied by Harris and Vickers (1985, 1987), Klumpp and Polborn (2006), and Konrad and Kovenock (2009).

${ }^{19}$ For empirical results on multi-stage elimination tournaments in sports see Ehrenberg and Bognanno (1990) and Bognanno (2001).

${ }^{20}$ Shogren and Baik (1991) do not find excessive expenditure.

${ }^{21}$ Exception is a study by Amegashie et al. (2007) on multi-stage all-pay auction.
} 
own groups by expending efforts, and the winner of each group proceeds to the second stage. In the second stage, players compete with one another to win a prize by expending additional efforts subject to budget constraints. The experimental studies of Parco et al. (2005) and Amaldoss and Rapoport (2009) reject the equilibrium model of Stein and Rapoport (2005) because of significant over-dissipation in the first stage. Both experimental studies conjecture that the non-monetary utility of winning plays a crucial role in explaining excessive over-dissipation in the first stage. Our experimental design is based on Gradstein's and Konrad's (1999) theoretical model, which compares the performance of a one-stage contest versus a multi-stage elimination contest.

\subsection{Theoretical Model}

In a simple one-stage contest $N$ identical players are competing for a prize of value $V$. Each risk-neutral player $i$ chooses his effort level, $e_{i}$, to win the prize. The probability that a contestant $i$ wins the prize is given by a lottery contest success function:

$$
p_{i}\left(e_{i}, e_{-i}\right)=\frac{e_{i}}{\sum_{j=1}^{N} e_{j}} .
$$

The contestant's probability of winning increases monotonically in own effort and decreases in the opponents' efforts. The expected payoff for risk-neutral player $i$ is given by

$$
E\left(\pi_{i}\right)=p_{i}\left(e_{i}, e_{-i}\right) V-e_{i} .
$$

That is, the probability of winning the prize, $p_{i}\left(e_{i}, e_{-i}\right)$, times the value of the prize, $V$, minus the effort expended, $e_{i}$. Differentiating (2) with respect to $e_{i}$ and 
accounting for the symmetric Nash equilibrium leads to a classical solution (Tullock, 1980),

$$
e^{*}=\frac{(N-1)}{N^{2}} V
$$

The simple model considered above is the building block of the contest theory. Gradstein and Konrad (1999) extended this model to study a multi-stage elimination contest. In their contest, $N$ players expend irreversible efforts in attempt to advance to the final stage. In the first stage, all players are divided into several groups. The winner of each group proceeds to the second stage, where contestants again are divided into competing groups, etc. The winner of the final stage receives a prize of value $V$. For our analysis, assume that there are only two stages. In the first stage, all players are divided into $K$ equal groups ( $N / K$ players per each group), with the winner of each group proceeding to the final. To analyze the two-stage contest, we apply backward induction. According to (3), in the second stage each finalist will expend effort of

$$
e_{2}^{*}=\frac{(K-1)}{K^{2}} V
$$

The resulting expected payoff in the second stage is $E\left(\pi_{2}^{*}\right)=V / K^{2}$. Knowing this, in the first stage $N / K$ players within each group compete as if the value of the prize was $E\left(\pi_{2}^{*}\right)$. Therefore, according to (3), the first stage equilibrium effort is given by

$$
e_{1}^{*}=\frac{(N-K)}{N^{2} K} V
$$

It is straightforward to show that, under the equilibrium strategy, the second order conditions hold and the resulting expected payoff is non-negative. ${ }^{22}$ Formulas (4) and (5)

\footnotetext{
${ }^{22}$ For a more detail derivations see Amegashie (1999), Gradstein and Konrad (1999), and Baik and Lee (2000).
} 
demonstrate how the first and second stage equilibrium efforts of each player depend on the prize value and the number of contestants in each stage.

\subsection{Experimental Design and Procedures}

\section{A. Experimental Design}

Our experiment consists of two different contests. The outline of the experimental design and theoretical predictions for each contest are shown in Table 2.3.1. In each contest there are 4 players and the prize value is 120 experimental francs. In a baseline treatment, all 4 contestants compete with each other for the prize in a one-stage (OS) contest. In equilibrium the revenue collected in such contest is 90 . The resulting dissipation rate, defined as the total efforts divided by the value of the prize, is 0.75 .

The second treatment is a two-stage (TS) contest which consists of 4 players split between 2 equal groups. The first stage winner of each group proceeds to the second stage and the winner of the second stage receives the prize. This contest resembles many real life situations. For instance, swimming or track tournaments often place competitors in different groups called "heats" with the winner of each "heat" proceeding to the finale. From Table 2.3.1, one can see that the major competition in TS arises between two players in the second stage. Therefore, the revenue collected from the second stage is substantially higher than the revenue collected from the first stage. The total revenue collected from both stages in TS treatment is 90 , which is equivalent to the revenue collected in OS treatment. This equivalence was proved by Gradstein and Konrad (1999) for a more general multi-stage contest under lottery contest success function. 
Table 2.3.1 - Experimental Design and Equilibrium Effort Levels

\begin{tabular}{lcc}
\hline \hline Treatment & OS & TS \\
\hline Value of the Prize, $V$ & 120 & 120 \\
Number of Players, $N$ & 4 & 4 \\
Number of Groups, $K$ & 1 & 2 \\
\hline Effort in stage 1, $e_{1}$ & 22.5 & 7.5 \\
Effort in stage 2, $e_{2}$ & - & 30 \\
Total Revenue & 90 & 90 \\
Dissipation Rate & 0.75 & 0.75 \\
\hline
\end{tabular}

\section{B. Experimental Procedures}

The experiment was conducted at the Vernon Smith Experimental Economics Laboratory. A total of 84 subjects participated in seven sessions (12 subjects per session). All subjects were Purdue University undergraduate students who participated in only one session of this study. Some students had participated in other economics experiments that were unrelated to this research.

The computerized experimental sessions were run using z-Tree (Fischbacher, 2007). Each experimental session proceeded in four parts. Subjects were given the instructions, available in the Appendix, at the beginning of each part and the experimenter read the instructions aloud. Before the actual experiment, subjects completed the quiz on the computer to verify their understanding of the instructions. The experiment started only after all subjects had answered all quiz questions. In the first part subjects made 15 choices in simple lotteries, similar to Holt and Laury (2002). Subjects 
were asked to state whether they preferred safe option A or risky option B. ${ }^{23}$ This method was used to elicit subjects' risk preferences. The second and the third parts corresponded to OS and TS treatments ran in different orders. In three sessions we ran OS treatment first and in three other sessions we ran TS treatment first. Each subject played 30 periods in OS treatment and 30 periods in TS treatment.

In each period, subjects were randomly and anonymously placed into a group of 4 players designated as participant $1,2,3$, or 4 . Subjects were randomly re-grouped after each period. In the first stage of TS treatment, participant 1 was paired against participant 2 and participant 3 was paired against participant 4 . In OS treatment, all 4 participants were paired against each other. At the beginning of each period, each subject received an endowment of 120 experimental francs. Subjects could use their endowments to expend efforts (make bids). After all subjects submitted their efforts, the computer chose the winner by implementing a simple lottery rule. In TS treatment, the two finalists - one from each pair - again made their efforts in the second stage. At the end of the second stage the computer chose the winner of the prize and displayed the following information to all subjects: the opponent's effort in the first stage, the other opponent's effort in the second stage, the result of the random draw in the first and second stage, and personal period earnings. Subjects who did not proceed to the second stage in TS treatment did not receive any information about the decisions made in the second stage. All subjects were informed that by increasing their efforts, they would increase their chance of winning and

\footnotetext{
${ }^{23}$ Option A yielded $\$ 1$ payoff with certainty, while option B yielded a payoff of either $\$ 3$ or $\$ 0$. The probability of receiving $\$ 3$ or $\$ 0$ varied across all 15 lotteries. The first lottery offered a $5 \%$ chance of winning $\$ 3$ and a $95 \%$ chance of winning $\$ 0$, while the last lottery offered a $70 \%$ chance of winning $\$ 3$ and a $30 \%$ chance of winning $\$ 0$.
} 
that, regardless of who wins the prize, all subjects would have to pay for their efforts. The instructions explained the structure of the game in detail.

In the final fourth part of the experiment, subjects were given an endowment of 120 francs and were asked to expend efforts in a one-stage contest in order to be a winner. The procedure followed closely to the OS treatment. The only difference was that the prize value was 0 francs. Subjects were told that they would be informed whether they won the contest or not. We used this procedure to receive an indication of how important it is for subjects to win when winning is costly and there is no monetary reward for winning.

At the end of the experiment, 1 out of 15 decisions subjects made in part one was randomly selected for payment. Subjects were also paid for 5 out of 30 periods in part two, for 5 out of 30 periods in part three, and for 1 decision they made in part four. The earnings were converted into US dollars at the rate of 60 francs to $\$ 1$. On average, subjects earned \$25 each which was paid in cash. The experimental sessions lasted for about 90 minutes.

2.4 Results

\section{A. General Results}

Table 2.4.1 summarizes average efforts, average net payoffs, and average dissipation rates over the treatments. The first striking feature of the data is that, on average, net payoffs in both treatments are negative and the actual dissipation rates are 
significantly greater than predicted. ${ }^{24}$ Similar findings are also reported in Davis and Reilly (1998) and Gneezy and Smorodinsky (2006). In both studies, revenues collected repeatedly exceeded the prize and subjects earned, on average, negative payoffs.

Result 1: There is significant over-dissipation in one-stage and two-stage contests.

Table 2.4.1 - Average Statistics

\begin{tabular}{lccccc}
\hline \hline \multirow{2}{*}{ Treatment } & \multicolumn{3}{c}{ OS } & & \multicolumn{3}{c}{ TS } \\
\cline { 2 - 3 } \cline { 5 - 6 } \cline { 5 - 6 } & Equilibrium & Actual & & Equilibrium & Actual \\
\hline Effort in stage 1 & 22.5 & $34.1(0.7)$ & & 7.5 & $18.9(0.6)$ \\
Effort in stage 2 & - & - & & 30 & $47.2(0.9)$ \\
Net Payoff & 7.5 & $-4.1(1.1)$ & & 7.5 & $-12.5(1.2)$ \\
Total Revenue & 90 & 136 & & 90 & 170 \\
Dissipation Rate & 0.75 & 1.14 & & 0.75 & 1.42 \\
\hline
\end{tabular}

Standard error of the mean in parentheses

There are several possible explanations for significant over-dissipation. First, it is possible that subjects expend significantly higher efforts because each period they receive a "free" endowment of 120 francs. ${ }^{25}$ Note that this endowment is substantially higher than the Nash equilibrium predictions. While the endowment itself has no theoretical impact, it certainly may have a behavioral impact, causing subjects to over-dissipate. The second explanation, related to the endowment size effect, is that subjects are likely to make "errors." Sheremeta (2009) shows how the quantal response equilibrium developed by McKelvey and Palfrey (1995), which accounts for errors made by individual subjects,

\footnotetext{
${ }^{24} \mathrm{We}$ ran a random effect regression on a constant separately for each treatment. Then we tested whether the constant coefficients are equal to the predicted theoretical values as in Table 2.4.1. We found significant differences for all treatments $(p$-value $<0.01)$.

${ }^{25}$ The endowment was chosen for several reasons. First, the endowment was chosen to be equal to the prize value to be consistent with other studies (Anderson and Stafford, 2003; Herrmann and Orzen, 2008). Second, the endowment of 120 francs was also chosen to be substantially higher than the Nash equilibrium predictions in order to make sure that in the two-stage contest subjects are not budget constrained (otherwise, we would have to provide additional endowment in the second stage of a two-stage contest which would cause substantial differences in earnings between two treatments).
} 
can explain some over-dissipation in lottery contests. Finally, and probably most importantly, subjects may have a non-monetary utility of winning. If that is the case, then in addition to the monetary value of 120 francs, subjects also compete to be winners. In Section $\mathrm{C}$ we provide evidence consistent with subjects having a non-monetary utility of winning which may explain why there is persistent over-dissipation in both treatments.
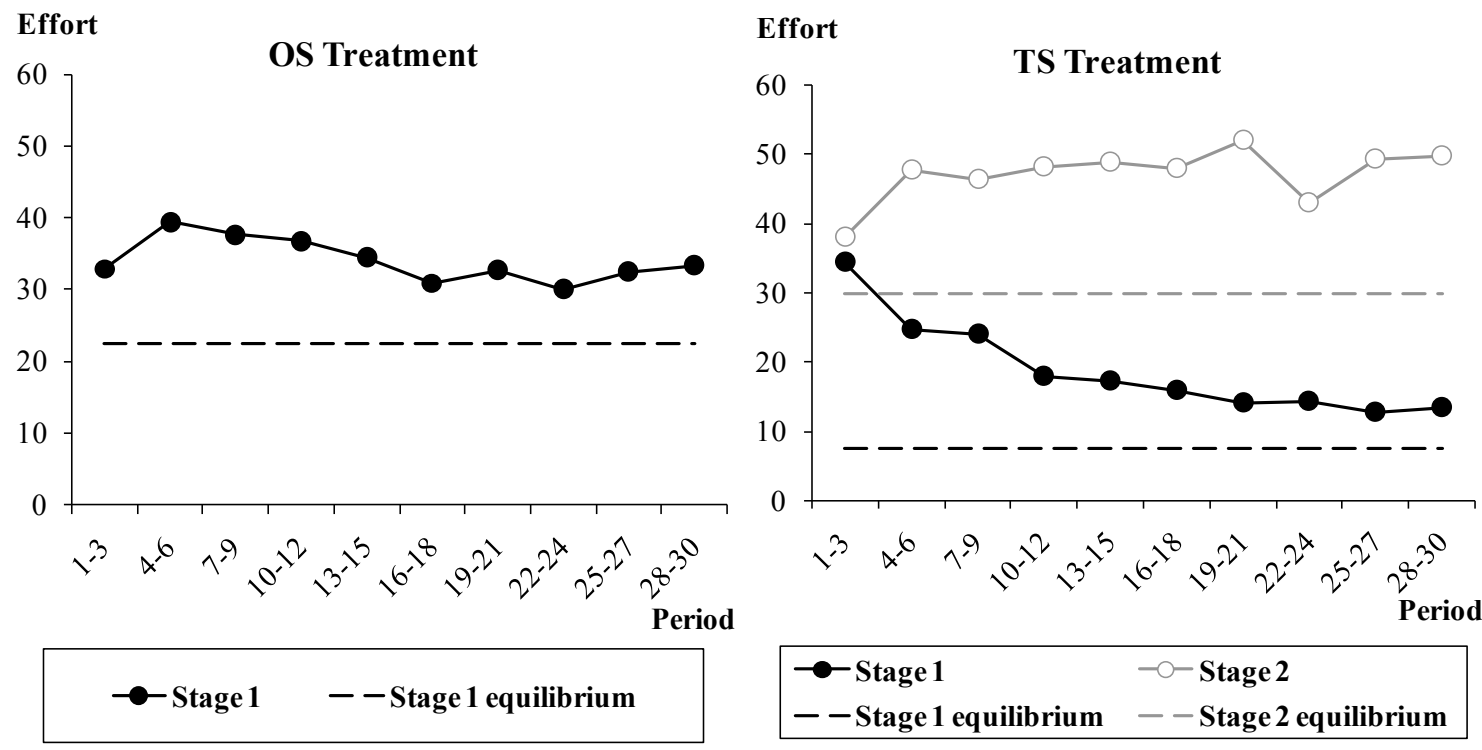

Figure 2.4.1 - Average Efforts by Treatments

It is important to emphasize that the over-dissipation in the TS treatment takes place in both stages of the competition. In the first stage of TS treatment, subjects expend an average effort of 18.9 which is more than double the equilibrium effort of 7.5 (Table 2.4.1). In the second stage, instead of the equilibrium effort of 30 , subjects expend an average effort of 47.2. The first and the second stage efforts in TS treatment are higher than theoretical values in all periods of the experiment (Figure 2.4.1).

Result 2: In two-stage contest, significant over-dissipation is observed in both stages. 
This result is very different from previous experimental findings. In a related study, Parco et al. (2005) find significant over-dissipation only in the first stage of a twostage contest. Given the first stage over-dissipation, and the fact that subjects are budget constrained, there is significant under-dissipation in the second stage. Our study shows that, after eliminating the budget constraints, over-dissipation in a two-stage contest occurs in both stages.

It is often argued that subjects need to get some experience in order to learn how to play the equilibrium. For that reason, Figure 2.4.1 displays the average effort over all 30 periods of the experiment. As players become more experienced, the average efforts made in the first stage of OS and TS treatments decrease. A simple regression of the first stage effort on a period trend shows a significant and negative relationship ( $p$-value $<$ 0.01). Although this is true for the first stage, it is not the case for the subjects' behavior in the second stage.

Result 3: Experience diminishes over-dissipation in the first stage but not in the second stage.

One possible reason for this finding is that at the beginning of the TS treatment, subjects apply similar strategies to both stages of the competition. This may occur because the decisions are cognitively difficult, which causes subjects to apply similar heuristics or "rules of thumb" to both stages (Gigerenzer and Goldstein, 1996). But with the repetition, subjects learn the strategic aspect of the two-stage contest and correctly redistribute their efforts between the first stage and the second stage. ${ }^{26}$ Note that in the

\footnotetext{
${ }^{26}$ We estimated a convergence model as in Noussair et al. (1995) and found that the first stage effort in OS and TS treatments does not converge to the predicted level of 22.5 and 7.5 ( $p$-value $<0.01$ for both
} 
second half of the experiment the magnitude of relative to the equilibrium overdissipation in the first stage is very similar to the magnitude of relative over-dissipation in the second stage (efforts are approximately one and a half times higher than the equilibrium predictions).

Another point that is worth noting is that subjects' efforts are distributed on the entire strategy space, which is clearly inconsistent with play at a unique pure strategy Nash equilibrium. Figure 2.4.2 displays the full distribution of efforts made in the first stage of the OS treatment and both stages of the TS treatment. Instead of a single point equilibrium, efforts range from 0 to 120 .

Result 4: There is substantial variance in individual efforts.
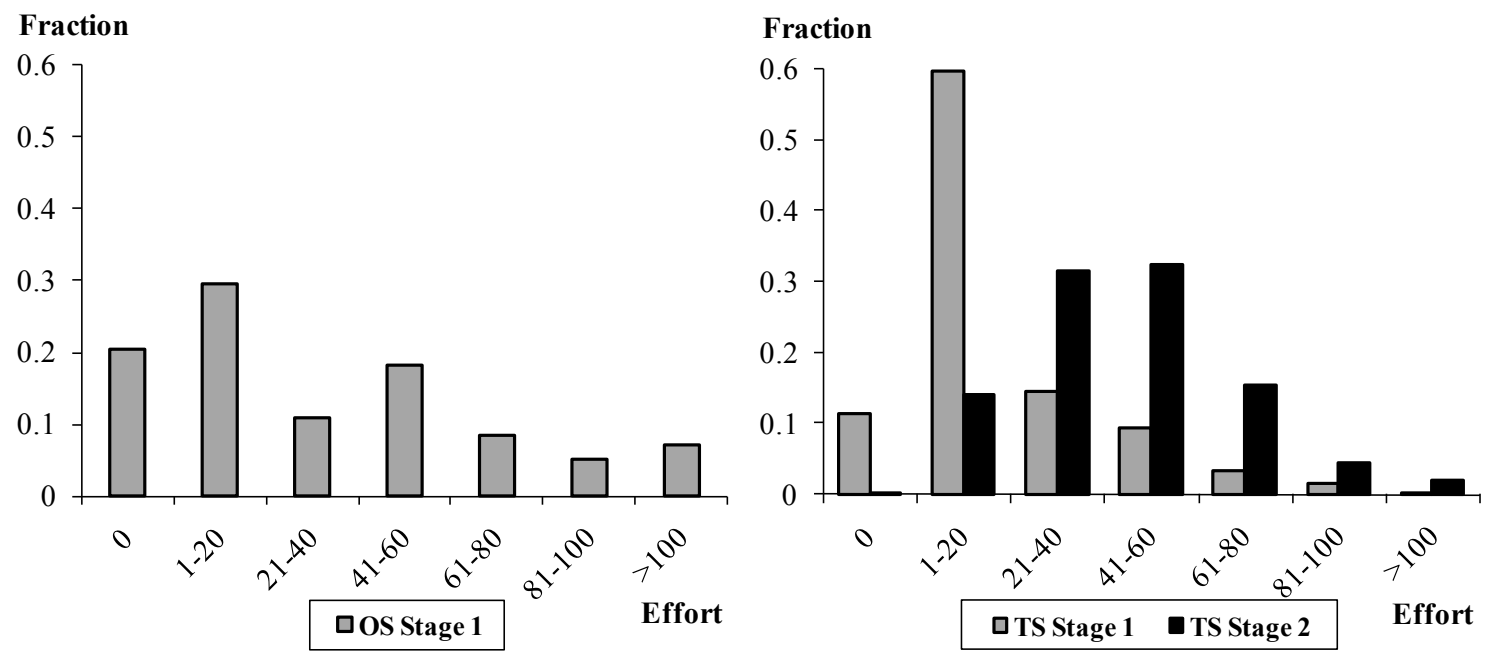

Figure 2.4.2 - Distribution of Efforts

High variance in individual efforts is consistent with previous experimental findings of the contest literature (Davis and Reilly, 1998; Potters et al., 1998). Several explanations have been offered. The first is that players may play an asymmetric 
equilibrium instead of a symmetric equilibrium. However, this argument does not apply to rent-seeking contests since the equilibrium in such contests is unique (Szidarovszky and Okuguchi, 1997). A second explanation is that subjects play a quantal response equilibrium by drawing their effort levels from the equilibrium distribution and thus causing some variance. A third explanation for effort fluctuations is based on the probabilistic nature of a contest which may from period to period affect individual decisions. Finally, it might be the case that subjects have different preferences towards risk which affect their behavior. In our experiment we elicited a measure of risk attitudes from a series of lotteries. We find substantial evidence that the measurement of risk attitude is a good predictor of subject's behavior in a contest: less risk-averse subjects expend higher efforts than more risk-averse subjects. ${ }^{27}$ This observation is consistent with theoretical work by Hillman and Katz (1984) and it can explain why individual efforts are not identical and instead are distributed on the entire strategy space.

\section{B. One-Stage versus Multi-Stage}

The major purpose of this study is to compare the performance of a one-stage contest with a multi-stage contest. Theoretically, OS and TS treatments should produce the same revenues and the same dissipation rates. However, Table 2.4.1 reveals a big difference in the revenue collected between the two treatments. The total revenue in the OS treatment is 136 , while the total revenue in the TS treatment is 170 . Subjects behave more aggressively in the multi-stage contest, exerting efforts that are $25 \%$ higher than

\footnotetext{
${ }^{27}$ We estimate several random effects models where the dependent variable is the total effort expended and the independent variables are the measurements of risk-aversion, session, and treatment dummy-variables. All specifications indicate that risk attitudes elicited from lotteries have significant influence on the effort expended in contests. The results of the estimation are available from the author upon request.
} 
efforts in the one-stage contest. The estimation of a random effects model, where the dependent variable is the effort and the independent variables are a treatment dummyvariable and a period trend, indicates that the treatment difference is significant ( $p$-value $<0.01)$. The difference is significant even when we exclude the first 15 periods of the experiment $(p$-value $<0.01)$.

Result 5: Two-stage contest generates higher revenue and higher dissipation rates than an equivalent one-stage contest.

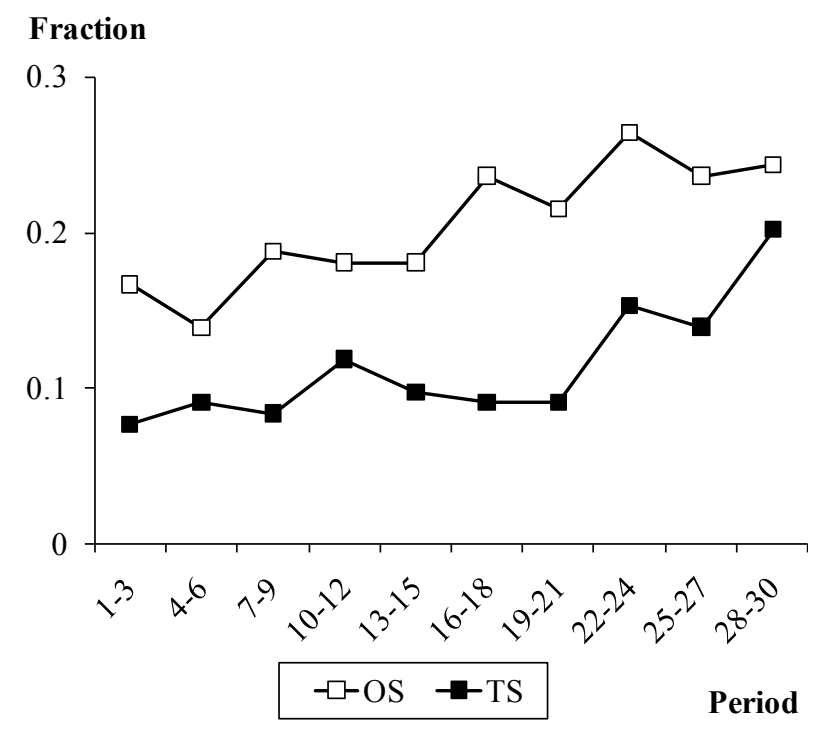

Figure 2.4.3 - Fraction of Drop-Outs (0 Effort) over 30 Periods

What is causing this substantial treatment difference? A closer look at the distribution of first stage efforts in Figure 2.4.2 reveals that there are almost twice as many drop-outs (effort of 0 ) in the OS treatment than in the TS treatment. From Figure 2.4.3 we see that this difference persists throughout all periods of the experiment. This difference is significant based on the estimation of a random effects probit model, where the dependent variable is whether or not the subject expended any effort and the independent variables are a treatment dummy-variable and a period trend ( $p$-value $<$ 
0.01). One immediate explanation comes from the fact that in the OS treatment each subject always competes with three other subjects at the same time while in the TS treatment each subject competes with only one other subject at the same time. Therefore, less competitive subjects drop out of the contest more often in the OS treatment than in the TS treatment. To look for more evidence on the "drop-out" effect, we conducted an additional session (12 subjects) where two subjects were given the endowment of 120 francs and were competing in a contest for a prize value of 120 francs. The results fully support the "drop-out" phenomenon: when the contest is between two players, there are only $2 \%$ of drop-outs, and when the contest is between four players, there are $16 \%$ of drop-outs. These differences suggest that "drop-out" phenomenon may partially explain the higher over-dissipation in TS treatment relative to OS treatment. ${ }^{28}$
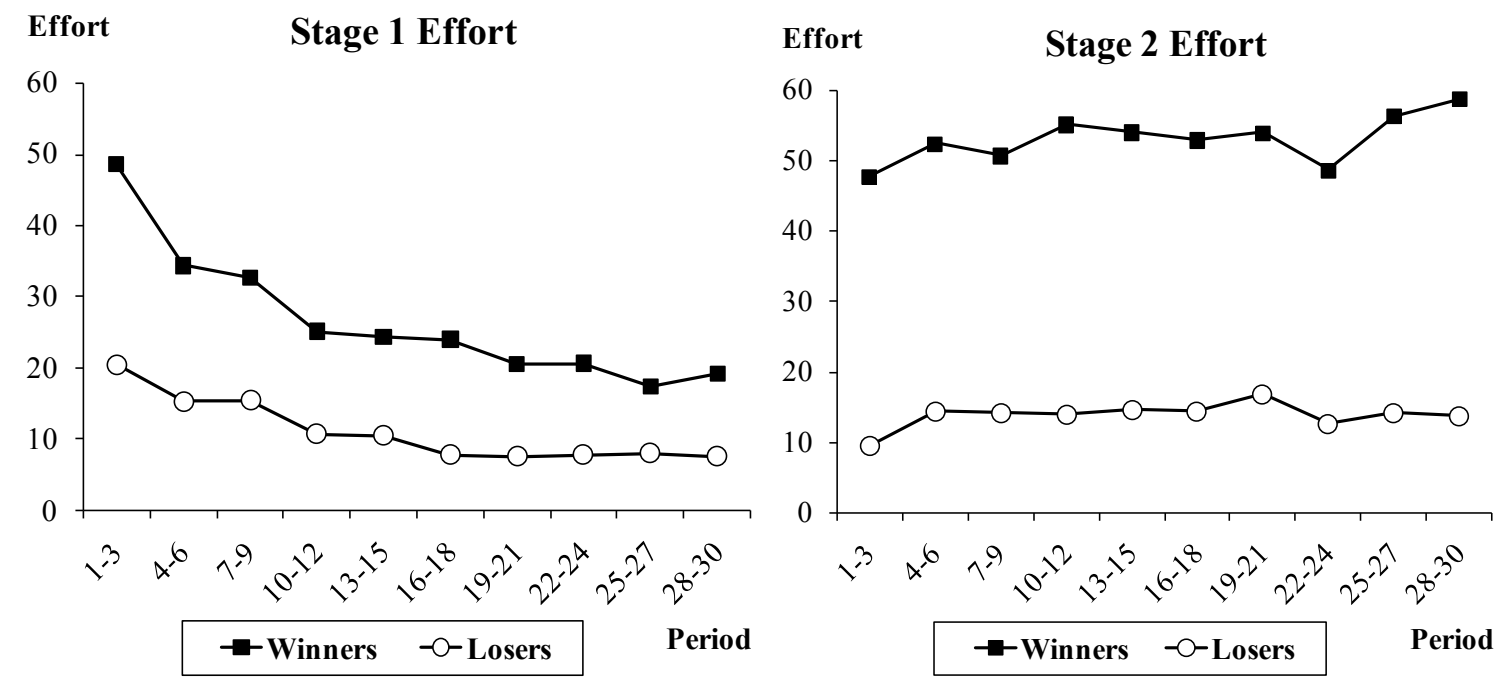

Figure 2.4.4 - The Average Effort by Outcome of Stage in TS treatment

Another explanation for significant over-dissipation in the TS treatment comes from the dynamic nature of the multi-stage contest. Figure 2.4.4 displays the average

\footnotetext{
${ }^{28}$ Muller and Schotter (2009) also documented the drop-out phenomenon in a contest developed by Moldovanu and Sela (2001).
} 
efforts by both winners and losers in each stage of the TS treatment. In equilibrium, symmetric players should expend the same effort and therefore should have equal probability of winning the first and second stage. However, in contrast to the equilibrium predictions, in both stages there is strong heterogeneity in individual behavior with winners expending significantly higher efforts than losers (the difference is especially large in the second stage). This important observation can also help to explain why a multi-stage contest generates significantly higher revenue than a one-stage contest. Subjects who expend higher efforts in the first stage are more likely to proceed to the second stage. Therefore, the first stage serves as a catalyst that helps to select more competitive subjects into the second stage. As a result of the selection effect, more competitive subjects compete twice in the same TS treatment.

To look for more evidence on the selection effect, we conducted two additional sessions (24 subjects) with a treatment very similar to the TS treatment. The only difference was that, instead of subjects making their own decisions in the first stage, subjects had to choose the efforts suggested by the computer. The computer randomly chose the first stage efforts, drawn independently for each subject from efforts observed in the first stage of original TS treatment. In the second stage, the two finalists made their own second stage efforts. This treatment was designed to eliminate the selection effect by exogenously assigning different subjects to the second stage. Consistent with our hypothesis, the average effort in the second stage significantly dropped from 47.2 originally to 35.3 ( $p$-value $<0.01) .{ }^{29}$ This finding suggests that the selection effect in fact

\footnotetext{
${ }^{29}$ We estimated a random effects model, where the dependent variable is the second stage effort and independent variable is a session dummy. The session dummy was significant with confidence level of $1 \%$.
} 
contributes to the over-dissipation in the TS treatment and it can also explain why the TS treatment generates higher dissipation than the OS treatment. ${ }^{30}$

Behavioral economists may recognize yet another possible explanation for significant over-dissipation in TS treatment. Instead of a selection effect in the first stage, one may argue that significant over-dissipation in the second stage is a result of a sunk cost fallacy. In economics, sunk costs are costs that have been incurred and which cannot be recovered. Rational economic agents should not let sunk costs influence their decisions. However, there is some evidence that economic agents fall prey to a sunk cost fallacy (Arkes and Blumer, 1985; Meyer, 1993; Friedman et al., 2007). In our experiment, subjects who get to the second stage of the TS treatment are the subjects who expended some positive efforts in the first stage. If subjects do not discard sunk costs associated with the first stage efforts, they will expend more efforts in the second stage. This implies that the second stage efforts should decrease when the first stage efforts decrease. The data clearly rejects this prediction. Although, with experience, subjects decrease the first stage efforts in TS treatment, they do not decrease the second stage efforts, as the sunk cost fallacy would predict (Result 3, right panel of Figure 2.4.1). Moreover, the data from the session investigating "drop-out" effects indicates that in a two-player contest subjects expend the average effort of 33.5. This effort is very close to effort expenditures of 35.3 in the session where subjects are exogenously assigned into the second stage of TS treatment. Note that the difference between these two sessions is that in the first session the selection and sunk cost effects are eliminated while in the

\footnotetext{
${ }^{30}$ Eriksson et al. (2009) report results from an experiment where subjects could self-select into a tournament. Their results show that when the subjects choose to enter a tournament, the average effort is higher than when the tournament payment scheme is imposed.
} 
second session only the selection effect is eliminated. Only minor differences in effort expenditures (33.5 versus 35.3 ) indicate that additional elimination of the sunk costs effect does change individual behavior. Therefore, we conclude that the sunk cost fallacy is unlikely to explain the differences in dissipation rates between TS and OS treatments. ${ }^{31}$

\section{Non-Monetary Utility of Winning}

Our theoretical predictions are based on the assumption of risk neutrality and symmetry among all the players. However, previous experimental research has found a significant effect of risk attitudes and demographic characteristics on the dissipation rate (Miller and Pratt, 1991; Schmidt et al., 2005; Sheremeta, 2009). Understanding individual differences and how these differences affect the behavior is very important since it can help to uncover important selection effects in contests.

Table 2.4.2 - Total Effort versus Different Characteristics

\begin{tabular}{lcc}
\hline \hline $\begin{array}{c}\text { Effort in a Contest } \\
\text { with No Prize }\end{array}$ & $\begin{array}{c}\text { Percent of } \\
\text { Subjects }\end{array}$ & $\begin{array}{c}\text { Average Effort in } \\
\text { Contests with Prize }\end{array}$ \\
\hline 0 & $57.7 \%$ & 31.3 \\
$0-10$ & $17.3 \%$ & 33.4 \\
$10-20$ & $2.6 \%$ & 39.9 \\
$20-30$ & $10.3 \%$ & 45.1 \\
$30-40$ & $1.3 \%$ & 50.6 \\
$40-50$ & $2.6 \%$ & 73.2 \\
$50-60$ & $2.6 \%$ & 74.3 \\
$>60$ & $5.8 \%$ & 54.2 \\
\hline
\end{tabular}

\footnotetext{
${ }^{31}$ Note that the sunk cost fallacy works in a different way than the selection effect. The sunk cost fallacy means that subjects who get to the second stage expend higher efforts because they are not willing to forgo their efforts in the first stage. The selection effect means that more competitive subjects get to the second stage and therefore they compete more during the second stage. We believe that selection effect and possibly sunk cost fallacy can explain why TS treatment generates higher dissipation than OS treatment.
} 
In our experiment we elicited a non-monetary value of winning. At the end of each session subjects were given a trivial task. In a treatment similar to OS treatment, all subjects were given an initial endowment of 120 francs and were asked to submit their efforts for a prize value 0 . Subjects were explicitly told that they would have to pay for their efforts. This task was used to elicit subject's non-monetary utility of winning. It is reasonable to assume that subjects who exert higher efforts in such a task have a higher non-monetary utility of winning. We were very surprised to discover that about $30 \%$ of subjects submitted efforts between 1 and 30 , and about $12 \%$ of subjects chose efforts higher than 30 (30 francs is equivalent to $\$ 0.5$ ). Table 2.4.2 shows that the higher efforts subjects expend in a contest with no prize, indicating higher non-monetary utility of winning, the higher their total effort in contests with prize is.

Table 2.4.3 - Determinants of Effort in Contests with Prize

\begin{tabular}{|c|c|c|c|c|}
\hline Specification & (1) & (2) & (3) & (4) \\
\hline Dependent variable, total effort & $\mathrm{OS}+\mathrm{TS}$ & $\mathrm{OS}+\mathrm{TS}$ & $\mathrm{OS}$ & $\mathrm{TS}$ \\
\hline period-trend & $-0.27 * * *$ & $-0.27 * * *$ & $-0.11^{* *}$ & $-0.56 * * *$ \\
\hline [inverse of a period trend, $1 / t$ ] & $(0.05)$ & $(0.05)$ & $(0.05)$ & $(0.10)$ \\
\hline non-monetary & $0.28 * * *$ & $0.26 * * *$ & $0.22 * * *$ & $0.41 * * *$ \\
\hline [effort in a contest with no prize] & $(0.08)$ & $(0.08)$ & $(0.08)$ & $(0.13)$ \\
\hline quiz & & $-2.93 *$ & -1.97 & $-5.48^{*}$ \\
\hline [number of correct quiz answers] & & $(1.75)$ & $(1.66)$ & $(2.27)$ \\
\hline OS dummy & $-6.24 * * *$ & $-6.24 * * *$ & & \\
\hline [1 if OS treatment] & $(1.12)$ & $(1.12)$ & & \\
\hline Observations & 3960 & 3960 & 2520 & 1440 \\
\hline \multicolumn{5}{|l|}{ Robust standard errors in parentheses } \\
\hline \multicolumn{5}{|c|}{$*$ significant at $10 \%, * *$ significant at $5 \%, * * *$ significant at $1 \%$} \\
\hline \multicolumn{5}{|c|}{ Random effect models account for individual characteristics of subjects } \\
\hline In each regression we control for ses & & & & \\
\hline
\end{tabular}

An obvious question that one may ask is whether the non-monetary utility of winning is a good predictor of subject's effort expenditures in a contest. To answer this question we estimate several random effects models where the dependent variable is the 
total effort expended and the independent variables are a period trend, a treatment dummy-variable, and non-monetary expenditures. We also include dummy-variables to control for session effects (not shown in the table). The results of the estimation are presented in Table 2.4.3. Specifications (1) and (2) use the data from both treatments, while specifications (3) and (4) use the data from OS and TS treatments separately.

The estimation of specification (1) in Table 2.4.3 indicates a very significant and positive correlation between the total effort and the non-monetary variable. One may argue that non-monetary coefficient is capturing confusion instead of a non-monetary utility of winning. The problem with such an argument is that subjects participated in the contest with no prize at the very end of the experiment, after they played other contests for 60 periods. In specification (2) we use the quiz variable measuring the number of correct quiz answers to further control for confusion. ${ }^{32}$ We find that subjects who understand the instructions better expend significantly lower efforts in contests. Nevertheless, controlling for confusion, the non-monetary coefficient is still positive and highly significant. This finding suggests that winning is a component in a subject's utility and that higher non-monetary utility of winning causes higher over-dissipation in contests. It is also evident that the non-monetary coefficient is almost twice as high in the TS treatment as in the OS treatment (specifications 3 versus 4). This suggests that the non-monetary utility of winning may be more important in a two-stage contest than in a one-stage contest.

\footnotetext{
${ }^{32}$ This is a measure of how well subjects understand the instructions. Before the actual experiment, subjects completed the quiz on the computer to verify their understanding of the instructions. If a subject's answer was incorrect, the computer provided the correct answer. The experiment started only after all participants had answered all quiz questions.
} 
What are the implications of these findings? First, the non-monetary utility of winning can explain why there is persistent over-dissipation in numerous experimental studies, including our own. Second, the non-monetary utility of winning can explain why the two-stage contest generates higher revenue than an equivalent one-stage contest. To formalize this argument, consider the following revised version of the theoretical model presented in Section 2.2. To account for a non-monetary utility of winning, we assume that each player, in addition to the prize of value $V$, has a non-monetary value of winning $w$. In such a case, the expected payoff of a risk-neutral player $i$ competing in a simple $N$ player one-stage contest is given by

$$
E\left(\pi_{i}\right)=p_{i}\left(e_{i}, e_{-i}\right)[V+w]-e_{i}
$$

The crucial difference from the original model is that the total value of winning the contest is $V+w$. Differentiating (6) with respect to $e_{i}$ leads to a Nash equilibrium solution

$$
e^{*}=\frac{(N-1)}{N^{2}}[V+w]
$$

Next, consider a two-stage contest, where in the first stage $N$ players are divided into $K$ equal groups. By backward induction, according to (7), in the second stage each finalist will expend effort of

$$
e_{2}^{*}=\frac{(K-1)}{K^{2}}[V+w]
$$

The resulting expected payoff in the second stage is $[V+w] / K^{2}$. Knowing this, in the first stage $N / K$ players within each group compete as if the value of the prize was $[V+w] / K^{2}$, and the first stage non-monetary value of winning was $w$. Therefore, according to (7), the first stage equilibrium effort is given by 


$$
e_{1}^{*}=\frac{(N-K)}{N^{2} K}\left[V+w+w K^{2}\right] .
$$

Note that this simple behavioral model can explain several phenomena observed in our experiment. First, it can explain significant over-dissipation in both contests and in both stages of the competition. It is also straightforward to show that this model predicts higher effort expenditures in the two-stage contest, $\frac{(N-1)}{N}[V+w]+\frac{(N-K)}{N} K w$, than in the one-stage contest, $\frac{(N-1)}{N}[V+w]$. The reason behind this result is that in the two-stage contest some players receive non-monetary utility of winning twice (in the first stage and then in the second stage), while in the one-stage contest such utility is received only once. One possible extension to this model is to assume that the non-monetary value of winning depends on the number of contestants, i.e. $w=w(N)$. For example, one can replicate all qualitative predictions of our behavioral model under the assumption of linear nonmonetary utility of winning, i.e. $w(N)=w N$. Obviously, the correct specification of the non-monetary utility of winning is an important question for future research.

The non-monetary utility of winning $w$ in (7), (8), and (9) is not directly observable. It can be elicited through a simple experiment in which $V=0$, however, as we did in the final stage of our experiment. The data suggests that the average non-monetary value of winning is about 62.9 experimental francs, which is equivalent to $\$ 1.05 .{ }^{33}$ Accounting for such addition utility of winning, the revised equilibrium effort in the one-stage contest is 34.3. This prediction is almost identical to the average effort of 34.1 that subjects expended in OS treatment. In the two-stage contest, the revised first stage equilibrium effort is 27.1 and the second stage effort is 45.7 . These predictions are also relatively

\footnotetext{
${ }^{33}$ Equation (7) implies that $w=e N^{2} /(N-1)-V$. In a contest with no prize, $V=0$ and $N=4$, subjects expend an average effort of $e=11.8$. Therefore, the implied value of $w$ is 62.9.
} 
close to the observed actual efforts of 18.9 and 47.4 in TS treatment. One reason why our behavioral model overestimates the effort expenditures in the first stage is due to the assumption that subjects correctly account for the future utility of winning in the second stage. However, if subjects are myopic and they do not recognize the possibility of receiving an additional utility of winning in the second stage then their expenditures in the first stage will be lower.

\subsection{Conclusion}

Many contests in the real world last for multiple stages. In each stage contestants exert costly efforts in order to advance to the final stage and win the prize. The majority of experimental studies, however, focus on one-stage static contests. In this article, we depart from conventional practice by studying a multi-stage elimination contest and comparing its performance with a one-stage contest. We find significant over-dissipation in both contests and in both stages of the competition. This over-dissipation can be explained by a non-monetary utility of winning.

More importantly, contrary to the theory, the two-stage contest generates higher revenue than the equivalent one-stage contest. We propose several explanations for this finding. First explanation is based on the observation that there are twice as many dropouts in the one-stage contest than there are in the two-stage contest. Another explanation is a selection effect which implies that more competitive subjects win the first stage and thus proceed to the second stage. As a result, more competitive subjects compete twice in the same two-stage contest. We find evidence for the selection effect: when subjects are exogenously assigned into the second stage, subjects on average expend significantly 
lower second stage efforts than when the assignment is endogenous. Finally, and probably most importantly, we find that the non-monetary utility of winning can account for the majority of differences between the one-stage and two-stage contests.

The results of this study have important implications for contest design (Rosen, 1986; Gradstein and Konrad, 1999). By using a multi-stage contest instead of a one-stage contest, the designer can extract higher total efforts from contestants. Moreover, by using a multi-stage contest, the designer can increase participation rate. Knowing that the major competition takes place in the latter stages, the designer can guarantee high performance from contestants in the final stage of a multi-stage contest.

This study also points out the importance of modeling theoretically a number of behavioral considerations such as heterogeneity between players and a non-monetary utility of winning. By incorporating these behavioral considerations, we can understand why individual behavior does not comply with the equilibrium predictions of classical models. Obviously, this study also opens several interesting questions about how one should model the non-monetary utility of winning, what are the alternative elicitation mechanisms that can reveal individual preferences towards winning, and what are the implications of such preferences in different economic environments. 


\subsection{References}

Amaldoss, W., \& Rapoport, A. (2009). Excessive expenditure in two-stage contests: Theory and experimental evidence. In F. Columbus (Ed.), Game Theory: Strategies, Equilibria, and Theorems. Hauppauge, NY: Nova Science Publishers

Amegashie, J. A. (1999). The design of rent-seeking competitions: Committees preliminary and final contests. Public Choice, 99, 63-76.

Amegashie, J.A., Cadsby, C.B., \& Song, Y. (2007). Competitive burnout: Theory and experimental evidence. Games and Economic Behavior, 59, 213-239.

Anderson, L.R., \& Stafford, S.L. (2003). An experimental analysis of rent seeking under varying competitive conditions. Public Choice, 115, 199-216.

Arkes, H.R., \& Blumer, C. (1985). The psychology of sunk cost. Organizational Behavior and Human Decision Processes, 35, 124-140.

Baharad, E., \& Nitzan, S. (2008). Contest Efforts in Light of Behavioural Considerations. Economic Journal, 118, 2047-2059.

Baik, K.H., \& Lee, S. (2000). Two-stage rent-seeking contests with carryovers. Public Choice, 103, 285-296.

Bognanno, M.L., (2001). Corporate Tournaments, Journal of Labor Economics, 19, 290315.

Clark, D.J. \& Riis, C. (1996). A multi-winner nested rent-seeking contest. Public Choice, $87,177-184$.

Davis, D., \& Reilly, R. (1998). Do many cooks always spoil the stew? An experimental analysis of rent seeking and the role of a strategic buyer. Public Choice, 95, 89-115. 
Ehrenberg, R.G., \& Bognanno, M.L. (1990). Do Tournaments Have Incentive Effects?, Journal of Political Economy, 98, 1307-1324.

Eriksson, T., Teyssier, S., Villeval, M.C. (2009). Self-selection and the efficiency of tournaments, Economic Inquiry, forthcoming.

Fischbacher, U. (2007). z-Tree: Zurich Toolbox for Ready-made Economic experiments. Experimental Economics, 10, 171-178.

Friedman, D., Pommerenke, K., Lukose, R., Milam, G., \& Huberman, B. (2007). Searching for the sunk cost fallacy. Experimental Economics, 10, 79-104.

Fu, Q., \& Lu, J. (2009). Optimal Multi-Stage Contest. Economic Theory, forthcoming. Gigerenzer, G., \& Goldstein, D.G. (1996). Reasoning the fast and frugal way: Models of bounded rationality. Psychological Review. 103, 650-669.

Gneezy, U., \& Smorodinsky, R. (2006). All-Pay Auctions - An Experimental Study. Journal of Economic Behavior and Organization, 61, 255-275.

Goeree, J., Holt, C., \& Palfrey, T. (2002). Quantal Response Equilibrium and Overbidding in Private-Value Auctions. Journal of Economic Theory, 247-272.

Gradstein, M. (1998). Optimal contest design: Volume and timing of rent seeking in contests. European Journal of Political Economy, 14, 575-585.

Gradstein, M., \& Konrad, K.A. (1999). Orchestrating Rent Seeking Contests. Economic Journal, 109, 536-45.

Groh, C., Sela, A., Moldovanu, B., \& Sunde, U. (2009). Optimal Seedings in Elimination Tournaments. Economic Theory, forthcoming.

Harris, C., \& Vickers, J. (1985). Perfect equilibrium in a model of a race. Review of Economic Studies, 52, 193-209. 
Harris, C., \& Vickers, J. (1987). Racing with Uncertainty, Review of Economics Studies, 54, 1-21.

Herrmann, B., \& Orzen, H. (2008). The appearance of homo rivalis: Social preferences and the nature of rent seeking. University of Nottingham, Working Paper.

Hillman, A.L., \& Katz, E. (1984). Risk-averse rent seekers and the social cost of monopoly power. Economic Journal, 94, 104-110.

Holt, C.A., \& Laury, S.K. (2002). Risk Aversion and Incentive Effects. American Economic Review, 92, 1644-1655.

Klumpp, T., \& Polborn, M.K., (2006). Primaries and the New Hampshire Effect. Journal of Public Economics, 90, 1073 -3114.

Konrad, K. A., \& Kovenock, D. (2009). Multi-battle contests. Games and Economic Behavior, forthcoming.

McKelvey, R., \& Palfrey, T. (1995). Quantal Response Equilibria for Normal Form Games. Games and Economic Behavior, 10, 6-38.

Meyer, D. J. (1993). First price auctions with entry: An experimental investigation. The Quarterly Journal of Economics and Finance, 33, 107-122.

Millner, E.L., \& Pratt, M.D. (1989). An experimental investigation of efficient rentseeking. Public Choice, 62, 139-151.

Millner, E.L., \& Pratt, M.D. (1991). Risk aversion and rent seeking: An extension and some experimental evidence. Public Choice, 69, 91-92.

Moldovanu, B., \& Sela, A. (2001). The Optimal Allocation of Prizes in Contests. American Economic Review, 91, 542-558. 
Muller, W., \& Schotter, A. (2009). Workaholics and Drop Outs in Optimal Organizations. Journal of the European Economic Association, forthcoming.

Nitzan, S. (1994). Modelling rent-seeking contests. European Journal of Political Economy, 10, 41-60.

Noussair, C., Plott, C., Riezman, R. (1995). An Experimental Investigation of the Patterns of International Trade. American Economic Review, 85, 462-91.

Parco J., Rapoport A., \& Amaldoss W. (2005). Two-stage Contests with Budget Constraints: An Experimental Study. Journal of Mathematical Psychology, 49, 320338.

Potters, J.C., De Vries, C.G., \& Van Linden, F. (1998). An experimental examination of rational rent seeking. European Journal of Political Economy, 14, 783-800.

Rosen, S. (1986). Prizes and incentives in elimination tournaments. American Economic Review, 76, 701-715.

Schmitt, P., Shupp, R., Swope, K., \& Cadigan, J. (2004). Multi-period rent-seeking contests with carryover: Theory and experimental evidence. Economics of Governance, 5, 187-211.

Sheremeta, R.M. (2009). Contest Design: An Experimental Investigation. Economic Inquiry, forthcoming.

Shogren, J.F., \& Baik, K.H. (1991). Reexamining Efficient Rent-Seeking in Laboratory Markets. Public Choice, 69, 69-79.

Stein, W.E., \& Rapoport, A. (2005). Symmetric multi-stage contests with budget constraints. Public Choice, 124, 309-328. 
Szidarovszky, F., \& Okuguchi, K. (1997). On the Existence and Uniqueness of Pure Nash Equilibrium in Rent-Seeking Games. Games and Economic Behavior, 18, 135-140. Tullock, G. (1980). Efficient Rent Seeking. In James M. Buchanan, Robert D. Tollison, Gordon Tullock, (Eds.), Toward a theory of the rent-seeking society. College Station, TX: Texas A\&M University Press, pp. 97-112. 


\subsection{Appendix}

\section{GENERAL INSTRUCTIONS}

This is an experiment in the economics of strategic decision making. Various research agencies have provided funds for this research. The instructions are simple. If you follow them closely and make appropriate decisions, you can earn an appreciable amount of money.

The experiment will proceed in four parts. Each part contains decision problems that require you to make a series of economic choices which determine your total earnings. The currency used in Part 1 of the experiment is U.S. Dollars. The currency used in Part 2, 3 and 4 of the experiment is francs. Francs will be converted to U.S. Dollars at a rate of 60 francs to _ 1 dollar. At the end of today's experiment, you will be paid in private and in cash. 12 participants are in today's experiment.

It is very important that you remain silent and do not look at other people's work. If you have any questions, or need assistance of any kind, please raise your hand and an experimenter will come to you. If you talk, laugh, exclaim out loud, etc., you will be asked to leave and you will not be paid. We expect and appreciate your cooperation.

At this time we proceed to Part 1 of the experiment.

\section{INSTRUCTIONS FOR PART 1}

\section{YOUR DECISION}

In this part of the experiment you will be asked to make a series of choices in decision problems. How much you receive will depend partly on chance and partly on the choices you make. The decision problems are not designed to test you. What we want to 
know is what choices you would make in them. The only right answer is what you really would choose.

For each line in the table in the next page, please state whether you prefer option A or option B. Notice that there are a total of 15 lines in the table but just one line will be randomly selected for payment. You ignore which line will be paid when you make your choices. Hence you should pay attention to the choice you make in every line. After you have completed all your choices a token will be randomly drawn out of a bingo cage containing tokens numbered from 1 to 15 . The token number determines which line is going to be paid.

Your earnings for the selected line depend on which option you chose: If you chose option A in that line, you will receive $\$ 1$. If you chose option B in that line, you will receive either $\$ 3$ or $\$ 0$. To determine your earnings in the case you chose option B there will be second random draw. A token will be randomly drawn out of the bingo cage now containing twenty tokens numbered from 1 to 20 . The token number is then compared with the numbers in the line selected (see the table). If the token number shows up in the left column you earn $\$ 3$. If the token number shows up in the right column you earn $\$ 0$.

Are there any questions? 


\section{Participant ID}

\begin{tabular}{|c|c|c|c|c|}
\hline $\begin{array}{l}\text { Decis } \\
\text { ion } \\
\text { no. }\end{array}$ & $\begin{array}{l}\text { Optio } \\
\text { n A }\end{array}$ & & $\begin{array}{l}\text { Option } \\
\text { B }\end{array}$ & $\begin{array}{l}\text { Please } \\
\text { choose } \\
\text { A or B }\end{array}$ \\
\hline 1 & $\$ 1$ & $\$ 3$ never & $\begin{array}{l}\$ 0 \text { if } 1,2,3,4,5,6,7,8,9,10,11,12,13 \\
\quad 14,15,16,17,18,19,20\end{array}$ & \\
\hline 2 & $\$ 1$ & $\$ 3$ if 1 comes out & $\begin{array}{c}\$ 0 \text { if } 2,3,4,5,6,7,8,9,10,11,12,13 \\
\quad 14,15,16,17,18,19,20\end{array}$ & \\
\hline 3 & $\$ 1$ & $\$ 3$ if 1 or 2 comes out & $\begin{aligned} \$ 0 & \text { if } 3,4,5,6,7,8,9,10,11,12,13,14,15 \\
& 16,17,18,19,20\end{aligned}$ & \\
\hline 4 & $\$ 1$ & $\$ 3$ if 1,2 or 3 & $\begin{aligned} \$ 0 & \text { if } 4,5,6,7,8,9,10,11,12,13,14,15 \\
& 16,17,18,19,20\end{aligned}$ & \\
\hline 5 & $\$ 1$ & $\$ 3$ if $1,2,3,4$ & $\begin{aligned} \$ 0 & \text { if } 5,6,7,8,9,10,11,12,13,14,15 \\
& 16,17,18,19,20\end{aligned}$ & \\
\hline 6 & $\$ 1$ & $\$ 3$ if $1,2,3,4,5$ & $\begin{aligned} \$ 0 & \text { if } 6,7,8,9,10,11,12,13,14,15 \\
& 16,17,18,19,20\end{aligned}$ & \\
\hline 7 & $\$ 1$ & $\$ 3$ if $1,2,3,4,5,6$ & $\begin{aligned} \$ 0 & \text { if } 7,8,9,10,11,12,13,14,15 \\
& 16,17,18,19,20\end{aligned}$ & \\
\hline 8 & $\$ 1$ & $\$ 3$ if $1,2,3,4,5,6,7$ & $\begin{array}{l}\$ 0 \text { if } 8,9,10,11,12,13,14,15 \\
16,17,18,19,20\end{array}$ & \\
\hline 9 & $\$ 1$ & $\$ 3$ if $1,2,3,4,5,6,7,8$ & $\begin{array}{l}\$ 0 \text { if } 9,10,11,12,13,14,15 \\
\quad 16,17,18,19,20\end{array}$ & \\
\hline 10 & $\$ 1$ & $\$ 3$ if $1,2,3,4,5,6,7,8,9$ & $\begin{array}{ll}\$ 0 & \text { if } 10,11,12,13,14,15 \\
& 16,17,18,19,20\end{array}$ & \\
\hline 11 & $\$ 1$ & $\$ 3$ if $1,2,3,4,5,6,7,8,9,10$ & $\$ 0$ if $11,12,13,14,15,16,17,18,19,20$ & \\
\hline 12 & $\$ 1$ & $\$ 3$ if $1,2,3,4,5,6,7,8,9,10,11$ & $\$ 0$ if $12,13,14,15,16,17,18,19,20$ & \\
\hline 13 & $\$ 1$ & $\$ 3$ if $1,2,3,4,5,6,7,8,9,10,11,12$ & $\$ 0$ if $13,14,15,16,17,18,19,20$ & \\
\hline 14 & $\$ 1$ & $\begin{array}{l}\$ 3 \text { if } 1,2,3,4,5,6,7,8,9,10 \\
11,12,13\end{array}$ & $\$ 0$ if $14,15,16,17,18,19,20$ & \\
\hline 15 & $\$ 1$ & $\begin{array}{l}\$ 3 \text { if } 1,2,3,4,5,6,7,8,9,10 \\
11,12,13,14\end{array}$ & $\$ 0$ if $15,16,17,18,19,20$ & \\
\hline
\end{tabular}




\section{INSTRUCTIONS FOR PART 2}

\section{YOUR DECISION}

The second part of the experiment consists of 30 decision-making periods and each period consists of two stages. At the beginning of each period, you will be randomly and anonymously placed into a group of four participants. The composition of your group will be changed randomly every period. Each period you will be randomly and anonymously assigned as participant $1,2,3$, or 4 . In Stage 1 participant 1 will be paired with participant 2 and participant 3 will be paired with participant 4 . All four participants will be given an initial endowment of 120 francs. You will use this endowment to bid for a chance of participating in the final Stage 2. An example of your decision screen is shown below.

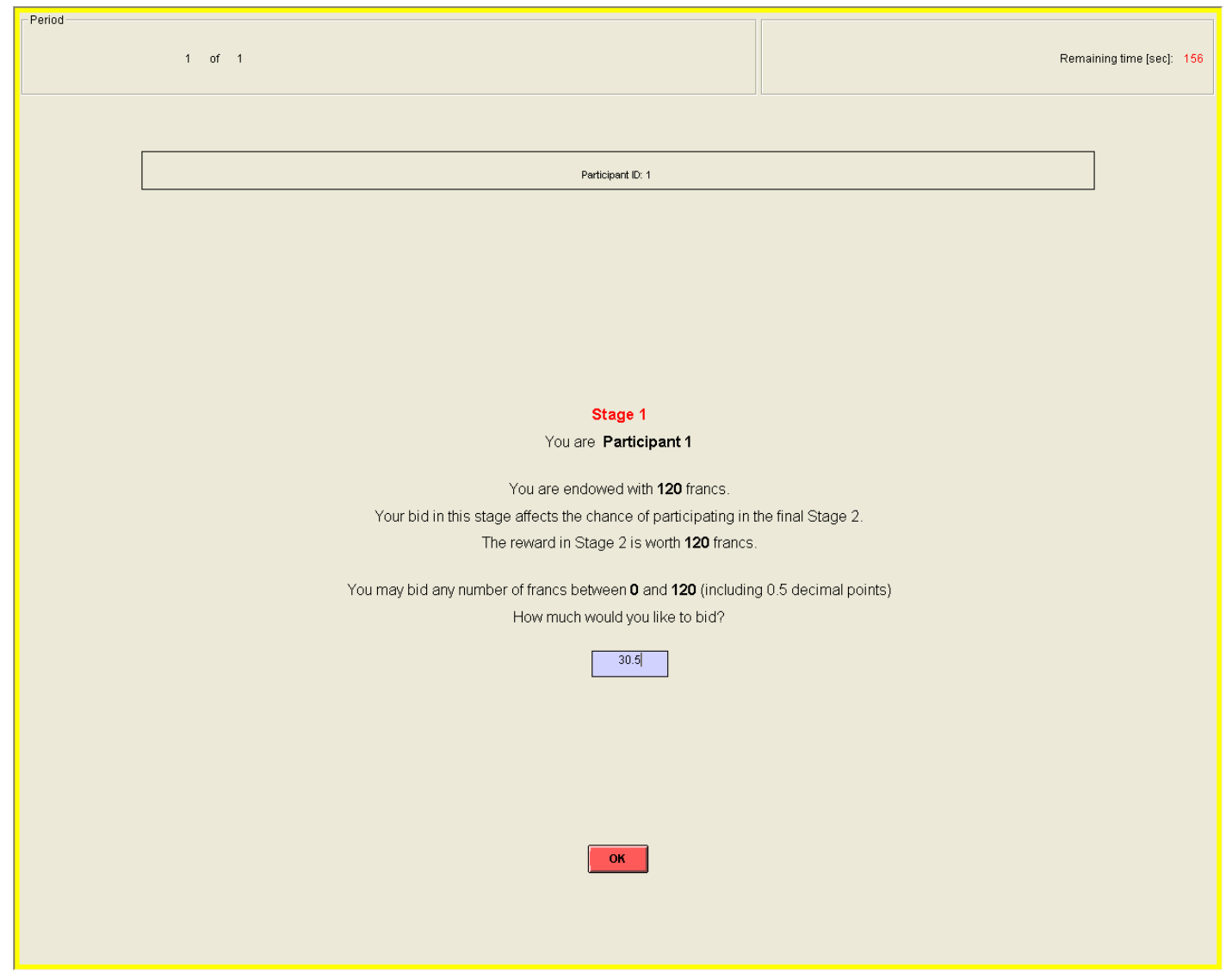


The two finalists - one from each pair - will proceed to Stage 2. The other two participants who did not win in Stage 1 will no longer participate in this period. In Stage 2 the two remaining participants will bid for a reward. The reward is worth 120 francs. The two participants may bid any number of francs between 0 and the amount of francs remaining from the initial endowment (including 0.5 decimal points). An example of the decision screen is shown below.

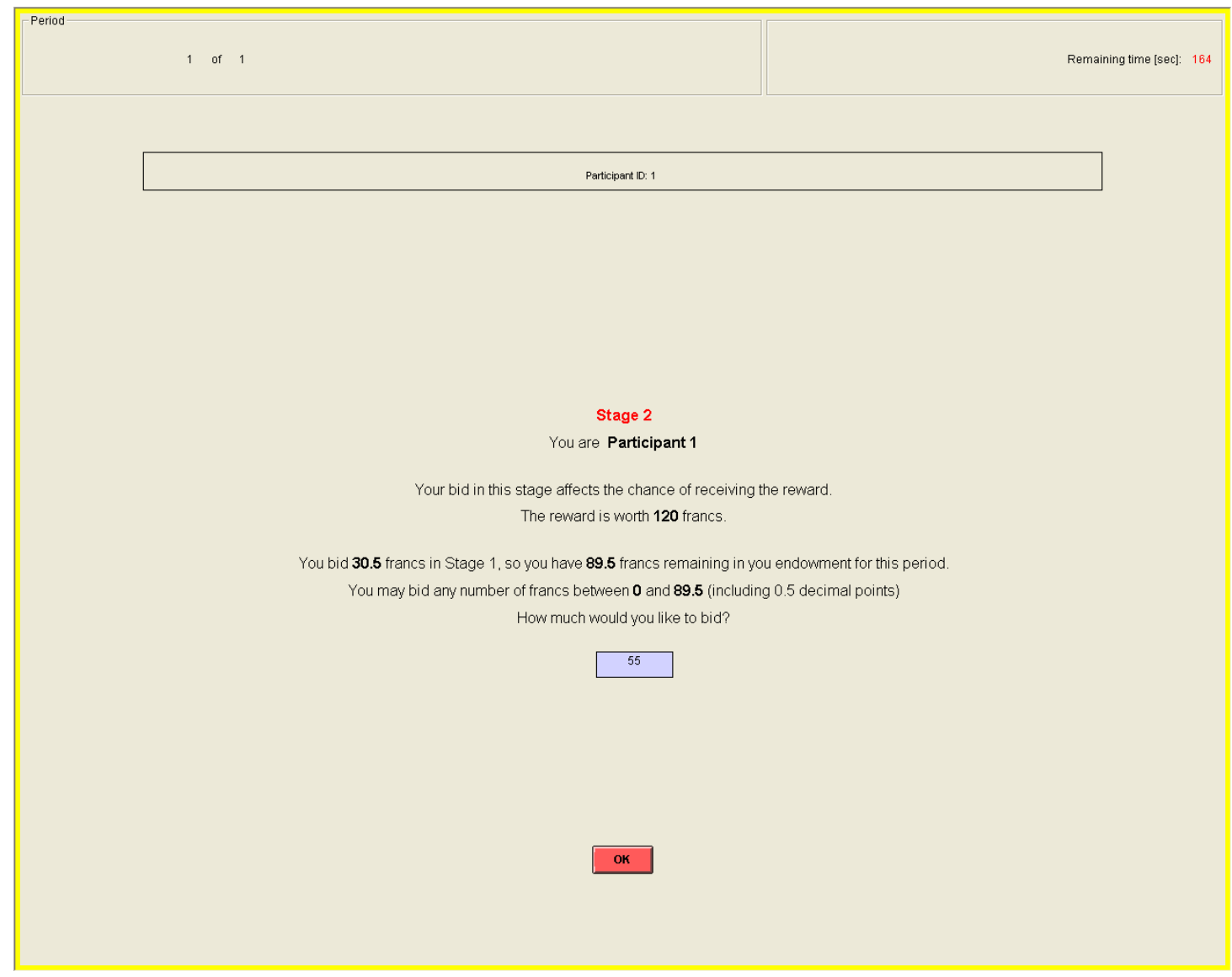


The diagram below depicts the basic structure of each period.

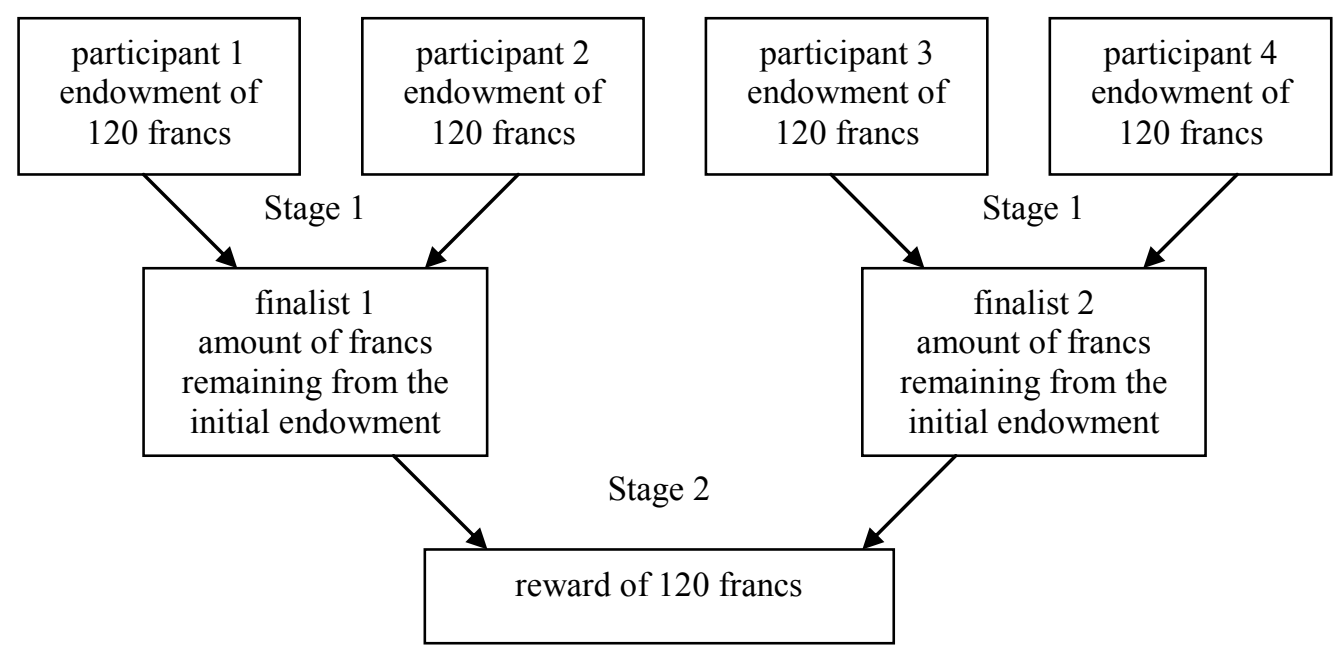

\section{YOUR EARNINGS}

If you receive the reward your period earnings are equal to your endowment plus the reward minus your bids in Stage 1 and Stage 2. If you do not receive the reward your period earnings are equal to your endowment minus your bids in Stage 1 and Stage 2. Note that if you do not win in Stage 1, your bid in Stage 2 is automatically assigned to zero.

If you receive the reward:

$$
\begin{aligned}
\text { Earnings } & =\text { Endowment }+ \text { Reward }- \text { Your Bid in Stage } 1-\text { Your Bid in Stage } 2= \\
& =120+120-\text { Your Bid in Stage } 1-\text { Your Bid in Stage } 2
\end{aligned}
$$

If you do not receive the reward:

$$
\begin{aligned}
\text { Earnings } & =\text { Endowment }- \text { Your Bid in Stage } 1-\text { Your Bid in Stage } 2= \\
& =120-\text { Your Bid in Stage } 1-\text { Your Bid in Stage } 2
\end{aligned}
$$

The more you bid in each stage, the more likely you are to win that stage. The more the other participants bid, the less likely you are to win. Specifically, in Stage 1, for 
each franc you bid you will receive one lottery ticket. At the end of Stage 1 the computer draws randomly one ticket among all the tickets purchased by you and the other participant. The owner of the drawn ticket wins Stage 1 and proceeds to Stage 2. Thus, your chance of winning in Stage 1 is given by the number of francs you bid divided by the total number of francs you and the other participant bids.

Chance of winning $=\frac{\text { Your Bid }}{\text { in Stage } 1}$

In case both participants bid zero in Stage 1, the computer randomly chooses one participant who wins Stage 1 and proceeds to Stage 2. In Stage 2, for each franc you bid you will also receive one lottery ticket. At the end of Stage 2 the computer draws randomly one ticket among all the tickets purchased by you and the other finalist of Stage 1. The owner of the drawn ticket wins Stage 2 and receives the reward of 120 francs. Thus, your chance of winning Stage 2 is given by the number of francs you bid divided by the total number of francs you and the other participant bids.

Chance of winning $=\frac{\text { Your Bid }}{\text { in Stage } 2}$

In case both participants bid zero in Stage 2, the winner is determined randomly.

\section{Example of the Random Draw}

This is a hypothetical example of how the computer makes a random draw. Let's say, in Stage 1, participant 1 bids 10 francs, participant 2 bids 5 francs, participant 3 bids 0 francs, and participant 4 bids 40 francs. Therefore, the computer assigns 10 lottery tickets to participant 1, 5 lottery tickets to participant 2, 0 lottery tickets to participant 3 , and 40 lottery tickets to participant 4 . In Stage 1, participant 1 is paired with participant 
2. Therefore, for this fist pair the computer randomly draws one lottery ticket out of 15 (10 lottery tickets for participant 1 and 5 lottery tickets for participant 2). As you can see, participant 1 has higher chance of winning in Stage 1: $0.67=10 / 15$. Participant 2 has $0.33=5 / 15$ chance of winning in Stage 1 . Similarly, participant 3 is paired with participant 4 in Stage 1. For this second pair, the computer randomly draws one lottery ticket out of 40 ( 0 lottery tickets for participant 3 and 40 lottery tickets for participant 4 ). As you can see, in this pair participant 3 has no chance of winning in Stage 1: 0=0/40.

Let's say that computer made a random draw in Stage 1 and the winner of the first pair is participant 2 while the winner of the second pair is participant 4 . Therefore, participant 2 and participant 4 proceed to Stage 2. Let's say, in Stage 2, participant 2 bids 60 francs and participant 4 bids 20 francs. Therefore, the computer assigns 60 lottery tickets to participant 2 and 20 lottery tickets to participant 4 . Then the computer randomly draws one lottery ticket out of $80(60+20)$. As you can see, participant 2 has higher chance of winning in Stage 2: $0.75=60 / 80$. Participant 4 has $0.25=20 / 80$ chance of winning in Stage 2.

After four participants make their bids in Stage 1, the computer will make a random draw which will decide who wins in Stage 1 and thus proceeds to Stage 2. Then after two remaining participants make their bids in Stage 2, the computer will make a random draw which will decide who wins in Stage 2. Then the computer will calculate your period earnings based on your bid in Stage 1 and Stage 2 and whether you received the reward or not. These earnings will be converted to cash and paid at the end of the experiment if the current period is one of the five periods that is randomly chosen for payment. 
At the end of each period, your bid in Stage 1, the other participant's bid in Stage 1, whether you won in Stage 1 or not, your bid in Stage 2, the other participant's bid in Stage 2, whether you received the reward or not, and the earnings for the period are reported on the outcome screen as shown below. Once the outcome screen is displayed you should record your results for the period on your Personal Record Sheet under the appropriate heading.

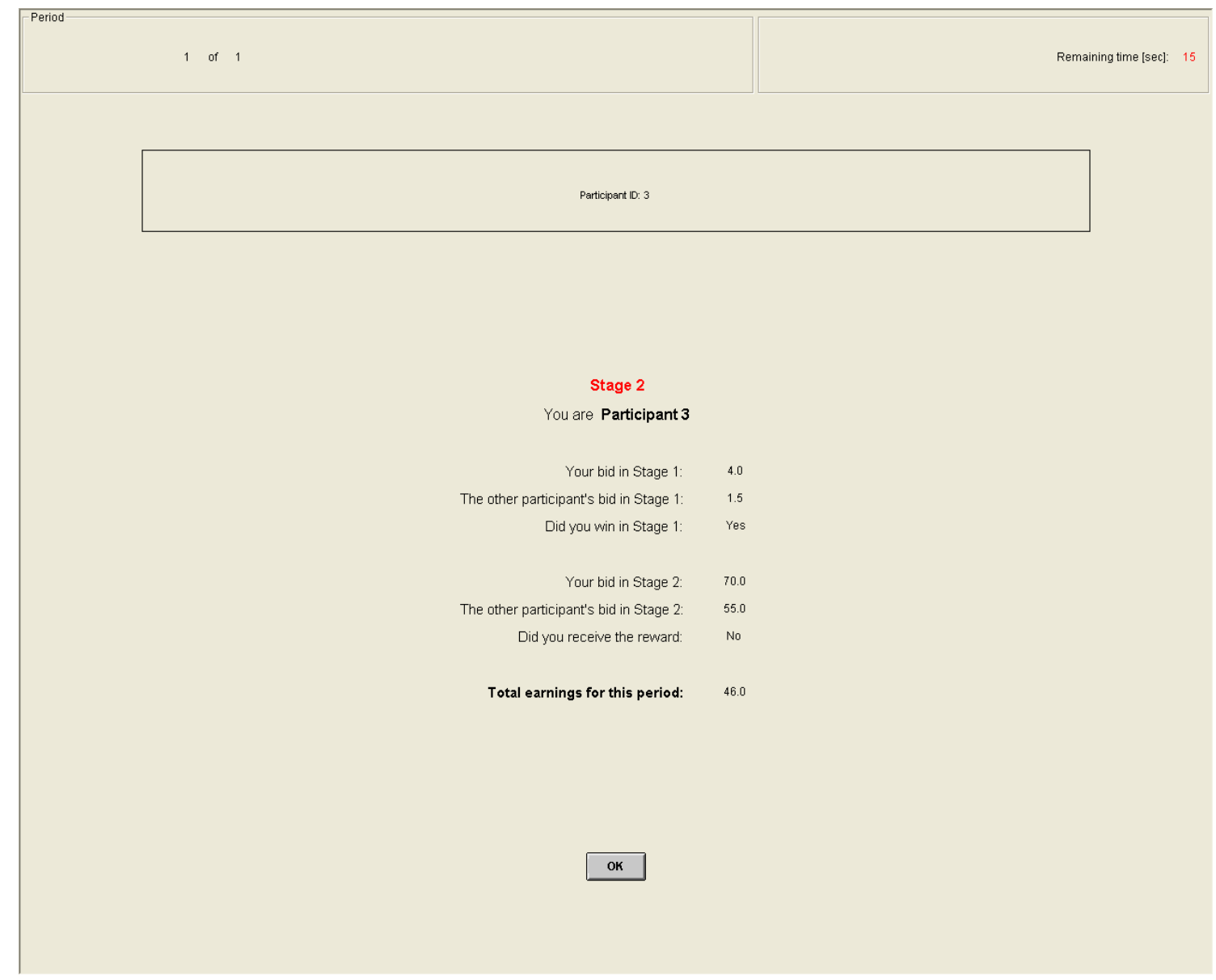

Outcome Screen 


\section{IMPORTANT NOTES}

You will not be told which of the participants in this room are assigned to which group. At the beginning of each period you will be randomly re-grouped with three other participants to from a four-person group. You can never guarantee yourself the reward. However, by increasing your contribution, you can increase your chance of winning in Stage 1 and Stage 2 and thus increase your chance of receiving the reward. Regardless of who receives the reward, all participants will have to pay their bids in Stage 1 and Stage 2.

At the end of the experiment we will randomly choose 5 of the 30 periods for actual payment in Part 2 using a bingo cage. You will sum the total earnings for these 5 periods and convert them to a U.S. dollar payment, as shown on the last page of your record sheet.

Are there any questions?

\section{INSTRUCTIONS FOR PART 3}

The third part of the experiment consists of 30 decision-making periods. The rules for part 3 are similar to the rules for part 2. At the beginning of each period, you will be randomly and anonymously placed into a group of 4 participants. The composition of your group will be changed randomly every period. Each period you will be given an initial endowment of 120 francs. You will use this endowment to bid for a reward. The reward is worth 120 francs to you and the other three participants in your group. The only difference is that in part 3 , there will be only one stage (instead of two stages). In that stage all four participants including you will bid for a reward. 
After all participants have made their decisions, your earnings for the period are calculated in the similar way as in part 2.

If you receive the reward:

Earnings $=$ Endowment + Reward - Your Bid $=120+120-$ Your Bid

If you do not receive the reward:

Earnings $=$ Endowment - Your Bid $=120-$ Your Bid

The more you bid, the more likely you are to receive the reward. The more the other participants in your group bid, the less likely you are to receive the reward. Specifically, for each franc you bid you will receive one lottery ticket. At the end of each period the computer draws randomly one ticket among all the tickets purchased by 4 participants in the group, including you. The owner of the drawn ticket receives the reward of 120 francs. Thus, your chance of receiving the reward is given by the number of francs you bid divided by the total number of francs all 4 participants in your group bid.

Chance of receiving
the reward

In case all participants bid zero, the reward is randomly assigned to one of the four participants in the group.

\section{Example of the Random Draw}

This is a hypothetical example used to illustrate how the computer is making a random draw. Let's say participant 1 bids 10 francs, participant 2 bids 15 francs, participant 3 bids 0 francs, and participant 4 bids 40 francs. Therefore, the computer 
assigns 10 lottery tickets to participant 1,15 lottery tickets to participant 2, 0 lottery tickets to participant 3 , and 40 lottery tickets for participant 4 . Then the computer randomly draws one lottery ticket out of $65(10+15+0+40)$. As you can see, participant 4 has the highest chance of receiving the reward: $0.62=40 / 65$. Participant 2 has $0.23=15 / 65$ chance, participant 1 has $0.15=10 / 65$ chance, and participant 3 has $0=$ 0/65 chance of receiving the reward.

After all participants make their bids, the computer will make a random draw which will decide who receives the reward. Then the computer will calculate your period earnings based on your bid and whether you received the reward or not.

At the end of each period, your bid, the sum of all bids in your group, whether you received the reward or not, and the earnings for the period are reported on the outcome screen. Once the outcome screen is displayed you should record your results for the period on your Personal Record Sheet under the appropriate heading.

At the end of the experiment we will randomly choose 5 of the 30 periods for actual payment in Part 3 using a bingo cage. You will sum the total earnings for these 5 periods and convert them to a U.S. dollar payment, as shown on the last page of your record sheet.

Are there any questions?

\section{INSTRUCTIONS FOR PART 4}

The fourth part of the experiment consists of only 1 decision-making period. The rules for part 4 are the same as the rules for part 3 . At the beginning of the period, you will be randomly and anonymously placed into a group of 4 participants. You will be 
given an initial endowment of 120 francs. You will use this endowment to bid in order to be a winner. For each franc you bid you will receive one lottery ticket. At the end of each period the computer draws randomly one ticket among all the tickets purchased by 4 participants in the group, including you. The owner of the drawn ticket becomes a winner. Thus, your chance of becoming a winner is given by the number of francs you bid divided by the total number of francs all 4 participants in your group bid. The only difference is that in part 4 the winner does not receive the reward. Therefore, the reward is worth 0 francs to you and the other three participants in your group. After all participants have made their decisions, your earnings are calculated.

$$
\text { Earnings }=\text { Endowment }- \text { Your Bid }=120-\text { Your Bid }
$$

After all participants have made their decisions, your earnings will be displayed on the outcome screen. Your earnings will be converted to cash and paid at the end of the experiment. 


\section{ESSAY 3 \\ EFFORT CARRYOVER AND INFORMATION DISCLOSURE IN TWO STAGE POLITICAL CONTESTS}

\subsection{Introduction}

Multi-stage contests are commonly characterized by the number of stages and the extent to which the expenditures in one stage affects the probability of winning in another stage. The US presidential race and many other political competitions fall into the category of multi-stage elimination contests. At each stage, candidates use self-promotion and campaign advertisement in order to advance to the final stage and win the election. Campaign advertising in earlier stages enhances the candidate's image and thus increases the probability of winning the final stage of the election. Another prominent example of multi-stage elimination contests is the international competition for hosting the Olympic Games. In this contest, countries are eliminated at each stage and the resources expended by each country in earlier stages affect the probability of winning the competition in later stages.

In this study we are interested in the following questions: What is the effect of effort carryover on the behavior of contestants? How does information about the effort carried over by the opponent affect behavior in different stages of the contest? To answer these questions we experimentally study a two-stage elimination contest between two 
political parties. In the first stage, parties run their primaries to select one candidate who proceeds to the final stage. The resources and efforts expended in the first stage by the winning candidates are partially or fully carried over to the second stage. In the second stage, the two finalists compete against each other in the general election. The winner of the second stage receives an "election prize".

The findings of the experiment indicate that efforts expended in both stages of the competition exceed theoretical predictions, with experience diminishing effort expenditures in the first stage but not in the second stage. Our experimental results support all major comparative statics predictions of the theory: the first stage effort and the total effort expenditures increase in the carryover rate, and the second stage effort decreases in the carryover rate. With regard to the effect of information, we find that disclosing information about the opponent's carryover effort increases the second stage effort and decreases the first stage effort.

To place our study into the context of previous literature, the following is a brief review of theoretical and experimental studies on contests. Major theories in contest literature are based on the seminal model of rent-seeking introduced by Tullock (1980). The focus of this literature is the relationship between effort expenditures and underlying contest characteristics (Nitzan, 1994). Most theoretical studies assume that contests last for only one stage. However, more recent theoretical studies point out the importance of analyzing multi-stage contests (Gradstein and Konrad, 1999; Baik and Lee, 2000; Stein and Rapoport, 2005; Kaplan and Sela, 2008). ${ }^{34}$ Gradstein and Konrad (1999), for

\footnotetext{
${ }^{34}$ Other theoretical studies of multi-stage elimination contests have been conducted by Rosen (1986), Clark and Riis (1996), Gradstein (1998), and Amegashie (1999). All these studies investigate different aspects of
} 
example, consider a multi-stage elimination contest in which contestants expend costly efforts in each stage in order to advance to the final stage and win the prize. The authors show that, depending on the contest success function, a multi-stage contest may induce higher effort by the participants than a one-stage contest. Two related studies by Baik and Lee (2000) and Stein and Rapoport (2005) consider two-stage elimination contests in which expenditures made in the first stage affect both the expenditures and the outcomes of the second stage. Stein and Rapoport (2005) create the inter-dependence between the efforts expended in two stages by introducing budget constraints. They derive the conditions under which the budget constraint is binding and show how it may affect the expenditures in both stages. Baik and Lee (2000) create inter-dependence between the efforts expended in two stages by allowing the first stage effort to be carried over to the second stage. In their contest, players in two groups compete non-cooperatively to win a prize. In the first stage, each group selects a finalist who competes for the prize in the second stage. First-stage efforts are partially (or fully) carried over to the second stage. Baik and Lee (2000) demonstrate that, in the case of player-specific carryovers, the total effort expenditures increase in the carryover rate and the rent is fully dissipated with full carryover.

Empirical studies of multi-stage elimination contests are hard to conduct since it is difficult to measure the effort and the ability of individual contestants (Ehrenberg and Bognanno, 1990; Bognanno, 2001; Szymanski, 2003). With this in mind, several researchers have turned to experimental tests of multi-stage elimination contests in a

multi-stage contests such as elimination procedures, interdependency between the stages, and asymmetry between contestants. 
laboratory setting. Parco et al. (2005) and Amaldoss and Rapoport (2009) report the results of experiments on two-stage contest with budget-constrained players. Their findings reject the equilibrium model of Stein and Rapoport (2005) because of significant over-dissipation in the first stage. Both experimental studies conjecture that the nonpecuniary utility of winning plays a crucial role in explaining excessive over-dissipation in the first stage. Sheremeta (2009b) finds that, contrary to theoretical predictions of Gradstein and Konrad (1999), a two-stage elimination contest generates higher revenue than an equivalent one-stage contest. Our experimental design is based on the theoretical work of Baik and Lee (2000) and it shares some features with experimental studies of Parco et al. (2005) and Sheremeta (2009b). ${ }^{35}$

\subsection{Theoretical Model}

Consider a two-stage contest with a total of $N \times K$ players. In the first stage, all players are split evenly between $K$ groups and each group consists of $N$ players. Each player $i$ chooses his effort level $e_{i 1}$ to influence the probability $p_{i 1}$ of winning the first stage. This probability is defined by a lottery contest success function:

$$
p_{i 1}\left(e_{i 1}, e_{-i 1}\right)=\frac{e_{i 1}}{\sum_{j=1}^{N} e_{j 1}}
$$

The contestant's probability of winning depends on his own effort relative to the total effort expended by all players. The winner in each group proceeds to the second stage. In the second stage, $K$ players compete for an exogenous prize of value $V$. The probability that contestant $i$ wins in the second stage is given by:

\footnotetext{
${ }^{35}$ Other experimental studies of multi-stage contests are done by Schmitt et al. (2004), Amegashie et al. (2007), and Altmann et al. (2008).
} 


$$
p_{i 2}\left(e_{i 1}, e_{i 2}, e_{-i 1}, e_{-i 2}\right)=\frac{e_{i 2}+\alpha e_{i 1}}{\sum_{j=1}^{K}\left(e_{j 2}+\alpha e_{j 1}\right)}
$$

In addition to the second stage effort $e_{i 2}$, a fraction of the first stage effort $e_{i 1}$ is carried over to the second stage. The carryover parameter $\alpha \in[0,1]$ denotes the extent to which the first stage effort is carried over to the second stage. This parameter is the same for all players and is common knowledge.

To analyze the two-stage contest, we apply backward induction. In the second stage, the efforts made in the first stage are already determined. Therefore, the second stage expected payoff of a risk-neutral player $i, E\left(\pi_{i 2}\right)$, is derived by multiplying player $i$ 's probability of winning the second stage, $p_{i 2}$, by prize value, $V$, minus second stage effort, $e_{i 2}$.

$$
E\left(\pi_{i 2}\right)=\frac{e_{i 2}+\alpha e_{i 1}}{\sum_{j=1}^{K}\left(e_{j 2}+\alpha e_{j 1}\right)} V-e_{i 2}
$$

Taking first order conditions with respect to $e_{i 2}$ for all $i=1, \ldots, K$ and solving them simultaneously we obtain

$$
e_{i 2}+\alpha e_{i 1}=e_{j 2}+\alpha e_{j 1}=\frac{(K-1)}{K^{2}} V, \quad \forall i, j
$$

From equations (4) and (2), the equilibrium probability of player $i$ winning the second stage is given by $p_{i 2}=\frac{1}{K}$. Furthermore, the expected payoff in the second stage is $E\left(\pi_{i 2}\right)=\frac{1}{K^{2}} V+\alpha e_{i 1}$. We can now analyze the contest in the first stage between $N$ players. Assuming each player $i$ has correct expectations about the second stage expected payoff, the first stage expected payoff, $E\left(\pi_{i 1}\right)$, can be derived by multiplying player $i$ 's probability of winning the first stage, $p_{i 1}$, by the expected payoff from the second stage, $E\left(\pi_{i 2}\right)$, minus the first stage effort, $e_{i 1}$. 


$$
E\left(\pi_{i 1}\right)=\frac{e_{i 1}}{\sum_{j=1}^{N} e_{j 1}}\left(\frac{1}{K^{2}} V+\alpha e_{i 1}\right)-e_{i 1}
$$

Taking first order conditions with respect to $e_{i 1}$, and assuming a symmetric pure strategy equilibrium, we obtain the first stage subgame perfect equilibrium effort:

$$
e_{1}^{*}=\frac{V}{K^{2}} \frac{(N-1)}{\left(N^{2}-2 \alpha N+\alpha\right)}
$$

Combining (4) and (6), the equilibrium solution for the second stage effort is

$$
e_{2}^{*}=\frac{V}{K^{2}}\left(K-\frac{\left(N^{2}-\alpha N\right)}{\left(N^{2}-2 \alpha N+\alpha\right)}\right)
$$

It is straightforward to show that, under the equilibrium strategy, the second order conditions hold and the resulting expected payoff is non-negative (Baik and Lee, 2000). Formulas (6) and (7) demonstrate how the first and second stage equilibrium efforts depend on the prize value, the carryover rate, and the number of contestants in each stage. Simple comparative statics reveal that the first stage equilibrium effort $e_{1}^{*}$ increases while the second stage equilibrium effort $e_{2}^{*}$ decreases in the carryover rate $\alpha\left(\frac{\partial e_{1}^{*}}{\partial \alpha}>0\right.$ and $\left.\frac{\partial e_{2}^{*}}{\partial \alpha}<0\right)$. It is also easy to show that the total expenditures - sum of all individual expenditures in the first and second stage - increase in the carryover rate $\left(N \frac{\partial e_{1}^{*}}{\partial \alpha}+\right.$ $\left.K \frac{\partial e_{2}^{*}}{\partial \alpha}>0\right)$

\subsection{Experimental Design and Procedures}

\section{A. Experimental Design and Hypotheses}

Our experiment is based on the theoretical model described in the previous section. The outline of the experimental design and theoretical predictions for each 
treatment are shown in Table 3.3.1. Each treatment studies a two-stage contest with two groups, $K=2$, and with two players per group, $N=2$. The first stage winner of each group proceeds to the second stage and the winner of the second stage receives the prize of $V=120$ experimental francs.

Table 3.3.1 - Experimental Design and Equilibrium Effort Levels

\begin{tabular}{|c|c|c|c|c|c|c|c|c|}
\hline \multirow{2}{*}{ Treatment } & \multirow{2}{*}{$\begin{array}{c}\text { Carryover } \\
\text { rate, } \alpha\end{array}$} & \multirow{2}{*}{$\begin{array}{c}\text { Groups, } \\
K \\
\end{array}$} & \multirow{2}{*}{$\begin{array}{c}\text { Players, } \\
N \\
\end{array}$} & \multirow{2}{*}{$\begin{array}{c}\text { Prize, } \\
V \\
\end{array}$} & \multirow{2}{*}{ Stage } & \multicolumn{2}{|c|}{ Equilibrium } & \multirow{2}{*}{$\begin{array}{c}\text { Dissipation } \\
\text { Rate }\end{array}$} \\
\hline & & & & & & Effor & Total Effort & \\
\hline \multirow{2}{*}{ PCI (PCNI) } & \multirow{2}{*}{0.5} & \multirow{2}{*}{2} & \multirow{2}{*}{2} & \multirow{2}{*}{120} & 1 & 12 & 48 & \multirow{2}{*}{0.80} \\
\hline & & & & & 2 & 24 & 48 & \\
\hline FCI (FCNI) & 1 & 2 & 2 & 120 & $\begin{array}{l}1 \\
2\end{array}$ & $\begin{array}{c}30 \\
0\end{array}$ & $\begin{array}{c}120 \\
0\end{array}$ & 1.00 \\
\hline
\end{tabular}

In partial carryover treatments (PCI and PCNI), half of the first stage winner's effort is carried over to the second stage $(\alpha=0.5)$. In full carryover treatments (FCI and FCNI), the entire first stage winner's effort is carried over to the second stage $(\alpha=1)$. The theoretical model described in Section 3.2 generates several intuitive predictions. As the extent of carryover increases, the effort made in the first stage increases and the effort made in the second stage decreases. From Table 3.3.1, the first stage effort increases from 12 to 30 and the second stage effort decreases from 24 to 0 as we move from $\alpha=0.5$ to $\alpha$ $=1$. Based on these predictions we formulate the following hypothesis.

Hypothesis 1: The first stage effort increases and the second stage effort decreases in the carryover rate.

Note that the total effort also depends on the carryover rate. According to the theoretical model, the total effort expenditures increase in the carryover rate and they are equal to the value of the prize when $\alpha=1$. Table 3.3.1 shows that the total effort increases from 96 to 120 as $\alpha$ increases from 0.5 to 1 . The resulting dissipation rate, 
defined as the sum of all efforts divided by the value of the prize, also increases from 0.8 to 1 .

Hypothesis 2: The dissipation rate and the total effort increase in the carryover rate.

We also study two information conditions: full information and no information. In PCI and FCI treatments, players receive full information about the opponent's efforts carried over from the first stage ("I" stands for full information). In PCNI and FCNI treatments, players receive no information about the opponent's efforts carried over from the first stage ("NI" stands for no information). If players behave according to the subgame perfect equilibrium, there should be no difference in the effort expenditures between the two conditions.

Hypothesis 3: The information about the opponent's carryover effort does not affect individual behavior.

\section{B. Experimental Procedures}

The experiment was conducted at the Vernon Smith Experimental Economics Laboratory. A total of 96 Purdue University undergraduate students participated. All students participated in only one session of this study; however, some students had participated in other economics experiments that were unrelated to this research.

The computerized experimental sessions were run using z-Tree (Fischbacher, 2007). We study four treatments in eight sessions as shown in Table 3.3.2. Each experimental session proceeded in three parts. Subjects were given instructions, available in the Appendix, at the beginning of each part and the experimenter read the instructions 
aloud. Before the actual experiment, subjects completed a quiz on the computer to verify their understanding of the instructions. The experiment started only after all subjects had answered all quiz questions. In the first part subjects made 15 choices in simple lotteries, similar to Holt and Laury (2002). ${ }^{36}$ This method was used to elicit individual subjects' risk preferences.

Table 3.3.2 - Summary of Treatments and Sessions

\begin{tabular}{lccccc}
\hline \hline Design & $\begin{array}{c}\text { Number of } \\
\text { Sessions }\end{array}$ & $\begin{array}{c}\text { Participants } \\
\text { per Session }\end{array}$ & $\begin{array}{c}\text { Total Number } \\
\text { of Decisions }\end{array}$ & $\begin{array}{c}\text { Periods per } \\
\text { Treatment }\end{array}$ & $\begin{array}{c}\text { Conversion } \\
\text { Rate }\end{array}$ \\
\hline PCI $\rightarrow$ FCI & 2 & 12 & 2160 & 30 & 60 francs to $\$ 1$ \\
FCI $\rightarrow$ PCI & 2 & 12 & 2160 & 30 & 60 francs to $\$ 1$ \\
PCNI $\rightarrow$ FCNI & 2 & 12 & 2160 & 30 & 60 francs to $\$ 1$ \\
FCNI $\rightarrow$ PCNI & 2 & 12 & 2160 & 30 & 60 francs to $\$ 1$ \\
\hline
\end{tabular}

The second and the third parts corresponded to two out of four treatments. For example, in PCI $\rightarrow$ FCI, each subject played in the PCI treatment for 30 periods, then played in the FCI treatment for 30 periods. In each period, subjects were randomly and anonymously placed into a group of 4 participants. Subjects were randomly re-grouped after each period. In the first stage, participant 1 was paired against participant 2 and participant 3 was paired against participant 4 . At the beginning of each period, each subject received an endowment of 120 experimental francs. Subjects could use their endowments to expend efforts (place bids). After all subjects submitted their efforts in the first stage, the computer then informed them if they were chosen to proceed to the second stage. The computer chose the winner of each pair randomly by implementing a simple lottery rule. The two finalists - one from each pair - again submitted efforts in the second

\footnotetext{
${ }^{36}$ Subjects were asked to state whether they preferred safe option A or risky option B. Option A yielded $\$ 1$ payoff with certainty, while option B yielded a payoff of either $\$ 3$ or $\$ 0$. The probability of receiving $\$ 3$ or $\$ 0$ varied across all 15 lotteries. The first lottery offered a 5\% chance of winning $\$ 3$ and a $95 \%$ chance of winning $\$ 0$, while the last lottery offered a $70 \%$ chance of winning $\$ 3$ and a $30 \%$ chance of winning $\$ 0$.
} 
stage. At the end of the second stage the computer chose the winner of the prize and displayed the following information to all subjects: the opponent's effort in the first stage, the other opponent's effort in the second stage, the result of the random draw in the first and second stage, and personal period earnings. Subjects who did not proceed to the second stage did not receive any information about the decisions made in the second stage. The instructions explained the structure of the game in detail.

In the final fourth part of the experiment, subjects were given an endowment of 120 francs and were asked to expend efforts in a one-stage contest for a prize value 0. Subjects were told that they would be informed whether they won the contest or not. We used this procedure to receive an indication of how important it is for subjects to win when winning is costly and there is no monetary reward for winning.

At the end of the experiment, 1 out of 15 decisions subjects made in part one was randomly selected for payment. Subjects were also paid for 5 out of 30 periods in part two, for 5 out of 30 periods in part three, and for the 1 decision they made in part four. The earnings were converted into US dollars at the rate of 60 francs to $\$ 1$. On average, subjects earned \$25 each which was paid in cash. Each experimental session lasted about 90 minutes.

\subsection{Results}

\section{A. General Results}

Table 3.4.1 summarizes, by treatments, the average effort, average payoff, and average dissipation rate. The striking feature of the data is that, in all two-stage contests, subjects exert much higher efforts relative to the subgame perfect equilibrium prediction. 
As a result, average payoffs are negative and average dissipation rates, defined as the ratio of the total effort expended to the prize value, are significantly greater than equilibrium dissipation rates. ${ }^{37}$ This finding is consistent with previous experimental studies of Davis and Reilly (1998), Gneezy and Smorodinsky (2006), and Sheremeta (2009a, b). In all four studies, the total effort expenditures exceeded the prize value and subjects earned, on average, negative payoffs.

Result 1: Significant over-dissipation is observed in all contests.

Table 3.4.1 - Average Statistics

\begin{tabular}{|c|c|c|c|c|c|c|c|c|}
\hline \multirow{2}{*}{ Treatment } & \multirow{2}{*}{ Stage } & \multicolumn{2}{|c|}{ Average Effort, $e$} & \multirow{2}{*}{$\begin{array}{l}\text { Total } \\
\text { Effort }\end{array}$} & \multicolumn{2}{|c|}{ Average Payoff, $\pi$} & \multicolumn{2}{|c|}{ Dissipation Rate } \\
\hline & & Equilibrium & Actual & & Equilibrium & Actual & Equilibrium & Actual \\
\hline \multirow{2}{*}{ PCI } & 1 & 12.0 & $18.2(0.6)$ & \multirow{2}{*}{148.2} & \multirow{2}{*}{6.0} & \multirow{2}{*}{$-7.0(1.2)$} & \multirow{2}{*}{0.80} & \multirow{2}{*}{1.23} \\
\hline & 2 & 24.0 & $37.7 \quad(0.9)$ & & & & & \\
\hline \multirow{2}{*}{ FCI } & 1 & 30.0 & $21.0(0.7)$ & \multirow{2}{*}{152.5} & \multirow{2}{*}{0.0} & \multirow{2}{*}{$-8.1(1.1)$} & \multirow{2}{*}{1.00} & \multirow{2}{*}{1.27} \\
\hline & 2 & 0.0 & $34.3 \quad(1.1)$ & & & & & \\
\hline \multirow{2}{*}{ PCNI } & 1 & 12.0 & $22.0 \quad(0.7)$ & \multirow{2}{*}{153.1} & \multirow{2}{*}{6.0} & \multirow{2}{*}{$-8.3(1.2)$} & \multirow{2}{*}{0.80} & \multirow{2}{*}{1.28} \\
\hline & 2 & 24.0 & $32.6 \quad(0.9)$ & & & & & \\
\hline \multirow{2}{*}{ FCNI } & 1 & 30.0 & $33.4 \quad(0.9)$ & \multirow{2}{*}{171.6} & \multirow{2}{*}{0.0} & \multirow{2}{*}{$-12.9(1.2)$} & \multirow{2}{*}{1.00} & \multirow{2}{*}{1.43} \\
\hline & 2 & 0.0 & $18.9(0.9)$ & & & & & \\
\hline
\end{tabular}

Standard error of the mean in parentheses

Two recent studies by Parco et al. (2005) and Amaldoss and Rapoport (2009) found significant over-dissipation in the first stage of a two-stage contest with budget constraints. Given the first stage over-dissipation, and the fact that subjects were budget constrained, there was a significant under-dissipation in the second stage. In contrast, Sheremeta (2009b) found significant over-dissipation in both stages of a two-stage contest without budget constraints. The current study is more closely related to Sheremeta (2009b) since subjects are not budget constrained. Thus, it is not surprising

\footnotetext{
${ }^{37}$ We ran a random effect regression on a constant separately for each treatment. Then we tested whether the constant coefficients are equal to the predicted theoretical values as in Table 3.4.1. We found that these differences are significant for all treatments $(p$-value $<0.01)$.
} 
that we find significant over-dissipation not only in the first stage but also in the second stage of a two-stage contest.

The left panel of Figure 3.4.1 indicates that, in all two-stage contests, as players become more experienced, the first stage average effort decreases. The declining trend over the periods in each treatment is significant based on the estimation of a random effect model $(p$-value $<0.01)$, where the dependent variable is an effort and the independent variable is an inverse of a period trend. Although subjects decrease their first stage effort over the periods, this is not the case for the subjects' behavior in the second stage.

Result 2: Experience diminishes over-dissipation in the first stage but not in the second stage.
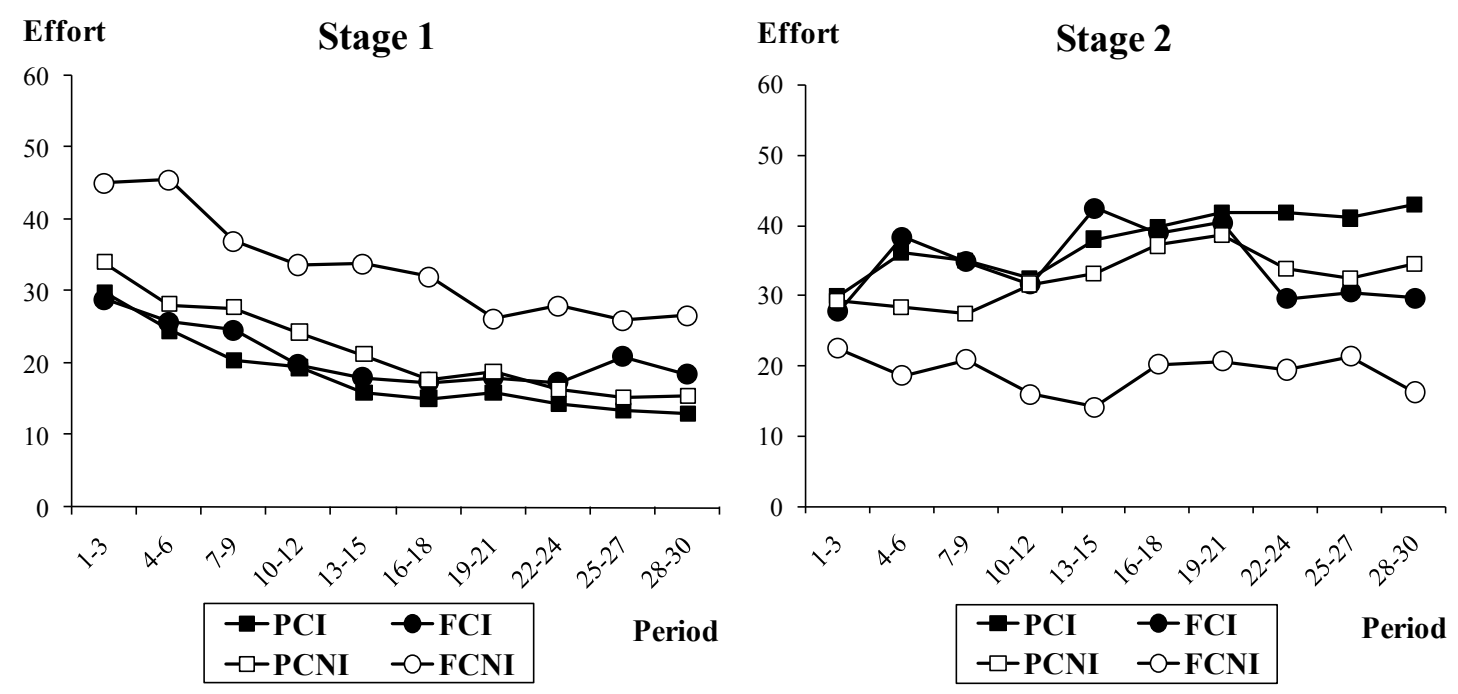

Figure 3.4.1 - Average Effort by Treatments

Another point worth noting is the substantial variance in the distribution of effort.

Figures $3.4 .2 \mathrm{a}$ and $3.4 .2 \mathrm{~b}$ display, by treatment, the full distribution of the first and 
second stage efforts. Note that, instead of following a pure strategy equilibrium, individual efforts are instead distributed on the entire strategy space between 0 and 120 .

Result 3: There is substantial variance in individual efforts.
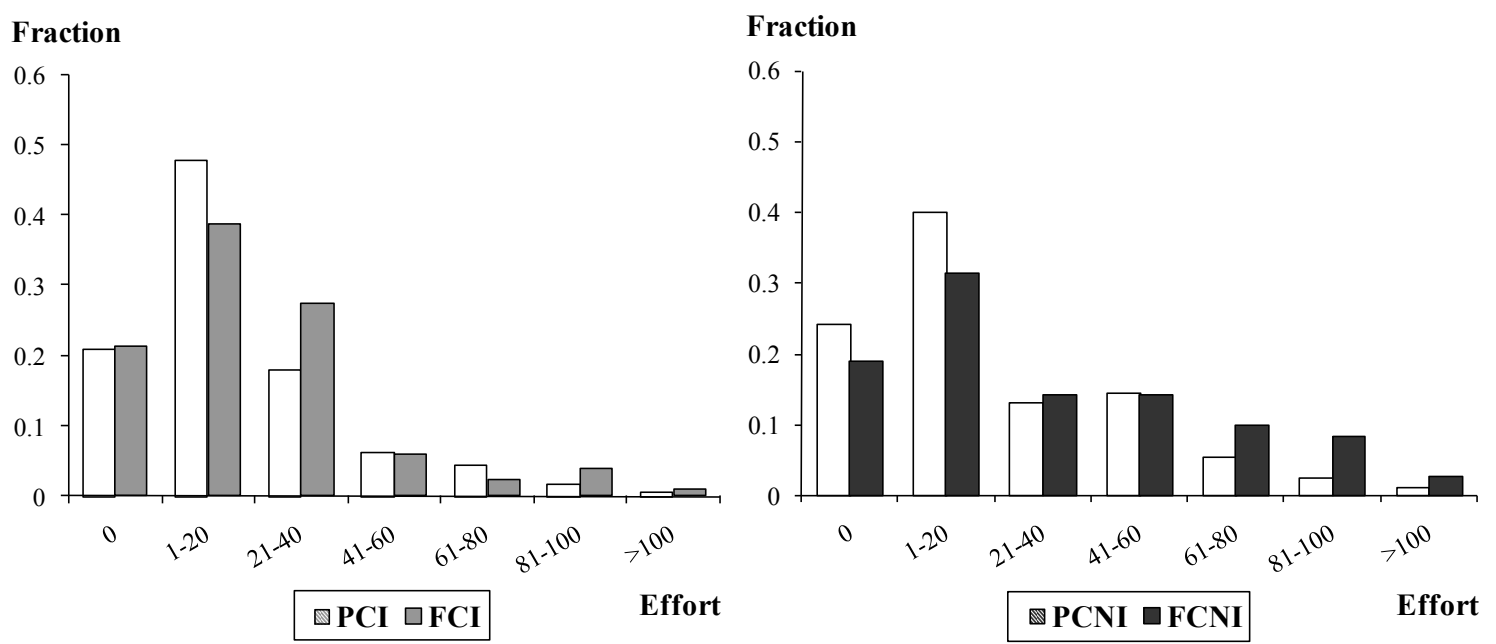

Figure 3.4.2a - Distribution of Efforts in Stage
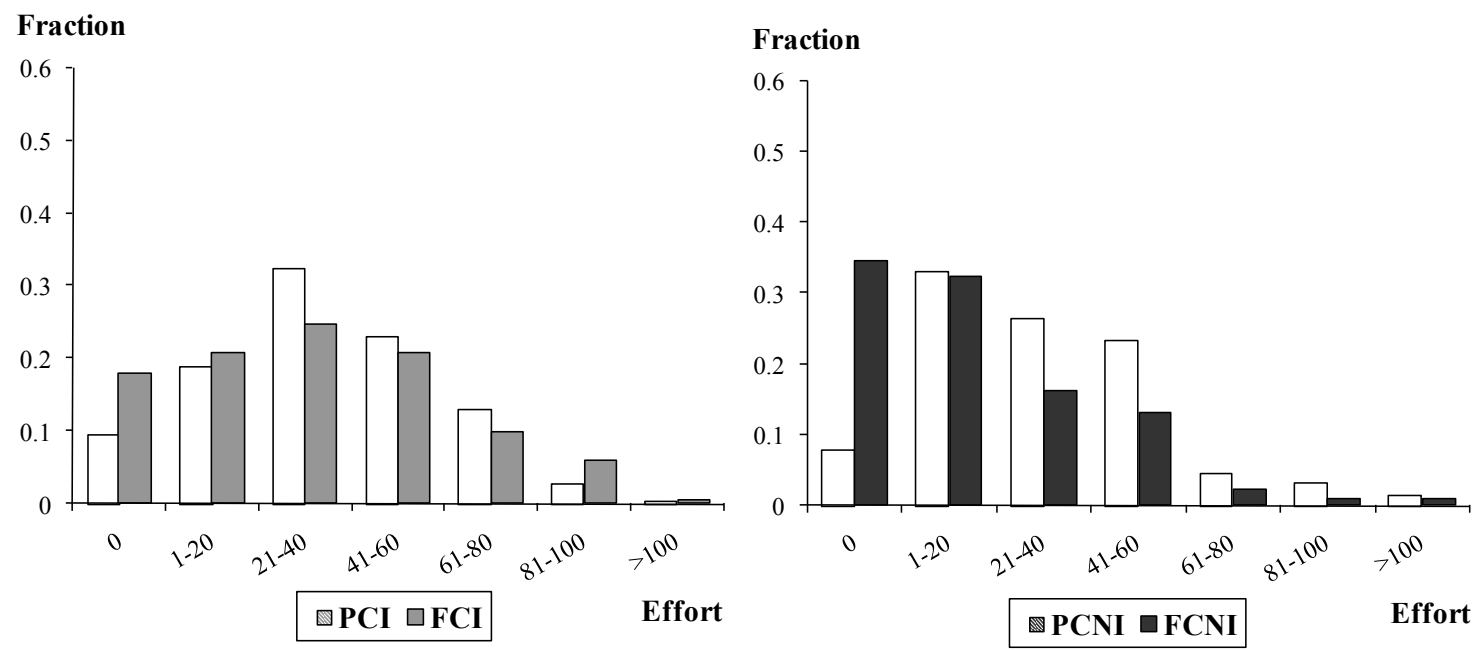

Figure 3.4.2b - Distribution of Efforts in Stage 2

Result 3 is consistent with previous experimental findings (Davis and Reilly, 1998; Potters et al., 1998; Sheremeta, 2009a,b). Several explanations have been offered. The first explanation is that subjects make mistakes, causing some variance in efforts 
(McKelvey and Palfrey, 1995; Goeree et al., 2002). The second explanation is that subjects behave differently because of demographic differences (Casari et al., 2007; Sheremeta, 2009a). And the third explanation for effort fluctuation is that success in contests is based on a random draw which may influence individual decisions over the periods (Sheremeta, 2009a).

\section{B. The Effect of Carryover}

The subgame perfect equilibrium derived in Section 3.2 predicts that, as the extent of carryover increases, the effort made in the first stage increases and the effort made in the second stage decreases. Table 3.4.1 shows that in treatments with partial carryover (PCI and PCNI) the first stage efforts are 18.2 and 22, while in treatments with full carryover (FCI and FCNI) the first stage efforts are 21 and 33.4. This finding is consistent with Hypothesis 1, indicating that the first stage expenditures increase in the carryover rate. ${ }^{38}$ Table 3.4.1 also shows that in PCI and PCNI treatments the second stage efforts are 37.7 and 32.6, while in FCI and FCNI treatments the second stage efforts are 34.3 and 18.9. This finding is also consistent with Hypothesis 1, indicating that efforts in the second stage decrease in the carryover rate. ${ }^{39}$

Result 4: The first stage effort increases while the second stage effort decreases in the carryover rate.

\footnotetext{
${ }^{38}$ We estimated random effect models separately for each information condition (I and NI), with effort expenditures as the dependent variable and treatment dummy as the independent variable. In both conditions the dummy-variable is significant $(p$-value $<0.05)$. When clustering standard errors at the session level, the difference is significant only for the last 15 periods of the experiment $(p$-value $<0.05)$.

${ }^{39}$ The differences are statistically significant based on the estimation of random effect models ( $p$-value $<$ $0.05)$. When clustering standard errors at the session level, the difference is significant only for the last 15 periods of the experiment $(p$-value $<0.05)$.
} 
Another theoretical prediction concerns the effect of effort carryover on the total effort expended. Theory predicts that the total effort expenditures should increase in the carryover rate. Table 3.4.1 indicates that this theoretical prediction is supported when comparing the PCNI treatment with the FCNI treatment. In the PCNI treatment the total effort is 153.1 and it increases to 171.6 in the FCNI treatment. Consistent with Hypothesis 2, the difference is significant based on the estimation of a random effect model ( $p$-value $<0.01)$. The difference between PCI and FCI is also positive but it is not significant $(p$-value $=0.32)$.

Result 5: The dissipation rate and the total effort increase in the carryover rate.

Overall, general comparative statics predictions with regard to the effect of effort carryover on the first stage effort, the second stage effort, and the total effort are supported by our experiment (Results 4 and 5). While qualitative predictions are supported by the data, the quantitative predictions of the theory are clearly rejected. This is mainly because there is significant over-dissipation (Result 1) as well as substantial variation in efforts (Result 3).

\section{The Effect of Information Disclosure}

One of the purposes of this study is to investigate how the information about the effort carried over by the opponent affects the behavior in the two-stage contest. Our null hypothesis is that there should be no difference in the effort expenditures between "I" and "NI" conditions. Contrary to Hypothesis 3, Table 3.4.1 reveals a strong difference in the aggregate behavior under the two information conditions. In particular, subjects expend less effort in the first stage and more effort in the second stage when they receive the 
information about the effort carried over by the opponents. The differences between effort expenditures in PCI and FCI treatments and PCNI and FCNI treatments are significant $(p$-value $<0.05){ }^{40}$

Result 6: The first stage efforts are higher under the "NI" condition and the second stage efforts are higher under the "I" condition.

It is interesting to note that the actual efforts are closer to the equilibrium efforts under the "NI" condition than under the "I" condition. The point is especially clear when comparing FCI and FCNI treatments. The absolute difference between the equilibrium effort and the actual effort in the first stage is 9 in the FCI treatment and only 3.4 in the FCNI treatment (Table 3.4.1). The difference between the equilibrium effort and the actual effort in the second stage is 34.3 in the FCI treatment and only 18.9 in the FCNI treatment. Consequently, the experimental results indicate that under the "NI" condition individual behavior is more consistent with the equilibrium than under "I" condition. This is a surprising result, because one would expect that the complete information condition more closely imitates the theoretical model described in Section 3.2, and thus it should elicit behavior that is more consistent with the equilibrium. However, we find that disclosing information leads subjects away from the equilibrium behavior in a two-stage contest with effort carryover.

The findings of the current study suggest that the earlier findings of market and bargaining experiments about the negative effect of information disclosure on equilibrium behavior may also apply to some contest environments. It has been

\footnotetext{
${ }^{40}$ This finding is different from the findings of Parco et al. (2005), who do not find any significant effect of information disclosure on individual behavior in a two-stage contest with budget constraints.
} 
documented in market experiments that information disclosure can harm the competitive equilibrium (Smith, 1991, 1994; Noussair and Porter, 1992; Cason and Plott, 2005). Smith (1991) found that in continuous double auction under private information convergence to the Nash equilibrium is faster than under complete information. Noussair and Porter (1992) reported that English and the uniform price sealed bid auctions are more efficient when there is a lack of common information. The principle that private information can yield more equilibrium-consistent results has also been established in the Nash bargaining games (Roth, 1987).

\section{The Determinants of Effort}

To provide a multivariate analysis, we estimate several regression models which are summarized in Table 3.4.2. To allow for time effects we include an inverse of a period trend. All regressions also include dummy-variables to capture individual subject, treatment, and session effects. The dependent variable in specifications (1) and (2) is the first stage effort. The dependent variable in specifications (3) and (4) is the second stage effort. The independent lagged variables are designed to capture the dynamic nature of the experiment. The effort1-lag and effort2-lag denote the first and second stage efforts expended by the same subject in period $t$-1. The other-effort1-lag and other-ffort2-lag denote the first and second stage effort expended by the opponent in period $t-1$.

From specifications (1) and (2) we see that effort1-lag is positive and significant, indicating that subjects who expend higher first stage efforts in period $t-1$ are also more likely to expend higher efforts in period $t$. Another interesting finding from specification (1) is that the other-effort1-lag is also positive and significant. This means that subjects 
expend higher efforts in response to higher efforts in period $t-1$ by the opponents. This finding suggests that the physiological impact of seeing higher effort by the opponents may be one of the reasons for significant over-dissipation in the first stage of PCNI and FCNI treatments. Note that no such effect is found in PCI and FCI treatments (specification 2).

Table 3.4.2 - Determinants of Effort

\begin{tabular}{|c|c|c|c|c|}
\hline Treatments & PCNI, FCNI & PCI, FCI & PCNI, FCNI & PCI, FCI \\
\hline $\begin{array}{l}\text { Dependent variable, } \\
\text { effort in }\end{array}$ & $\begin{array}{c}(1) \\
\text { stage } 1\end{array}$ & $\begin{array}{c}(2) \\
\text { stage } 1\end{array}$ & $\begin{array}{c}(3) \\
\text { stage2 }\end{array}$ & $\begin{array}{c}(4) \\
\text { stage } 2\end{array}$ \\
\hline $\begin{array}{l}\text { effort1-lag } \\
\quad \text { [effort in stage } 1 \text { in period } t-1]\end{array}$ & $\begin{array}{c}0.60 * * * \\
(0.06)\end{array}$ & $\begin{array}{c}0.56 * * * \\
(0.06)\end{array}$ & $\begin{array}{c}0.26 * * * \\
(0.03)\end{array}$ & $\begin{array}{c}0.25 * * * \\
(0.04)\end{array}$ \\
\hline $\begin{array}{l}\text { effort2-lag } \\
\quad \text { [effort in stage } 2 \text { in period } t-1]\end{array}$ & $\begin{array}{c}0.00 \\
(0.04)\end{array}$ & $\begin{array}{c}0.02 \\
(0.03)\end{array}$ & $\begin{array}{c}0.62 * * * \\
(0.03)\end{array}$ & $\begin{array}{c}0.43 * * * \\
(0.03)\end{array}$ \\
\hline $\begin{array}{l}\text { other-effort1-lag } \\
\text { [opponent's effort in stage } 1 \text { in period } t-1 \text { ] }\end{array}$ & $\begin{array}{c}0.09 * * * \\
(0.03)\end{array}$ & $\begin{array}{l}0.03 * \\
(0.02)\end{array}$ & $\begin{array}{c}0.00 \\
(0.02)\end{array}$ & $\begin{array}{c}0.00 \\
(0.03)\end{array}$ \\
\hline $\begin{array}{l}\text { other-effort2-lag } \\
\quad \text { [opponent's effort in stage } 2 \text { in period } t-1 \text { ] }\end{array}$ & $\begin{array}{l}-0.01 \\
(0.02)\end{array}$ & $\begin{array}{l}-0.01 \\
(0.02)\end{array}$ & $\begin{array}{l}0.05 * * * \\
(0.02)\end{array}$ & $\begin{array}{l}0.04 * * \\
(0.02)\end{array}$ \\
\hline $\begin{array}{l}1 / t \\
\quad[\text { inverse of a period trend] }\end{array}$ & $\begin{array}{c}13.77 * * \\
(5.76)\end{array}$ & $\begin{array}{c}14.29 * * * \\
(5.30)\end{array}$ & $\begin{array}{c}5.84 \\
(4.75)\end{array}$ & $\begin{array}{l}-2.76 \\
(6.13)\end{array}$ \\
\hline $\begin{array}{l}\mathrm{PCI} \\
\quad[1 \text { if treatment is } \mathrm{PCI}]\end{array}$ & $\begin{array}{l}-3.37 * \\
(1.75)\end{array}$ & & $\begin{array}{c}4.10 * * * \\
(1.06)\end{array}$ & \\
\hline $\begin{array}{l}\text { PCNI } \\
\text { [1 if treatment is } \mathrm{PCNI}]\end{array}$ & & $\begin{array}{l}-1.90^{*} \\
(0.99)\end{array}$ & & $\begin{array}{c}0.56 \\
(1.18)\end{array}$ \\
\hline $\begin{array}{l}\text { effort } 1 \\
\quad \text { [effort in stage } 1 \text { in period } t] \\
\text { other-carryover } \\
\quad \text { [effort carried over by the opponent] }\end{array}$ & & & $\begin{array}{c}-0.38 * * * \\
(0.03)\end{array}$ & $\begin{array}{c}-0.59 * * * \\
(0.04) \\
0.09 * * * \\
(0.02) \\
\end{array}$ \\
\hline Observations & 1392 & 1392 & 2255 & 2287 \\
\hline
\end{tabular}

Table 3.4.2 also reports two regressions where the dependent variable is the second stage effort. To account for selection effect, specifications (3) and (4) follow Heckman's (1979) two-step estimation procedure. In the first step, we estimate probit models similar to specifications (1) and (2), where the dependent variable is whether the 
player won the first stage or not. ${ }^{41}$ Then we use the results from the first step to estimate coefficients in specifications (3) and (4). From both specifications we can see that the other-effort1-lag, which affects the first stage effort, has no significant effect, while the other-effort2-lag has positive and significant effect on the second stage effort. The effort2-lag is positive and significant, indicating that subjects who expend higher second stage efforts in period $t-1$ are also more likely to expend higher second stage efforts in period $t$.

Specifications (3) and (4), also include the effort1 variable which denotes own effort in period $t$. From the theoretical analysis in Section 3.2 (equation 4), one can conclude that, given the positive carryover rate $\alpha>0$, an increase in the first stage effort decreases the second stage effort. This finding is supported by the regression analysis in Table 3.4.2. In both specifications (3) and (4) the effortl coefficient is negative and significant. Note that specification (4) also uses an additional variable, other-carryover. This variable captures the amount of effort carried over by the opponent from the first stage to the second stage. The other-carryover variable cannot be used in the estimation of specification (3) because in PCNI and FCNI treatments subjects did not receive any information about the efforts carried over by their opponents. From the estimation of specification (4) we can see that subjects expend higher second stage efforts in response to higher opponent's effort carryover. This finding supports Result 6 and it suggests that information disclosure shifts the individual effort from the first stage to the second stage.

\footnotetext{
${ }^{41}$ We also tried using the elicited risk attitudes to control for selection effect. The estimates were virtually the same.
} 


\subsection{Conclusion}

This experiment studies two-stage contests with carryover. Experimental results support all major theoretical predictions: the first stage effort and the total effort increase, while the second stage effort decreases in the carryover rate. Disclosing information about the opponent's carryover effort increases the second stage effort and decreases the first stage effort. These findings have important implications for designing an optimal political contest. By manipulating the information and the extent of carryover rate, the designer can minimize socially wasteful expenditures in the first stage and encourage the winning candidates to incur all major expenditures in the second stage. The 1972 Federal Election Campaign Act requires all candidates to disclose their campaign expenditures. Our findings suggest that such a policy shifts the campaign expenditures from the first stage to the second stage, minimizing socially wasteful resources.

The results of the experiment also indicate that, in all two-stage contests, expenditures are much higher than predicted. This finding is different from the findings of Parco et al. (2005) and Amaldoss and Rapoport (2009), who find significant overexpenditures only in the first stage of a two-stage contest with budget constraints, and not in the second stage. The disparity between our findings and the two studies mentioned above implies that removing the budget constraints results in wasteful over-expenditures. One policy implication of this finding is that the designer of a political contest should impose budget constraints on candidates' expenditures in order to reduce wasteful overexpenditures. Such argument speaks in favor of the 1974 FECA Amendments, which are designed to lower the cost of campaigning by setting limits on expenditures in Presidential elections. 


\subsection{References}

Altmann, S., Falk, A., \& Wibral, M. (2008) Promotions in Multi-Stage Elimination Tournaments: an Experimental Investigation. University of Bonn and IZA, Working Paper.

Amaldoss, W., \& Rapoport, A. (2009). Excessive expenditure in two-stage contests: Theory and experimental evidence. In F. Columbus (Ed.), Game Theory: Strategies, Equilibria, and Theorems. Hauppauge, NY: Nova Science Publishers.

Amegashie, J. A. (1999). The design of rent-seeking competitions: Committees preliminary and final contests. Public Choice, 99, 63-76.

Amegashie, J.A., Cadsby, C.B., \& Song, Y. (2007). Competitive burnout: Theory and experimental evidence. Games and Economic Behavior, 59, 213-239.

Baik, K. H., \& Lee, S. (2000). Two-stage rent-seeking contests with carryovers. Public Choice, 103, 285-296.

Bognanno, M.L., (2001). Corporate Tournaments. Journal of Labor Economics, 19, 290315.

Casari, M., Ham, J.C., \& Kagel, J.H. (2007). Selection bias, demographic effects, and ability effects in common value auction experiments. American Economic Review, 97, 1278-1304.

Cason, T.N., \& Plott, C.R. (2005). Forced Information Disclosure and the Fallacy of Transparency in Markets. Economic Inquiry, 43, 699-714.

Clark, D.J. \& Riis, C. (1996). A multi-winner nested rent-seeking contest. Public Choice, $87,177-184$. 
Davis, D., \& Reilly, R. (1998). Do many cooks always spoil the stew? An experimental analysis of rent seeking and the role of a strategic buyer. Public Choice, 95, 89-115.

Ehrenberg, R.G., \& Bognanno, M.L. (1990). Do Tournaments Have Incentive Effects?, Journal of Political Economy, 98, 1307-24.

Fischbacher, U. (2007). z-Tree: Zurich Toolbox for Ready-made Economic experiments. Experimental Economics, 10, 171-178.

Gneezy, U., \& Smorodinsky, R. (2006). All-Pay Auctions - An Experimental Study. Journal of Economic Behavior \& Organization, 61, 255-275.

Goeree, J., Holt, C., \& Palfrey, T. (2002). Quantal Response Equilibrium and Overbidding in Private-Value Auctions. Journal of Economic Theory, 247-272.

Gradstein, M. (1998). Optimal contest design: Volume and timing of rent seeking in contests. European Journal of Political Economy, 14, 575-585.

Gradstein, M., \& Konrad, K.A. (1999). Orchestrating Rent Seeking Contests. Economic Journal, 109, 536-45.

Heckman, J.J. (1979). Sample Selection Bias as a Specification Error. Econometrica, 47, $153-61$.

Holt, C.A., \& Laury, S.K. (2002). Risk Aversion and Incentive Effects. American Economic Review, 92, 1644-1655.

Kaplan, T.R., \& Sela, A. (2008). Effective Political Contests, Centre for Economic Policy Research, Working Paper.

McKelvey, R., \& Palfrey, T. (1995). Quantal Response Equilibria for Normal Form. Games and Economic Behavior, 10, 6-38. 
Nitzan, S. (1994). Modelling rent-seeking contests. European Journal of Political Economy, 10, 41-60.

Noussari, C., \& Porter, D. (1992). Allocating Priority with Auctions: An Experimental Analysis. Journal of Economic Behavior and Organization, 19, 169-195.

Parco J., Rapoport A., \& Amaldoss W. (2005). Two-stage Contests with Budget Constraints: An Experimental Study. Journal of Mathematical Psychology, 49, 320338.

Potters, J.C., De Vries, C.G., \& Van Linden, F. (1998). An experimental examination of rational rent seeking. European Journal of Political Economy, 14, 783-800.

Rosen, S. (1986). Prizes and incentives in elimination tournaments. American Economic Review, 76, 701-715.

Roth, A.E. (1987). Bargaining Phenomena and Bargaining Theory. In Roth, A. E., (ed.), Laboratory Experimentation in Economics. Cambridge, U.K.: Cambridge University Press, pp. 14-41.

Schmitt, P., Shupp, R., Swope, K., \& Cadigan, J. (2004). Multi-period rent-seeking contests with carryover: Theory and experimental evidence. Economics of Governance, 5, 187-211.

Sheremeta, R.M. (2009a). Contest Design: An Experimental Investigation. Economic Inquiry, forthcoming.

Sheremeta, R.M. (2008). Experimental Comparison of Multi-stage and One-stage Contests. Purdue University, Working Paper.

Smith, V.L. (1991). Papers in Experimental Economics. New York: Cambridge University Press. 
Smith, V.L. (1994). Economics in the Laboratory. Journal of Economic Perspectives, 8, 113-131.

Stein, W.E., \& Rapoport, A. (2005). Symmetric multi-stage contests with budget constraints. Public Choice, 124, 309-328.

Szymanski, S. (2003). The economic design of sporting contests. Journal of Economic Literature, 41, 1137-1187.

Tullock, G. (1980). Efficient Rent Seeking. In James M. Buchanan, Robert D. Tollison, Gordon Tullock, (Eds.), Toward a theory of the rent-seeking society. College Station, TX: Texas A\&M University Press, pp. 97-112. 


\subsection{Appendix}

\section{GENERAL INSTRUCTIONS}

This is an experiment in the economics of strategic decision making. Various research agencies have provided funds for this research. The instructions are simple. If you follow them closely and make appropriate decisions, you can earn an appreciable amount of money.

The experiment will proceed in three parts. Each part contains decision problems that require you to make a series of economic choices which determine your total earnings. The currency used in Part 1 of the experiment is U.S. Dollars. The currency used in Part 2 and 3 of the experiment is francs. Francs will be converted to U.S. Dollars at a rate of $60 \_$francs to _ $1_{-}$dollar. At the end of today's experiment, you will be paid in private and in cash. 12 participants are in today's experiment.

It is very important that you remain silent and do not look at other people's work. If you have any questions, or need assistance of any kind, please raise your hand and an experimenter will come to you. If you talk, laugh, exclaim out loud, etc., you will be asked to leave and you will not be paid. We expect and appreciate your cooperation.

At this time we proceed to Part 1 of the experiment.

\section{INSTRUCTIONS FOR PART 1}

\section{YOUR DECISION}

In this part of the experiment you will be asked to make a series of choices in decision problems. How much you receive will depend partly on chance and partly on the choices you make. The decision problems are not designed to test you. What we want to 
know is what choices you would make in them. The only right answer is what you really would choose.

For each line in the table in the next page, please state whether you prefer option A or option B. Notice that there are a total of 15 lines in the table but just one line will be randomly selected for payment. You ignore which line will be paid when you make your choices. Hence you should pay attention to the choice you make in every line. After you have completed all your choices a token will be randomly drawn out of a bingo cage containing tokens numbered from 1 to 15 . The token number determines which line is going to be paid.

Your earnings for the selected line depend on which option you chose: If you chose option A in that line, you will receive $\$ 1$. If you chose option B in that line, you will receive either $\$ 3$ or $\$ 0$. To determine your earnings in the case you chose option B there will be second random draw. A token will be randomly drawn out of the bingo cage now containing twenty tokens numbered from 1 to 20 . The token number is then compared with the numbers in the line selected (see the table). If the token number shows up in the left column you earn $\$ 3$. If the token number shows up in the right column you earn $\$ 0$.

Are there any questions? 


\section{Participant ID}

\begin{tabular}{|c|c|c|c|c|}
\hline $\begin{array}{l}\text { Decis } \\
\text { ion } \\
\text { no. }\end{array}$ & $\begin{array}{l}\text { Optio } \\
\text { n A }\end{array}$ & & $\begin{array}{l}\text { Option } \\
\text { B }\end{array}$ & $\begin{array}{l}\text { Please } \\
\text { choose } \\
\text { A or B }\end{array}$ \\
\hline 1 & $\$ 1$ & $\$ 3$ never & $\begin{array}{l}\$ 0 \text { if } 1,2,3,4,5,6,7,8,9,10,11,12,13 \\
\quad 14,15,16,17,18,19,20\end{array}$ & \\
\hline 2 & $\$ 1$ & $\$ 3$ if 1 comes out & $\begin{array}{c}\$ 0 \text { if } 2,3,4,5,6,7,8,9,10,11,12,13 \\
\quad 14,15,16,17,18,19,20\end{array}$ & \\
\hline 3 & $\$ 1$ & $\$ 3$ if 1 or 2 comes out & $\begin{aligned} \$ 0 & \text { if } 3,4,5,6,7,8,9,10,11,12,13,14,15 \\
& 16,17,18,19,20\end{aligned}$ & \\
\hline 4 & $\$ 1$ & $\$ 3$ if 1,2 or 3 & $\begin{aligned} \$ 0 & \text { if } 4,5,6,7,8,9,10,11,12,13,14,15 \\
& 16,17,18,19,20\end{aligned}$ & \\
\hline 5 & $\$ 1$ & $\$ 3$ if $1,2,3,4$ & $\begin{aligned} \$ 0 & \text { if } 5,6,7,8,9,10,11,12,13,14,15 \\
& 16,17,18,19,20\end{aligned}$ & \\
\hline 6 & $\$ 1$ & $\$ 3$ if $1,2,3,4,5$ & $\begin{aligned} \$ 0 & \text { if } 6,7,8,9,10,11,12,13,14,15 \\
& 16,17,18,19,20\end{aligned}$ & \\
\hline 7 & $\$ 1$ & $\$ 3$ if $1,2,3,4,5,6$ & $\begin{aligned} \$ 0 & \text { if } 7,8,9,10,11,12,13,14,15 \\
& 16,17,18,19,20\end{aligned}$ & \\
\hline 8 & $\$ 1$ & $\$ 3$ if $1,2,3,4,5,6,7$ & $\begin{array}{l}\$ 0 \text { if } 8,9,10,11,12,13,14,15 \\
16,17,18,19,20\end{array}$ & \\
\hline 9 & $\$ 1$ & $\$ 3$ if $1,2,3,4,5,6,7,8$ & $\begin{array}{l}\$ 0 \text { if } 9,10,11,12,13,14,15 \\
\quad 16,17,18,19,20\end{array}$ & \\
\hline 10 & $\$ 1$ & $\$ 3$ if $1,2,3,4,5,6,7,8,9$ & $\begin{array}{ll}\$ 0 & \text { if } 10,11,12,13,14,15 \\
& 16,17,18,19,20\end{array}$ & \\
\hline 11 & $\$ 1$ & $\$ 3$ if $1,2,3,4,5,6,7,8,9,10$ & $\$ 0$ if $11,12,13,14,15,16,17,18,19,20$ & \\
\hline 12 & $\$ 1$ & $\$ 3$ if $1,2,3,4,5,6,7,8,9,10,11$ & $\$ 0$ if $12,13,14,15,16,17,18,19,20$ & \\
\hline 13 & $\$ 1$ & $\$ 3$ if $1,2,3,4,5,6,7,8,9,10,11,12$ & $\$ 0$ if $13,14,15,16,17,18,19,20$ & \\
\hline 14 & $\$ 1$ & $\begin{array}{l}\$ 3 \text { if } 1,2,3,4,5,6,7,8,9,10 \\
11,12,13\end{array}$ & $\$ 0$ if $14,15,16,17,18,19,20$ & \\
\hline 15 & $\$ 1$ & $\begin{array}{l}\$ 3 \text { if } 1,2,3,4,5,6,7,8,9,10 \\
11,12,13,14\end{array}$ & $\$ 0$ if $15,16,17,18,19,20$ & \\
\hline
\end{tabular}




\section{INSTRUCTIONS FOR PART 2}

\section{YOUR DECISION}

The second part of the experiment consists of 30 decision-making periods and each period consists of two stages. At the beginning of each period, you will be randomly and anonymously placed into a group of four participants. The composition of your group will be changed randomly every period. Each period you will be randomly and anonymously assigned as participant $1,2,3$, or 4 . In Stage 1 participant 1 will be paired against participant 2 and participant 3 will be paired against participant 4 . All four participants will be given an initial endowment of 120 francs. You will use this endowment to bid for a chance of participating in Stage 2. You may bid any number of francs between 0 and 120 (including 0.5 decimal points). An example of your decision screen is shown below. 


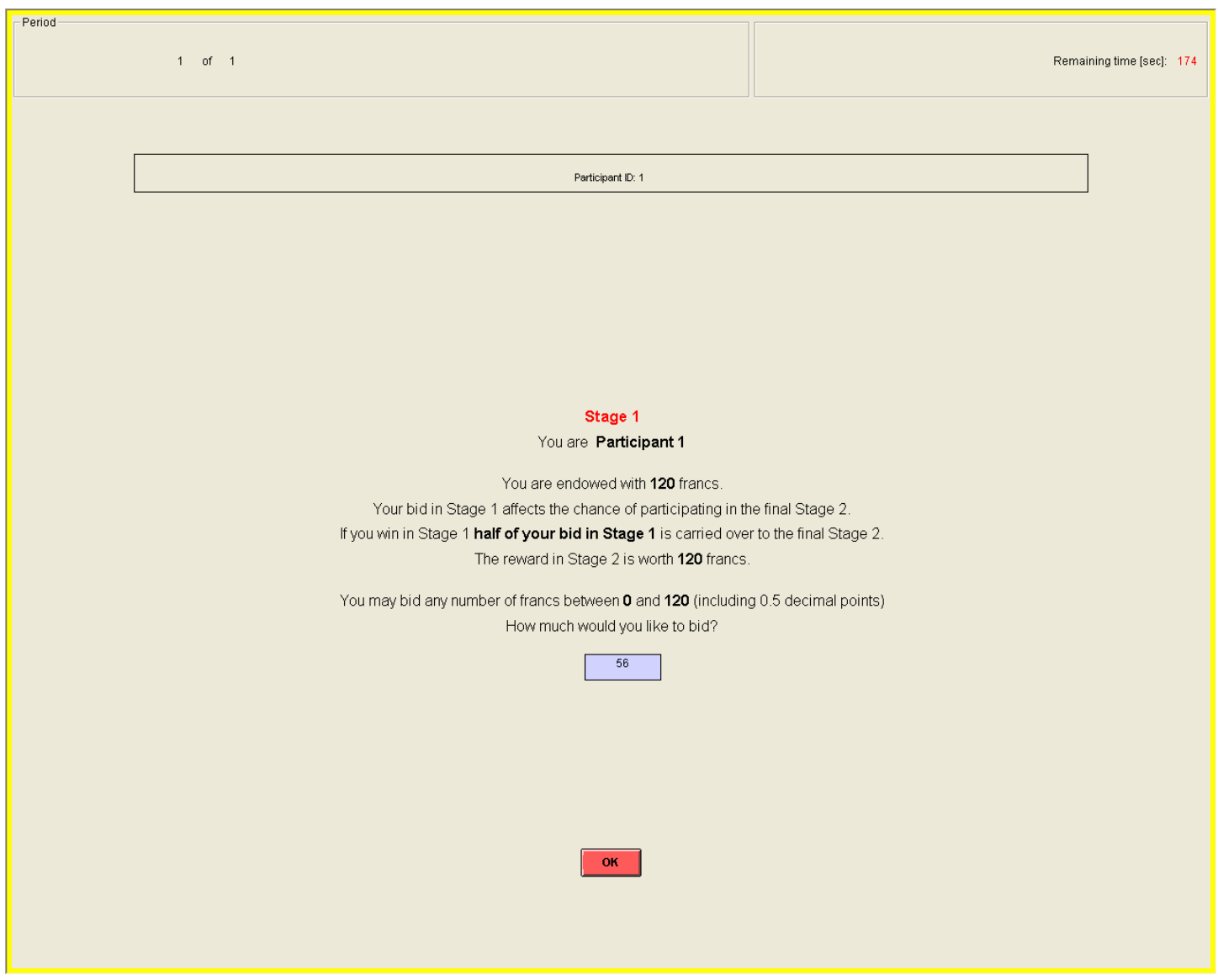

After four participants make their bids in Stage 1, the computer will determine two finalists - one from each pair. The rule used by the computer for choosing a finalist in each of the two pairs will be explained later. The two finalists will proceed to Stage 2 . The two other participants who did not win in Stage 1 will no longer participate in this period. If you proceed to Stage 2 half of your bid made in Stage 1 will be carried over to Stage 2. The other finalist will also carry over to Stage 2 half of the bid he or she made in Stage 1. In Stage 2 you and the other finalist will have an opportunity to make an additional bid which will be added to half of the bid you made in Stage 1. You may bid any number of francs between 0 and the amount of francs remaining from the initial 
endowment (including 0.5 decimal points). The winner of Stage 2 will receive the reward of 120 francs. An example of the decision screen in Stage 2 is shown below.

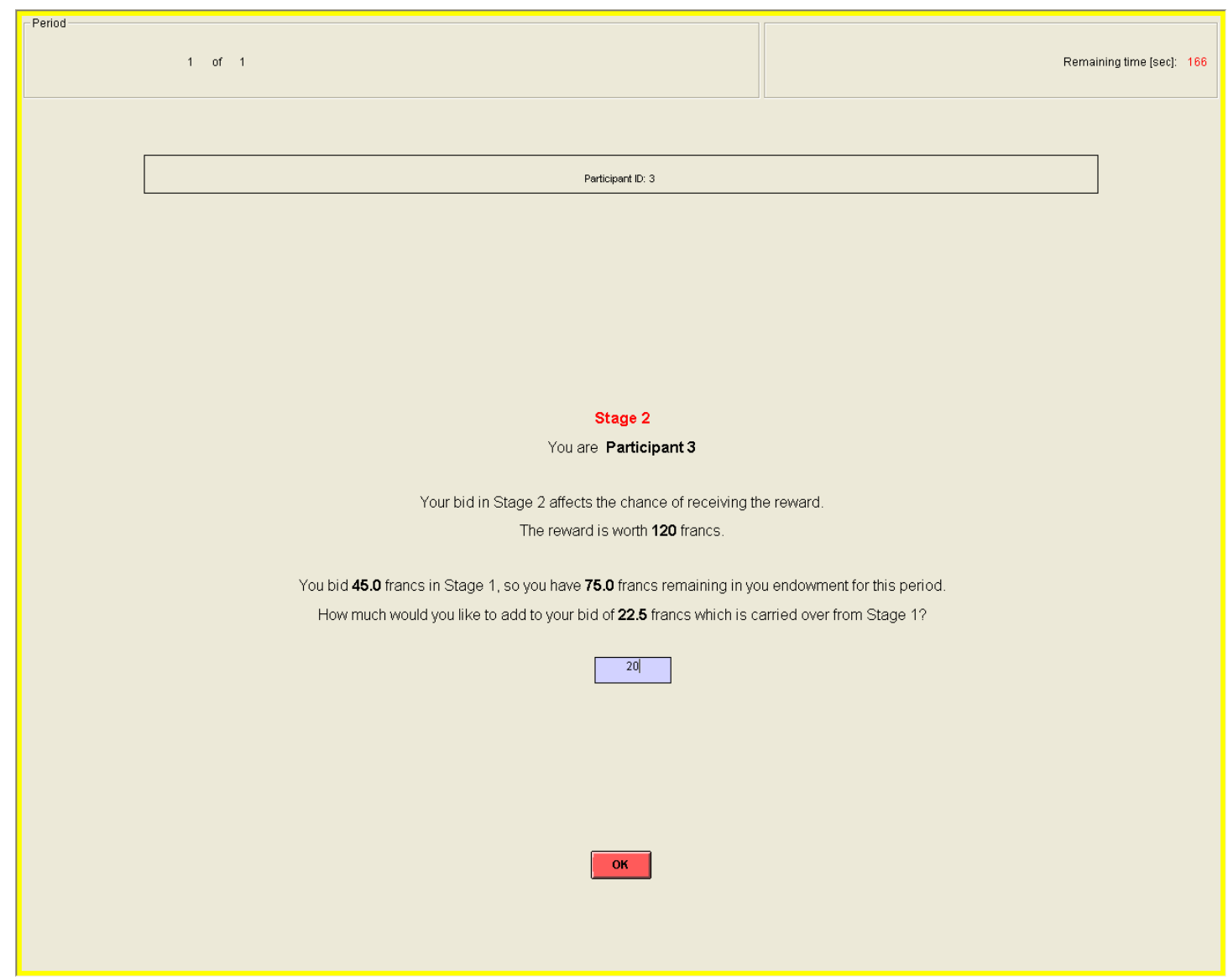

The diagram below depicts the basic structure of each period.

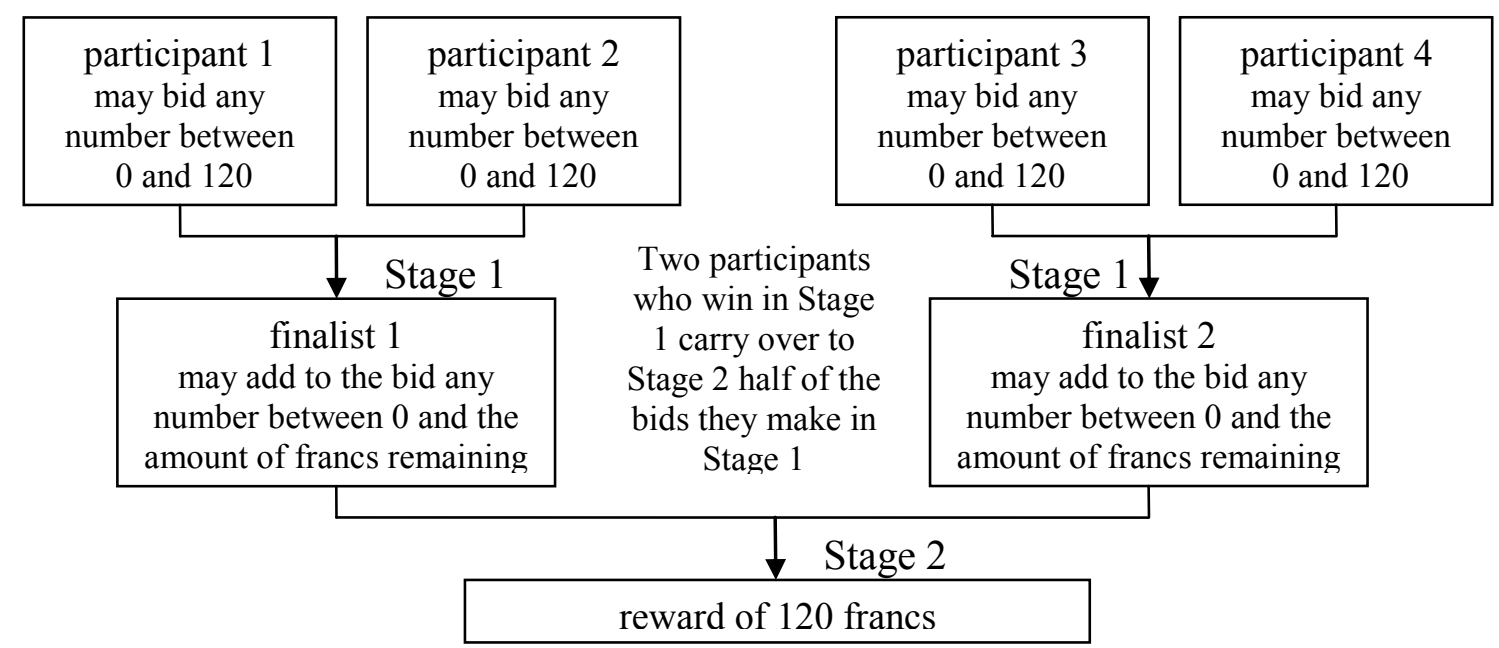




\section{YOUR EARNINGS}

If you receive the reward in Stage 2 your period earnings are equal to your endowment plus the reward minus your bids in Stage 1 and Stage 2. If you do not receive the reward in Stage 2 your period earnings are equal to your endowment minus your bids in Stage 1 and Stage 2. Note that if you do not win in Stage 1, your additional bid in Stage 2 is automatically assigned to zero.

If you receive the reward:

$$
\begin{aligned}
\text { Earnings } & =\text { Endowment }+ \text { Reward }- \text { Your Bid in Stage } 1-\text { Your Bid in Stage } 2= \\
& =120+120-\text { Your Bid in Stage } 1-\text { Your Bid in Stage } 2
\end{aligned}
$$

If you do not receive the reward:

$$
\begin{aligned}
\text { Earnings } & =\text { Endowment }- \text { Your Bid in Stage } 1-\text { Your Bid in Stage } 2= \\
& =120-\text { Your Bid in Stage } 1-\text { Your Bid in Stage } 2
\end{aligned}
$$

The more you bid in each stage, the more likely you are to win that stage. The more the other participants bid, the less likely you are to win. Specifically, in Stage 1, for each franc you bid you will receive one lottery ticket. At the end of Stage 1 the computer draws randomly one ticket among all the tickets purchased by you and the other participant. The owner of the drawn ticket wins Stage 1 and proceeds to Stage 2. Thus, your chance of winning in Stage 1 is given by the number of francs you bid divided by the total number of francs you and the other participant bids.

$\begin{aligned} & \text { Chance of winning } \\ & \text { in Stage } 1\end{aligned}=\begin{gathered}\text { Your Bid in Stage 1 } \\ \text { Your Bid in Stage 1+ The Other } \\ \text { Participant's Bid in Stage 1 }\end{gathered}$

If both participants bid zero in Stage 1, the computer randomly chooses one participant who wins Stage 1 and proceeds to Stage 2. If you proceed to Stage 2, half of 
your bid in Stage 1 is carried over to Stage 2. Your total bid in Stage 2 is equal to half of your bid in Stage 1 plus your additional bid in Stage 2. The total amount of lottery tickets in Stage 2 which computer will assign to you is equal to your total bid in Stage 2. At the end of Stage 2 the computer draws randomly one ticket among all the lottery tickets in Stage 2 owned by you and the other finalist. The owner of the drawn ticket wins Stage 2 and receives the reward of 120 francs. Thus, your chance of winning Stage 2 is given by your total bid in Stage 2 divided by your total bid in Stage 2 and the other finalist's total bid in Stage 2.

$\begin{aligned} & \text { Chance of winning } \\ & \text { in Stage 1 }\end{aligned}=\begin{gathered}\text { Your Total Bid in Stage 2 } \\ \begin{array}{c}\text { Your Total Bid in Stage 2+ The Other } \\ \text { Finalist's Total Bid in Stage 2 }\end{array}\end{gathered}$

\section{Example of the Random Draw}

This is a hypothetical example of how the computer makes a random draw. Let's say, in Stage 1, participant 1 bids 50 francs, participant 2 bids 30 francs, participant 3 bids 0 francs, and participant 4 bids 20 francs. Therefore, the computer assigns 50 lottery tickets to participant 1,30 lottery tickets to participant 2, 0 lottery tickets to participant 3, and 20 lottery tickets to participant 4 . In Stage 1, participant 1 is paired against participant 2 . Therefore, for this first pair the computer randomly draws one lottery ticket out of 80 (50 lottery tickets for participant 1 and 30 lottery tickets for participant 2). As you can see, participant 1 has higher chance of winning in Stage 1: $0.63=50 / 80$. Participant 2 has $0.27=30 / 80$ chance of winning in Stage 1. Similarly, participant 3 is paired against participant 4 in Stage 1. For this second pair, the computer randomly draws one lottery ticket out of 20 ( 0 lottery tickets for participant 3 and 20 lottery tickets for 
participant 4). As you can see, in this pair participant 3 has no chance of winning in Stage 1: $0=0 / 20$.

Let's say that computer made a random draw in Stage 1 and the winner of the first pair is participant 2 while the winner of the second pair is participant 4 . Therefore, participant 2 and participant 4 proceed to Stage 2. Let's say, in Stage 2, participant 2 bids additional 25 francs and participant 4 bids additional 15 francs. Therefore, the computer assigns 25 lottery tickets to participant 2 and 15 lottery tickets to participant 4 . In addition, computer assigns $15(30 / 2)$ lottery tickets to participant 2 and $10(20 / 2)$ lottery tickets to participant 4 which are carried over from Stage 1. Then the computer randomly draws one lottery ticket out of $65(25+15+15+10)$. As you can see, participant 2 has higher chance of winning in Stage 2: $0.62=(25+15) / 65$. Participant 4 has $0.38=(15+$ 10)/65 chance of winning in Stage 2.

After four participants make their bids in Stage 1, the computer will make a random draw which will decide who wins in Stage 1 and thus proceeds to Stage 2. Then after two remaining participants make their additional bids in Stage 2, the computer will make a random draw which will decide who wins in Stage 2 and thus receives the reward. Then the computer will calculate your period earnings based on your bid in Stage 1 and Stage 2 and whether you received the reward or not. These earnings will be converted to cash and paid at the end of the experiment if the current period is one of the five periods that is randomly chosen for payment.

At the end of each period the following information will be displayed on the outcome screen: your bid in Stage 1, the other participant's bid in Stage 1, whether you won in Stage 1 or not, half of your bid carried over from Stage 1 plus your additional bid 
in Stage 2, half of the other finalist's bid carried over from Stage 1 plus the other finalist's additional bid in Stage 2, whether you received the reward or not, and the earnings for the period. An example of the outcome screen is shown below. Once the outcome screen is displayed you should record your results for the period on your Personal Record Sheet under the appropriate heading.

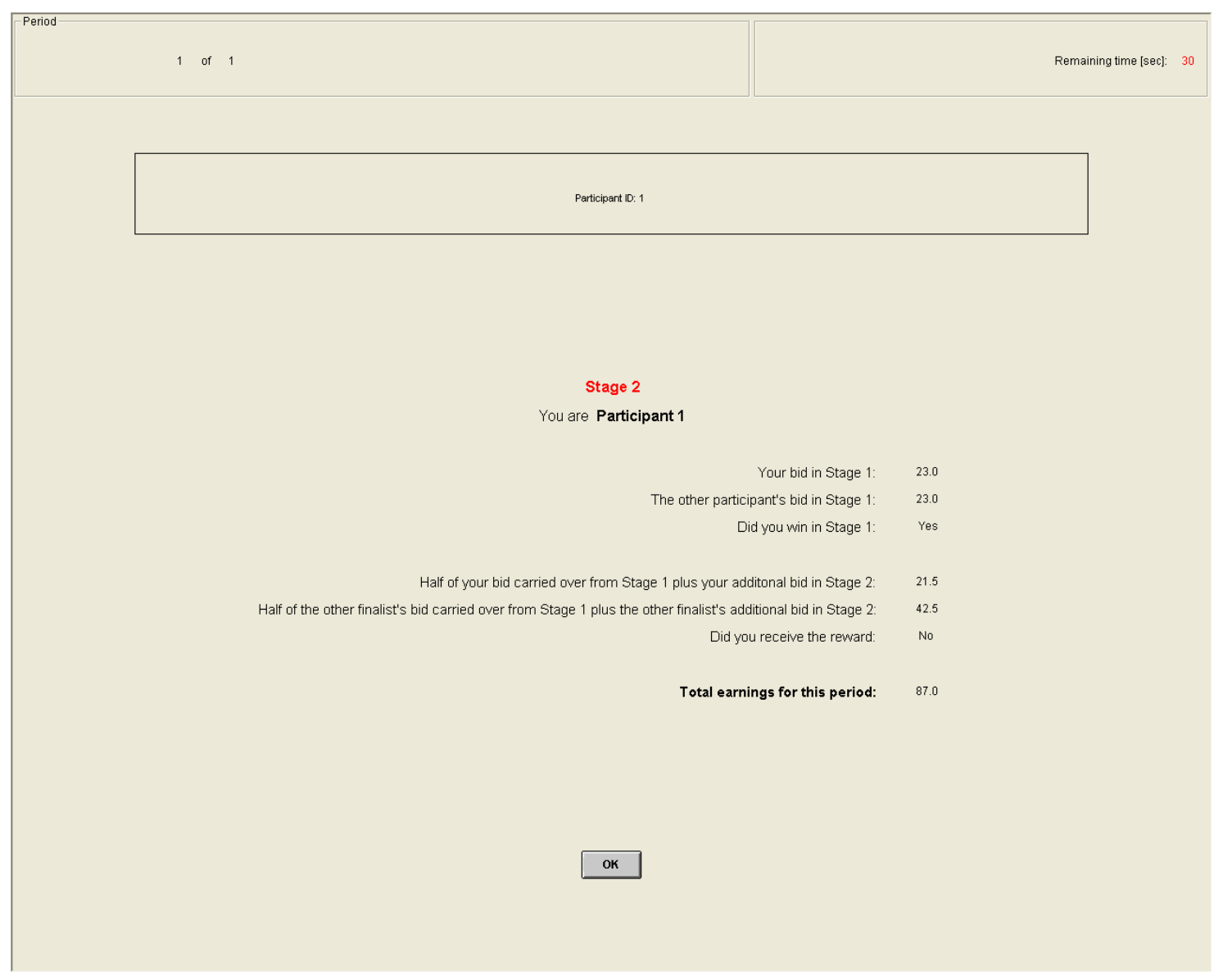

Outcome Screen

\section{IMPORTANT NOTES}

You will not be told which of the participants in this room are assigned to which group. At the beginning of each period you will be randomly re-grouped with three other 
participants to from a four-person group. Each period you will receive an endowment of 120 francs. You will use this endowment to bid for a reward which you will receive only if you win in Stage 1 and Stage 2. You can never guarantee yourself the reward. However, by increasing your bid, you can increase your chance of winning in Stage 1 and Stage 2 and thus increase your chance of receiving the reward. Remember, if you win in Stage 1 half of your bid made in Stage 1 will be carried over to Stage 2. Regardless of who receives the reward in Stage 2, all participants will have to pay their bids made in Stage 1 and Stage 2.

At the end of the experiment we will randomly choose 5 of the 30 periods for actual payment in Part 2 using a bingo cage. You will sum the total earnings for these 5 periods and convert them to a U.S. dollar payment.

Are there any questions?

\section{INSTRUCTIONS FOR PART 3}

The third part of the experiment consists of 30 decision-making periods and each period consists of two stages. The rules for part 3 are similar to the rules for part 2 . At the beginning of each period, you will be randomly and anonymously placed into a group of four participants. The composition of your group will be changed randomly every period. Each period you will be randomly and anonymously assigned as participant 1, 2, 3, or 4 . In Stage 1 participant 1 will be paired against participant 2 and participant 3 will be paired against participant 4. All four participants will be given an initial endowment of 120 francs. You will use this endowment to bid for a chance of participating in Stage 2. After four participants make their bids in Stage 1, the computer will determine two 
finalists who will proceed to Stage 2 - one from each pair. The two other participants who did not win in Stage 1 will no longer participate in this period. The only difference from part 2 is that in part 3, if you proceed to Stage 2 your entire bid made in Stage 1 will be carried over to Stage 2 (instead of half of the bid made in Stage 1). The other finalist will also carry over to Stage 2 the entire bid he or she made in Stage 1. In Stage 2 you and the other finalist will have an opportunity to make an additional bid. You may bid any number of francs between 0 and the amount of francs remaining from the initial endowment (including 0.5 decimal points). So, the additional bid you make in Stage 2 will be added to the bid you made in Stage 1 . The winner of Stage 2 will receive the reward of 120 francs.

The diagram below depicts the basic structure of each period.

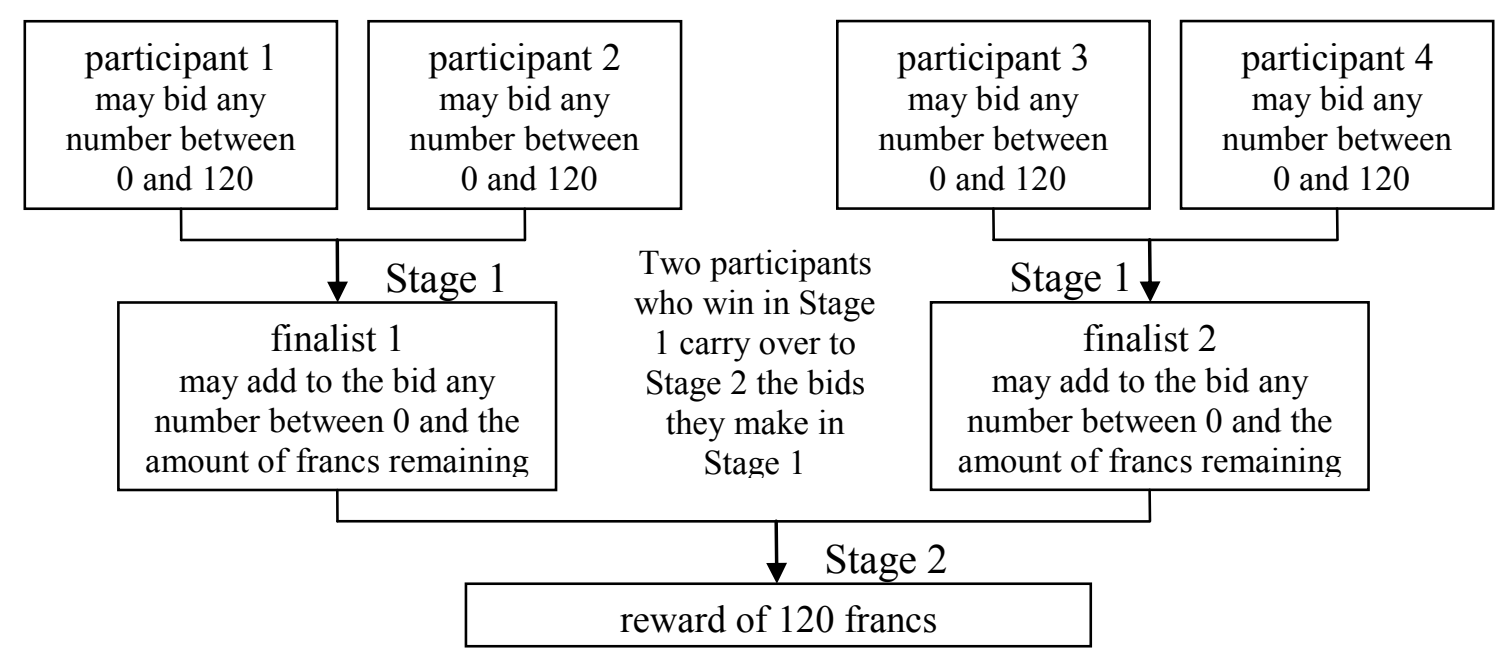




\section{YOUR EARNINGS}

Your earnings for the period are calculated in the same way as in part 2.

If you receive the reward:

Earnings $=$ Endowment + Reward - Your Bid in Stage $1-$ Your Bid in Stage $2=$

$$
=120+120-\text { Your Bid in Stage } 1-\text { Your Bid in Stage } 2
$$

If you do not receive the reward:

$$
\begin{aligned}
\text { Earnings } & =\text { Endowment }- \text { Your Bid in Stage } 1-\text { Your Bid in Stage } 2= \\
& =120-\text { Your Bid in Stage } 1-\text { Your Bid in Stage } 2
\end{aligned}
$$

The more you bid in each stage, the more likely you are to win that stage. The more the other participants bid, the less likely you are to win. Specifically, in Stage 1, for each franc you bid you will receive one lottery ticket. At the end of Stage 1 the computer draws randomly one ticket among all the tickets purchased by you and the other participant. The owner of the drawn ticket wins Stage 1 and proceeds to Stage 2. Thus, your chance of winning in Stage 1 is given by the number of francs you bid divided by the total number of francs you and the other participant bids.

$\begin{aligned} & \text { Chance of winning } \\ & \text { in Stage } 1\end{aligned}=\begin{gathered}\text { Your Bid in Stage 1 } \\ \text { Your Bid in Stage 1+ The Other } \\ \text { Participant's Bid in Stage 1 }\end{gathered}$

If both participants bid zero in Stage 1, the computer randomly chooses one participant who wins Stage 1 and proceeds to Stage 2. If you proceed to Stage 2, your entire bid in Stage 1 is carried over to Stage 2. Your total bid in Stage 2 is equal to your bid in Stage 1 plus your additional bid in Stage 2. The total amount of lottery tickets in Stage 2 which computer will assign to you is equal to your total bid in Stage 2. At the end of Stage 2 the computer draws randomly one ticket among all the lottery tickets in Stage 
2 owned by you and the other finalist. The owner of the drawn ticket wins Stage 2 and receives the reward of 120 francs. Thus, your chance of winning Stage 2 is given by your total bid in Stage 2 divided by your total bid in Stage 2 and the other finalist's total bid in Stage 2.

$\begin{aligned} & \text { Chance of winning } \\
& \text { in Stage } 1\end{aligned}=$\begin{tabular}{c} 
Your Total Bid in Stage 2 \\
\cline { 2 - 2 } Your Total Bid in Stage $2+$ The Other \\
Finalist's Total Bid in Stage 2
\end{tabular}

After four participants make their bids in Stage 1, the computer will make a random draw which will decide who wins in Stage 1 and thus proceeds to Stage 2. Then after two remaining participants make their additional bids in Stage 2, the computer will make a random draw which will decide who wins in Stage 2. Then the computer will calculate your period earnings based on your bid in Stage 1 and Stage 2 and whether you received the reward or not. These earnings will be converted to cash and paid at the end of the experiment if the current period is one of the five periods that is randomly chosen for payment.

At the end of each period the following information will be displayed on the outcome screen: your bid in Stage 1, the other participant's bid in Stage 1, whether you won in Stage 1 or not, your bid carried over from Stage 1 plus your additional bid in Stage 2, the other finalist's bid in Stage 1 plus the other finalist's additional bid in Stage 2, whether you received the reward or not, and the earnings for the period. Once the outcome screen is displayed you should record your results for the period on your Personal Record Sheet under the appropriate heading.

Remember, if you win in Stage 1 your entire bid made in Stage 1 will be carried over to Stage 2. At the end of the experiment we will randomly choose 5 of the 30 
periods for actual payment in Part 2 using a bingo cage. You will sum the total earnings for these 5 periods and convert them to a U.S. dollar payment. 


\section{ESSAY 4}

\section{PERFECT-SUBSTITUTES, BEST-SHOT, AND WEAKEST-LINK CONTESTS BETWEEN GROUPS}

\subsection{Introduction}

Many economic allocations are decided by contests in which individuals or groups expend costly resources while competing to win a specific prize. Examples include corporate competitions between consortia, $\mathrm{R} \& \mathrm{D}$ and patent competitions between firms, or election campaigns by political parties. Most of these contests are characterized by the fact that major decision are made by groups such as boards of directors, teams of researchers, or committees, and not by individuals.

As group contests unfold, conflicts arise within each group and between groups. Members of the same group have incentives to cooperate with each other by contributing individual efforts in order to win a contest. Since effort is costly, each member also has an incentive to abstain from contributing any effort and instead free-ride on the efforts of other members. The amount of free-riding that occurs within a group depends on the composition of the group and the rules that regulate the competition. Members of the same group who have less interest in winning the contest are more likely to free-ride on the efforts of members who have greater interest in winning. However, free-riding behavior is unlikely when the performance of the entire group depends crucially on the 
performance of each member of a group. We can gain valuable insights into what factors determine the outcome of the competition by studying different group compositions and different contest rules.

Take, for example, a contest between two firms for a patent: a "Good Manager" firm with a highly motivated manager but poorly motivated workers and a "Bad Manager" firm with a poorly motivated manager but highly motivated workers. Which firm will win the patent contest, the firm with the better motivated manager or the firm with the better motivated workers? What is the optimal compensation scheme that motivates the highest performance of each firm? How do the rules of the competition affect the effort expenditures and the amount of free-riding within each firm?

To answer these questions we design a novel experiment in which two groups compete in a contest. Each group has two types of players - one strong player and two weak players. The strong player values the prize more highly than the weak player and the valuations are common knowledge. The assumptions of the model allow us to interpret the heterogeneity in valuations as heterogeneity in abilities or heterogeneity in costs. All players within each group simultaneously and independently expend their efforts. The group performance is defined as some function of all individual efforts. In the public goods literature, the three most frequently used functional rules are perfectsubstitutes, best-shot, and weakest-link (Hirshleifer, 1983; Cornes, 1993). The novelty of our study is that we apply these rules to the contest setting. In the "perfect-substitutes" contest, the performance of a group depends on the sum of individual efforts. In the "best-shot" contest, the performance of a group depends on the best performer. In the "weakest-link" contest, the performance of a group depends on the worst performer. Each 
group's probability of winning the prize depends on its performance relative to the total performance by both groups. Therefore, the better performing group is more likely to win. However, the group that does not perform well still has some chance to receive the prize.

Contrary to theoretical predictions, we find significant over-contribution of efforts by both strong and weak players in contests where individual efforts are perfect substitutes. This over-contribution is neither explained by quantal response equilibrium nor by inequality aversion, but it can be partially explained by social identity theory. Consistent with theoretical predictions, in best-shot contests most of the effort is expended by strong players while weak players free-ride. One explanation for this finding is that the asymmetry between players serves as a coordination device by introducing a focal point where only strong players expend positive efforts (Schelling, 1960). This finding also suggests that such asymmetry can be used to solve the coordination failure problem in volunteer's dilemma games (Diekmann, 1985, 1993). In weakest-link contests all players expend similar positive efforts conforming to the group Pareto dominant equilibrium. A surprisingly strong coordination in weakest-link contests implies that the between-group competition serves as a strong incentive which facilitates coordination. It also suggests that introduction of between-group competition can be used to solve the coordination failure problem in games with Pareto-ranked equilibria such as the stag hunt (Van Huyck et al., 1990) and minimum effort public goods games (Weber, 2006).

When groups are asymmetric, as in the patent contest between the "Good Manager" firm and the "Bad Manager" firm, the outcome of the competition depends on the contest rules. The "Good Manager" firm with a better motivated manager is more 
likely to win the contest if the performance of both firms depends solely on the best performer within each firm. On the contrary, the "Bad Manager" firm is more likely to win the weakest-link and the perfect-substitutes contests. These results shed some light on how to develop an optimal managerial compensation scheme in cases where a chief executive officer (CEO) has to decide how to divide a bonus pool between a manager and workers. By wisely accounting for the type of underlying contest, the CEO can increase the team's chance of success. For example, if the team is participating in the best-shot type of contest then the CEO should allocate the largest bonus to the manager. However, given the fact that the majority of real life contests require considerable coordination (as in the weakest-link) and high level of joint effort (as in the perfect-substitutes), it is not optimal to allocate a very large bonus to the manager.

The rules that regulate the competition also determine the amount of total effort expenditures, amount of free-riding, and the relative performance of strong players. Perfect-substitutes contests generate the highest total effort expenditures among all contests, followed by best-shot and then weakest-link contests. The most free-riding behavior occurs in best-shot contests while there is almost no free-riding in weakest-link contests. We also find that strong players expend the highest relative effort in best-shot contests, followed by perfect-substitutes and then weakest-link contests. These findings have important implications for designing an optimal contest between groups. For example, a contest designer can choose the weakest-link rule to reduce free-riding by all players. However, by doing so the designer should anticipate the weakest-link contest to generate the lowest total effort expended, as well as weak performance of strong players. 
The general conclusion from our findings is that the advantage of one contest rule over another comes at a cost.

\subsection{Literature Review}

The most commonly used contest in the literature is the one proposed by Tullock (1980). In this contest, individual players expend costly efforts to influence the probability of winning a prize. The player's probability of winning is proportional to the player's relative expenditure. Thus, the player expending the highest effort has a higher probability of winning the prize.

The Tullock model considers competing individuals and thus reflects the conflict between individual players only. The first attempts to address inter-group conflict as well as intra-group conflict were made by Palfrey and Rosenthal (1983) and Katz et al. (1990). ${ }^{42}$ The pioneering study by Katz et al. (1990), which is built on the original Tullock contest, demonstrates that the effort expended by a group depends on individual valuations of the prize and not on the size of the group. One interpretation of this finding is that, as the size of a group increases, the amount of free-riding within the larger group increases to such an extent that the larger group has no advantage over the smaller group (Olson, 1965; Konrad, 2009). Baik (1993, 2008) refined the analysis of Katz et al. (1990) by considering intra-group heterogeneity. He showed that if the group members differ in their valuations of the prize, only the member with the highest valuation expends positive

\footnotetext{
42 Other theoretical studies of contests between groups include Nitzan (1991), Baik (1993; 2008), Katz and Tokatlidu (1996), Munster (2007), Cheikbossian (2008), and Lee (2009).
} 
effort. ${ }^{43}$ Other members of the same group choose to free-ride on the effort of the member with the highest valuation. Lee (2009) showed that when a group's probability of winning the contest depends only on the player who expends the lowest effort then multiple equilibria exist in which there is no free-riding.

The efforts expended in such contests are difficult to measure in the field since one can observe only the performance which is a function of effort, ability, and random noise (Ericsson and Charness, 1994). With this in mind, several researchers have turned to experimental tests of various contests. The first attempts to examine individual behavior in contests using laboratory methods were made by Millner and Pratt (1989, 1991). These studies, and many replications, employ individuals instead of groups. ${ }^{44}$ The exception to this is found in experimental studies of political voting models where, instead of individuals, groups are competing for the prize (Rapoport and Bornstein, 1987, 1989; Schram and Sonnemans, 1996; Cason and Mui, 2005). A major restriction of political models is that the subject's choice space limited to a binary decision: whether to cast a vote or not. The only experimental studies on group contest where subjects can make their decisions on continuous space are Gunnthorsdottir and Rapoport (2006),

\footnotetext{
${ }^{43}$ The result that the equilibrium effort levels depend exclusively on the highest valuation for the prize in each group and not on the group size is well known in the literature. This result is also robust to different specifications of contest success function (Nti, 1998; Baik et al., 2001). Several studies suggested using convex cost of effort or modified utility function in order to overcome free-riding and make group size meaningful. For example, Riaz et al. (1995) show that by modifying utility function the total effort expended by both groups increases if either group increases in size. In such case free riding exists within a group, but it is incomplete. Esteban and Ray (2001) show that in case of convex costs the group size is an important factor which influences the outcome of the contest.

${ }^{44}$ Laboratory studies of contests between individuals conclude: there is significant over-dissipation of rent (Millner and Pratt, 1989, 1991); all-pay auctions generate higher efforts than lottery contests (Davis and Reilly, 1998; Potters et al., 1998); risk-aversion and quantal response equilibrium can account for nonequilibrium behavior (Miller and Pratt, 1991; Goeree et al., 2002; Sheremeta, 2009a); the non-monetary utility of winning is an important factor to explain over-dissipation in contests (Parco et al., 2005; Sheremeta, 2009b).
} 
Kugler et al. (2009), and Abbink et al. (2009). ${ }^{45}$ The former two studies investigate the effect of egalitarian and proportional profit sharing rules on the individual behavior in the contest between groups. Both studies find that the proportional profit sharing rule elicits higher individual efforts than the egalitarian rule. Abbink et al. (2009) experimentally study the contest introduced by Katz et al. (1990) and find that groups behave more aggressively than individuals. Our experimental design shares some features with the three studies above. However, it differs substantially by the fact that we have heterogeneous players, instead of homogeneous players. Moreover, we also study the impact of three different contest rules, as in Harrison and Hirshleifer (1989), on the effort expenditures and the amount of free-riding.

\subsection{The Experimental Environment}

\section{A. The Model}

To simplify our analysis we assume that there are two groups expending costly efforts in order to win a contest. Group $G$ ("Good Manager” firm) consists of $N_{G}$ riskneutral players, and each player $i$ expends individual effort $x_{i G}$. Group $B$ ("Bad Manager" firm) is defined in a similar way. All players simultaneously and independently expend irreversible efforts. The group performance $X_{G}$ is a function of all individual efforts. The three functional forms considered in this study are perfect-substitutes, best-shot, and weakest-link (Hirshleifer, 1983).

\footnotetext{
45 Another two studies that employ team contests in the context of labor tournaments are Nalbantian and Schotter (1997) and Sutter and Strassmair (2009).
} 
In the perfect-substitutes contest the group performance is a sum of all individual efforts, $X_{G}=\sum_{i=1}^{N_{G}} x_{i G}$. This type of contest resembles many real life competitions where the performance of the group depends on the joint effort of all members within that group. Consider, for example, a contest between two towns for a county's road construction budget. The government of the county selects the winning town based on the lobbying efforts by the people within each town. In such a contest, the performance of a town depends on the sum of all individual lobbying efforts.

In the best-shot contest the group performance depends only on the best performer within a group, $X_{G}=\max \left\{x_{1 G}, \ldots, x_{N_{G} G}\right\}$. An example of such a contest is a competition between groups where each member of each group presents a design of a new product and the group whose member presents the best design receives a reward. In this contest the performance of a group depends only on the best performer within that group.

In the weakest-link contest the performance of the entire group depends on the worst performer within a group, $X_{G}=\min \left\{x_{1 G}, \ldots, x_{N_{G} G}\right\}$. Kremer (1993) discusses a devastating event caused by the failure of the weakest component. In 1986, the space shuttle Challenger broke apart 73 seconds into its flight after a failure of a small component called the O-ring seal. After investigation, the failure of the O-ring was attributed to a design flaw. Consequently, Kremer built a theoretical model of economic development called the "O-ring theory", where the performance of an organization depends mainly on the worst performing individual (or unit) - the "weakest link". An example of a weakest-link contest is a competition between groups where each member of the group is responsible for a specific task. If any of the members fails to perform the 
task then the group loses the competition. Other weakest-link, best-shot, and perfectsubstitutes examples can be found in Hirshleifer (1983), Bliss and Nalebuff (1984), and Harrison and Hirshleifer (1989).

The performance of each group determines the probability of winning the contest. After all players of group $G$ and group $B$ choose their efforts, $X_{G}$ and $X_{B}$ are compared. The better performing group has a higher chance of winning the prize. The probability of group $G$ winning the prize is defined by a lottery contest success function:

$$
p_{G}\left(X_{G}, X_{B}\right)=X_{G} /\left(X_{G}+X_{B}\right)
$$

That is, each group's probability of winning depends on its performance relative to the total performance by both groups. Our reason for choosing this specific contest success function is that it is simple enough for subjects to understand, but this simplicity does not affect the comparative statics predictions of the theory (Baik, 1993, 2008; Baik et al., 2001; Nti, 1998; Lee, 2009). The lottery contest success function is also commonly used in most of the Tullock contest literature, including virtually all of the experimental contest literature.

In the case where group $G$ wins the prize, player $i$ receives the valuation of $v_{i G}$. All prize valuations are common knowledge and may differ from player to player. Without loss of generality, assume that $v_{1 G}>v_{2 G} \geq \cdots \geq v_{N_{G} G}>0$ and $v_{1 B}>v_{2 B} \geq$ $\cdots \geq v_{N_{B} B}>0$. We will call players $1 G$ and $1 B$ "strong players" and other players "weak players". Given (1), the expected payoff for player $i$ in group $G$ can be written as:

$$
\pi_{i G}\left(x_{i G}, X_{G}, X_{B}\right)=p_{G}\left(X_{G}, X_{B}\right) v_{i G}-x_{i G}
$$

The first term of the expected payoff, $p_{G}\left(X_{G}, X_{B}\right) v_{i G}$, is simply the probability of group $G$ winning the prize times player $i$ 's valuation of the prize. By expending a higher 
effort, $x_{i G}$, player $i$ can increase the probability $p_{G}\left(X_{G}, X_{B}\right)$ of winning the contest. Therefore, player $i$ has an incentive to cooperate with other members of his group; but since cooperation is costly, $\left(-x_{i G}\right)$, there is also an incentive to free-ride. It is important to emphasize that, because of the lottery contest success function and the linear costs, heterogeneity in valuations can also be interpreted as heterogeneity in abilities or heterogeneity in costs. For example, without changing the nature of the current contest one could divide (2) by $v_{i G}$ and thus transform this contest into a contest where players have heterogeneous costs.

Theoretical implications of the model described in this section depend on the contest rule. In the perfect-substitutes contest, the pure-strategy Nash equilibrium, where each player's effort level is the best response to the effort levels of the other players, is unique and is characterized by player $1 G$ 's and $1 B$ 's optimal efforts of $x_{1 G}^{*}=$ $v_{1 G}^{2} v_{1 B} /\left(v_{1 G}+v_{1 B}\right)^{2}$ and $x_{1 B}^{*}=v_{1 G} v_{1 B}^{2} /\left(v_{1 G}+v_{1 B}\right)^{2}$ (Baik, 1993, 2008). All other players free-ride in the equilibrium and expend no effort. The intuition behind the equilibrium is that the strong player obtains the highest marginal payoff, whereas all players have the same constant marginal cost. Given this, at the equilibrium effort of the strong player, the marginal payoff for the weak players is always lower than the marginal cost. Therefore, the weak players have no incentive to expand any positive effort.

One would expect that the best-shot contest generates the same unique equilibrium as the perfect-substitutes contest. However, multiple equilibria can arise in which any two players, each from a different group, compete against each other as in a simple two-player contest, while other players fully free-ride. This multiplicity of equilibria arises when the valuations of strong players, $v_{1 G}$ and $v_{1 B}$, are not sufficiently 
higher than the valuations of weak players. In this case, strong players can free-ride on the efforts of weak players. In the next section we will discuss all possible equilibria in the best-shot contest used in our experiment.

The equilibrium of the weakest-link contest has recently been characterized by Lee (2009). In such a contest there exist multiple pure-strategy Nash equilibria in which there is no free-riding. In each equilibria the players in each group match all their efforts at the same level while best responding to the effort of the other group. Each individual player does not have any incentive to change his effort level, given the efforts of the other players. However, players within the same group have incentives to cooperate with each other and hence increase their effort levels. Lee (2009) proved that there is only one group Pareto dominant equilibrium in which no individual player or group has any incentive to deviate. In the Pareto equilibrium, all players expend efforts, which are derived from a simple two-player contest between the weakest player in group $G$ and the weakest player in group $B$, i.e. $x_{i G}^{*}=v_{N_{G} G}^{2} v_{N_{B} B} /\left(v_{N_{G} G}+v_{N_{B} B}\right)^{2}$ and $x_{i B}^{*}=$ $v_{N_{G} G} v_{N_{B} B}^{2} /\left(v_{N_{G} G}+v_{N_{B} B}\right)^{2}$ for all $i$.

\section{B. Experimental Design and Predictions}

Our experiment studies contests between symmetric and asymmetric groups. Table 4.3.1 summarizes the valuations of the players, the equilibrium efforts and the expected payoffs in contests between symmetric groups. Both groups $G$ and $B$ have three players - one strong player with higher valuation of 60 and two weak players with lower valuations of 30. The total group effort in Table 4.3.1 is defined as the sum of all individual efforts. The effective group effort in the perfect-substitutes contest is defined 
as the sum of all individual efforts, in the best-shot contest it is the maximum individual effort within a group, and in the weakest-link contest it is the minimum individual effort within a group.

Table 4.3.1 - Symmetric Contests

\begin{tabular}{|c|c|c|c|c|c|c|c|c|c|c|}
\hline \multirow[t]{2}{*}{ Treatment } & \multirow[t]{2}{*}{ Group } & \multicolumn{2}{|c|}{$\begin{array}{l}\text { Valuation of } \\
\text { Player }\end{array}$} & \multicolumn{2}{|c|}{$\begin{array}{c}\text { Equilibrium } \\
\text { Effort of Player }\end{array}$} & \multicolumn{2}{|c|}{$\begin{array}{c}\text { Equilibrium } \\
\text { Payoff of Player }\end{array}$} & \multicolumn{2}{|c|}{$\begin{array}{l}\text { Equilibrium } \\
\text { Group Effort }\end{array}$} & \multirow{2}{*}{$\begin{array}{c}\text { Probability } \\
\text { of } \\
\text { Winning }\end{array}$} \\
\hline & & 1 & 2,3 & 1 & 2,3 & 1 & 2,3 & Total & $\overline{\text { Effective }}$ & \\
\hline Perfect-substitutes & $G, B$ & 60 & 30 & 15 & 0 & 15 & 15 & 15 & 15 & 0.5 \\
\hline Best-shot & $G, B$ & 60 & 30 & 15 & 0 & 15 & 15 & 15 & 15 & 0.5 \\
\hline Weakest-link & $G, B$ & 60 & 30 & 7.5 & 7.5 & 22.5 & 7.5 & 22.5 & 7.5 & 0.5 \\
\hline
\end{tabular}

In the perfect-substitutes treatment the equilibrium is unique

In the best-shot and weakest-link treatments there are multiple equilibria (the table shows group Pareto equilibria)

In the perfect-substitutes contest, the equilibrium is unique and is characterized by player $1 G$ 's and $1 B$ 's optimal effort of 15 . The weak players in the equilibrium should free-ride and expend no effort. As a result, the total group effort and the effective group effort are 15. In the best-shot contest there are multiple equilibria, which are established each time when one player from group $G$ competes against one player from group $B$ as in a simple two-player contest, while other players fully free-ride. However, the Pareto equilibrium coincides with the equilibrium of the perfect-substitutes contest (Table 4.3.1). ${ }^{46}$ In the weakest-link contest there are multiple equilibria in which there is no freeriding. The unique Pareto dominant equilibrium is characterized by an effort of 7.5 for all players. In the Pareto dominant equilibrium the total group effort, defined as a sum of all

\footnotetext{
${ }^{46}$ Other equilibria in the best-shot are characterized by player $2 G$ 's (or $3 G$ 's) and $2 B$ 's (or $3 B$ 's) efforts of 7.5 while others expend 0 . In these equilibria, both groups have equal probability of winning the contest. The expected payoff of player 1 is 30 , player $2(3)$ is 7.5 , and player 3(2) is 15 . One can see that these equilibria, as well as the equilibria where one strong player competes against one weak player, will cause highly asymmetric payoffs. Based on the findings of the other-regarding preferences literature (Fehr and Schmidt, 1999; Bolton and Ockenfels, 2000), we expect that the equilibrium described in Table 4.3.1 is most likely to be chosen by players since all players within a group earn the same expected payoffs of 15 .
} 
efforts within a group, is 22.5; and the effective group effort, defined as a minimum effort within a group, is 7.5 .

Table 4.3.2 - Asymmetric Contests

\begin{tabular}{|c|c|c|c|c|c|c|c|c|c|c|}
\hline \multirow[t]{2}{*}{ Treatment } & \multirow[t]{2}{*}{ Group } & \multicolumn{2}{|c|}{$\begin{array}{c}\text { Valuation of } \\
\text { Player }\end{array}$} & \multicolumn{2}{|c|}{$\begin{array}{c}\text { Equilibrium } \\
\text { Effort of Player }\end{array}$} & \multicolumn{2}{|c|}{$\begin{array}{c}\text { Equilibrium } \\
\text { Payoff of Player }\end{array}$} & \multicolumn{2}{|c|}{$\begin{array}{l}\text { Equilibrium } \\
\text { Group Effort }\end{array}$} & \multirow{2}{*}{$\begin{array}{c}\text { Probability } \\
\text { of } \\
\text { Winning }\end{array}$} \\
\hline & & 1 & 2,3 & 1 & 2,3 & 1 & 2,3 & Total & $\overline{\text { Effective }}$ & \\
\hline \multirow{2}{*}{ Perfect-substitutes } & $G$ & 90 & 15 & 21.6 & 0 & 32.4 & 9 & 21.6 & 21.6 & 0.60 \\
\hline & $B$ & 60 & 30 & 14.4 & 0 & 9.6 & 12 & 14.4 & 14.4 & 0.40 \\
\hline \multirow{2}{*}{ Best-shot } & $G$ & 90 & 15 & 21.6 & 0 & 32.4 & 9 & 21.6 & 21.6 & 0.60 \\
\hline & $B$ & 60 & 30 & 14.4 & 0 & 9.6 & 12 & 14.4 & 14.4 & 0.40 \\
\hline \multirow{2}{*}{ Weakest-link } & $G$ & 90 & 15 & 3.3 & 3.3 & 26.4 & 1.7 & 10.0 & 3.3 & 0.33 \\
\hline & $B$ & 60 & 30 & 6.7 & 6.7 & 33.3 & 13.3 & 20.0 & 6.7 & 0.67 \\
\hline
\end{tabular}

In the perfect-substitutes treatment the equilibrium is unique

In the best-shot and weakest-link treatments there are multiple equilibria (the table shows group Pareto equilibria)

Although contests between symmetric groups are not uncommon, most contests in reality take place between asymmetric groups. In the introduction we discussed a contest for a patent between the "Good Manager" firm and the "Bad Manager" firm, in which the asymmetry of two competing firms comes primarily from the differences between managers and workers. To capture this we examine a contest between two asymmetric groups as shown in Table 4.3.2. Similar to the symmetric case, we study the effect of three contest rules: perfect-substitutes, best-shot, and weakest-link. In each contest the composition of group $B$ is the same as in symmetric contests. In group $G$, however, the prize valuation of player $1 G$ is increased to 90 , while the prize valuation of players $2 G$ and $3 G$ is decreased to 15 . The overall valuation of both groups is held constant.

In equilibrium, group $G$ has a higher chance of winning the perfect-substitutes and best-shot asymmetric contests. This result comes from the competition between the strong players. Since player $1 G$ (“Good Manager”) has higher valuation than player $1 B$ (“Bad Manager”), player $1 G$ expends higher effort in the equilibrium (21.6 versus 14.4). 
As a result, group $G$ wins the contest $60 \%$ of the time. In contrast, the outcome of the weakest-link asymmetric contest depends solely on the weakest player in each group. In group $G$ the weak player's valuation is 15 , while in group $B$ the weak player's valuation is 30. Therefore, equilibrium efforts by all players in group $G$ and group $B$ are 3.3 and 6.7. These efforts imply that group $G$ wins the contest only $33 \%$ of the time, while group $B$ wins the contest $67 \%$ of the time. That is, asymmetry helps the "Good Manager" firm except in the weakest-link contest.

\section{The Experimental Procedures}

The experiment was conducted at the Vernon Smith Experimental Economics Laboratory. A total of 108 subjects participated in six sessions (18 subjects per session). All subjects were Purdue University undergraduate students who participated in only one session of this study. Some students had participated in other economics experiments that were unrelated to this research.

The computerized experimental sessions were run using z-Tree (Fischbacher, 2007). Each session proceeded in three parts. Subjects were given the instructions, available in the Appendix, at the beginning of each part and the experimenter read the instructions aloud. In the first part, similar to Holt and Laury (2002), subjects' risk attitudes were elicited using multiple price list of 15 simple lotteries. ${ }^{47}$ At the end of the experiment, 1 out of the 15 lottery decisions made by subjects was randomly selected for payment. The second and the third parts corresponded to one symmetric and one

\footnotetext{
${ }^{47}$ Subjects were asked to state whether they preferred safe option A or risky option B. Option A yielded $\$ 1$ payoff with certainty, while option B yielded a payoff of either $\$ 3$ or $\$ 0$. The probability of receiving $\$ 3$ or $\$ 0$ varied across all 15 lotteries. The first lottery offered a 5\% chance of winning $\$ 3$ and a $95 \%$ chance of winning $\$ 0$, while the last lottery offered a $70 \%$ chance of winning $\$ 3$ and a $30 \%$ chance of winning $\$ 0$.
} 
asymmetric treatment using the same contest rule. In three sessions we ran symmetric treatments first and in three other sessions we ran asymmetric treatments first. Each subject played 30 periods in symmetric treatment and 30 periods in asymmetric treatment.

In each period subjects were randomly and anonymously placed into group $G$ or $B$ designated as either player 1,2 , or 3 within that group. Thus, all subjects had an equal chance to play as strong and weak players during different periods of the experiment. At the beginning of each period, each player received 60 experimental francs as an endowment (equivalent to $\$ 1.20){ }^{48}$ All subjects were told that by contributing 1 franc to their individual account they would earn 1 franc, while by contributing 1 franc to their group account they could increase the chance of their group receiving the reward. Subjects could contribute any integer number of francs between 0 and 60 . After all subjects submitted their effort contributions to the group account, a random draw determined the winning group. A simple lottery was used to explain how the computer chose the winning group. At the end of each period subjects were informed of group $G$ 's and $B$ 's efforts. Subjects were paid for 5 out of 30 periods in parts two and three at the end of the experiment. The earnings were converted into US dollars at the rate of 50 francs to $\$ 1$. On average, subjects earned $\$ 21$ each and the experimental sessions lasted for about 70 minutes.

\footnotetext{
${ }^{48}$ Although we restrict the endowment to 60 , it does not affect the equilibrium. The highest equilibrium effort of the strong player (whose valuation is 90 ) is only 21.6, which is much lower than the non-binding endowment of 60 .
} 


\subsection{Experimental Results}

\section{A. Symmetric Contests}

Table 4.4.1 summarizes the average effort and payoff in symmetric contests. In the perfect-substitutes contest the equilibrium of the game is characterized by the positive effort only for player 1. Contrary to theoretical predictions, weak players expend substantial efforts. Around $70 \%$ of all efforts expended by players 2 and 3 are positive. We also observe that subjects in the role of player 1 expend on average an effort of 18.9, which is significantly higher than the equilibrium effort of 15 ( $p$-value $<0.01) .{ }^{49}$ Even when we exclude the first 15 periods of the experiment, the actual efforts by weak and strong players are still significantly higher than the equilibrium $(p$-value $<0.05)$. As a result of significant over-contribution, the total group effort is almost three times higher than the equilibrium and all players earn significantly lower payoffs. The significant over-contribution of efforts is consistent with Abbink et al. (2008), who find that groups in a similar perfect-substitutes contest expend four times more than the equilibrium. ${ }^{50}$

Result 1: Contrary to theoretical predictions, significant over-contribution of efforts by both strong and weak players is observed in the perfect-substitutes contest.

\footnotetext{
${ }^{49}$ To support this conclusion we estimated a simple panel regression, where the dependent variable is effort and independent variables are period trend and a constant. The model included a random effects error structure, with the individual subject as the random effect, to account for the multiple bids made by individual subjects. Based on a standard Wald test, conducted on estimates of a model, we found that for both types of players the constant coefficients are significantly higher than the predicted theoretical values $(p$-value $<0.01)$.

${ }^{50}$ Significant over-contribution of efforts has been also observed in other contest studies that employ individual rather than group contestants (Millner and Pratt 1989, 1991; Davis and Reilly, 1998; Sheremeta, 2009a,b).
} 
Table 4.4.1 - Average Effort and Payoff in Symmetric Contests

\begin{tabular}{|c|c|c|c|c|c|c|c|c|c|}
\hline \multirow[t]{2}{*}{ Treatment } & \multirow[t]{2}{*}{ Group } & \multicolumn{2}{|c|}{$\begin{array}{c}\text { Equilibrium } \\
\text { Effort of Player }\end{array}$} & \multicolumn{2}{|c|}{$\begin{array}{c}\text { Average } \\
\text { Effort of Player }\end{array}$} & \multicolumn{2}{|c|}{ Group Effort } & \multicolumn{2}{|c|}{$\begin{array}{c}\text { Payoff as \% of } \\
\text { Equilibrium Payoff }\end{array}$} \\
\hline & & 1 & 2,3 & 1 & 2,3 & $\overline{\text { Total }}$ & Effective & 1 & 2,3 \\
\hline Perfect-substitutes & $G, B$ & 15 & 0 & $18.9(0.7)$ & $10.8(0.4)$ & 40.5 & 40.5 & $74.0 \%$ & $28.0 \%$ \\
\hline Best-shot & $G, B$ & 15 & 0 & $15.2(0.8)$ & $4.7(0.4)$ & 24.6 & 19.9 & $98.4 \%$ & $68.9 \%$ \\
\hline Weakest-link & $G, B$ & 7.5 & 7.5 & $7.7(0.4)$ & $7.0(0.2)$ & 21.6 & 4.8 & $99.3 \%$ & $107.0 \%$ \\
\hline
\end{tabular}

Standard error of the mean in parentheses

There are several possible explanations for significant over-contribution of efforts. First, participants who are assigned as weak players may think that they are expected to "play the game" and thus should expend some positive efforts. ${ }^{51}$ In other words, it might be unnatural for participants to expend no effort. Second, both strong and weak players are likely to make "errors." Sheremeta (2009a) showed how the quantal response equilibrium (QRE) developed by McKelvey and Palfrey (1995), which accounts for errors made by individual subjects, can explain some over-contribution of efforts in lottery contests. The crucial parameter of QRE is the error parameter, $\lambda$, which determines the sensitivity of the choice probabilities with respect to payoffs. Following standard estimation procedures (Goeree et al., 2002) we estimated QRE for all symmetric contests. ${ }^{52}$

\footnotetext{
${ }^{51}$ The concern of boundary equilibrium is well recognized in studies of linear public goods games (Keser, 1996; Sefton and Steinberg, 1996).

${ }^{52}$ The numerical computation of the equilibrium was feasible only after restricting the strategy space to $\{0$, $5,10,15, \ldots, 60\}$. We used the logit probabilistic choice rule, where the probability of choosing a certain action is proportional to an exponential function of the associated expected payoff. A more detail description of the estimation procedures is available from the author upon a request.
} 

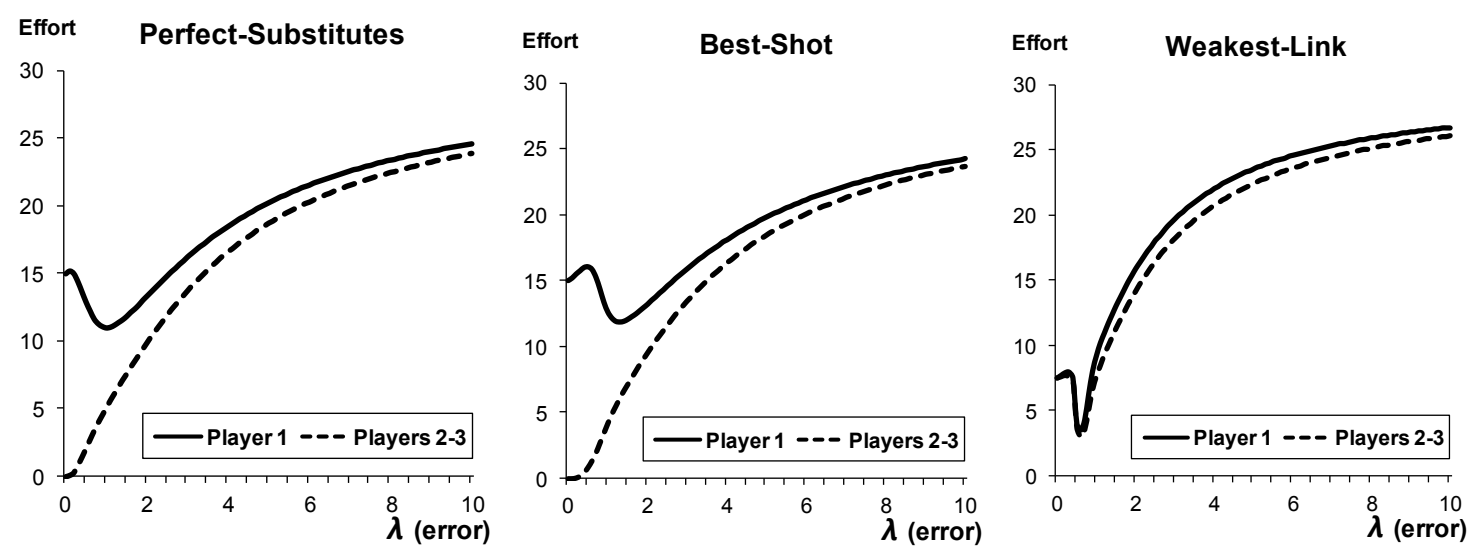

Figure 4.4.1 - Average Effort at the QRE in Symmetric Contests

The left panel of Figure 4.4.1 shows the average effort (on the vertical axis) at the QRE as a function of $\lambda$ in the perfect-substitutes contest. When $\lambda$ is zero, the behavior is consistent with the Nash equilibrium: player 1 expends 15 and players 2 and 3 expend no effort. As the level of errors increases, the weak players over-contribute relative to the Nash equilibrium. The strong players initially under-contribute and then, after a certain level of errors, over-contribute relative to the Nash equilibrium. As both types of players move closer to a random play, i.e., putting equal weights on each strategy, the average effort approaches 30 (one half of the endowment). Assuming a common level of error for both types of players in the perfect-substitutes contest, the maximum likelihood estimate of $\lambda$ is 2.42 . At this level of error weak players expend the average effort of 11.35 and the strong players expend the average effort of 14.4. Compared with the actual decisions made (Table 4.4.1), the QRE model overestimates the efforts of the weak players and underestimates the efforts of the strong players, and thus it cannot account for significant over-contribution by both types of players simultaneously. 


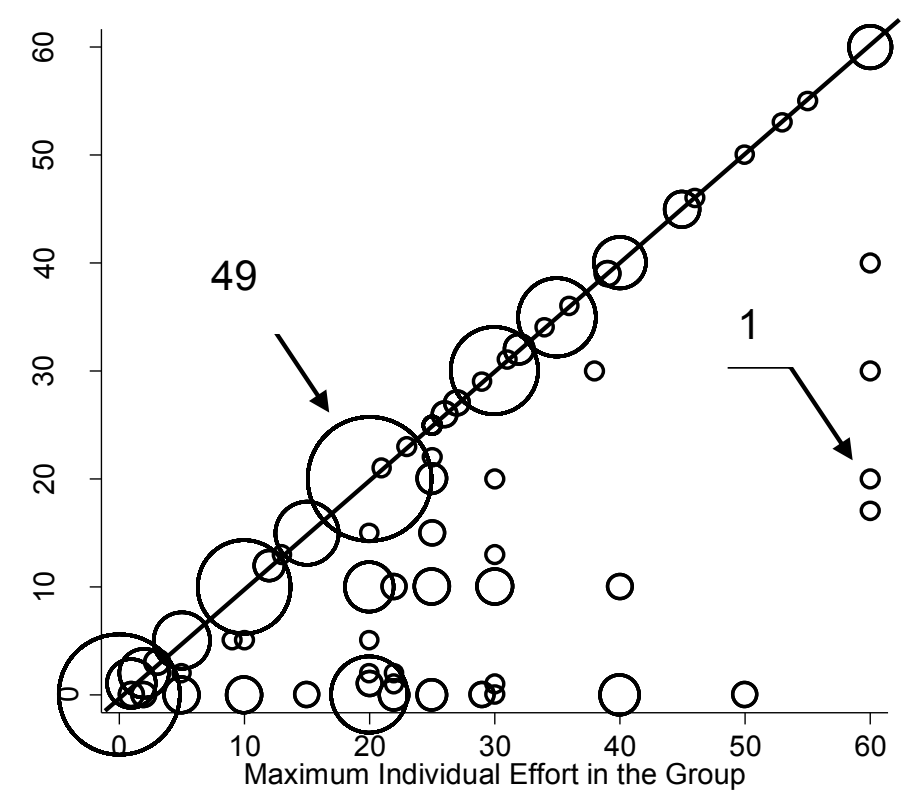

Figure 4.4.2 - Effort of Player 1 vs Maximum Individual Effort in the Group (Best-Shot)

In the symmetric best-shot contest many subjects select a strategy where only strong players expend positive efforts. Figure 4.4.2 displays the effort made by player 1 and the corresponding maximum individual effort in the group. The size of the bubble indicates the frequency of observation (the total number of observations is 360). For example, the biggest bubble on the graph indicates that 49 times player 1's effort of 20 turned out to be the highest effort within a group. Over $75 \%$ of all observations lie on the 45 degree line, indicating that player 1 most frequently has the highest effort within a group. Moreover, in the best-shot contest only $28 \%$ of efforts made by players 2 and 3 are above 0 (compared to $70 \%$ in the perfect-substitutes contest).

Result 2: In the best-shot contest most of the efforts are made by strong players, while weak players tend to free-ride.

As mentioned in Section 4.3, multiple equilibria exist where one weak player from group $G$ competes against one weak player from group $B$ in what effectively 
becomes a two-player contest. Thus, it can be optimal for strong players to expend no effort when some weak players expend positive efforts. This may explain why $26 \%$ of efforts made by strong players are 0 in the best-shot contest, compared to only $12 \%$ in the perfect-substitutes contest. The difference is significant based on the estimation of a random effect probit model, where the dependent variable is whether the weak strong contributes or not, and the independent variable is a dummy for the best-shot contest ( $p$ value $<0.01)$.

Overall, the behavior we observe in the best-shot contest is consistent with theoretical predictions. This finding is different from previous findings of Harrison and Hishleifer (1989) who document that, in the best-shot public goods game, players expend four times higher efforts than predicted. The difference between our findings and findings of Harrison and Hishleifer (1989) is likely due to the fact that, instead of symmetric players, we have asymmetric players. In the equilibrium of the best-shot contest only one player should expend positive effort while other players should expend no effort. The introduction of asymmetry between players results in a focal point where only the strong player expends positive effort (Schelling, 1960; Ochs, 1995; Kroll et al., 2007; Crawford et al., 2008). This finding suggests that the asymmetry between players serves as a coordination device and thus it may solve the coordination failure problem in volunteer's dilemma games (Diekmann, 1985, 1993).

Next we look at the behavior of players in the symmetric weakest-link contest. The striking difference between the weakest-link contest and the two other contests is that, in the weakest-link contest, all players expend very similar efforts. Table 4.4.1 
reports that player 1 on average expends effort of 7.7 and players 2 and 3 expend efforts of 7. In the Pareto dominant equilibrium all players should expend 7.5 as their effort. ${ }^{53}$

Result 3: In the weakest-link contest both strong and weak players expend similar positive efforts, at levels consistent with the Pareto dominant equilibrium.

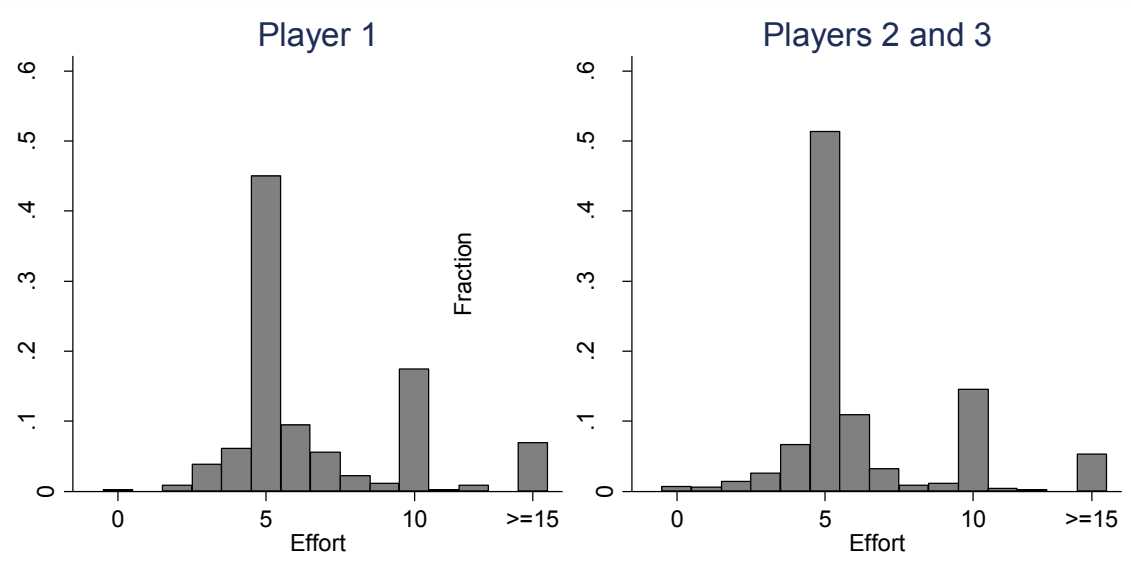

Figure 4.4.3 - Distribution of Effort in the Weakest-Link Contest

It is important to emphasize, however, that nearly $50 \%$ of all individual efforts do not precisely coincide with the minimum individual effort within the group (the effective group effort in Table 4.4.1) suggesting some coordination failure. Figure 4.4.3 displays the distribution of efforts in the weakest-link contest. Most frequently, strong and weak players coordinate their efforts around 5. Consequently, the average effective group effort of 4.8 is lower than the optimal Pareto dominant effort of 7.5. Figure 4.4 .4 displays the dynamics of the average effort and the standard deviation in the weakest-link contest. As players become more experienced, the within-group standard deviation decreases. This is

\footnotetext{
${ }^{53}$ Based on a standard Wald test, conducted on estimates of a random effect model, we cannot reject the hypothesis that the weak players expend the Pareto equilibrium effort ( $p$-value $=0.12$ when we use the first 15 periods and $p$-value $=0.26$ when we use the last 15 periods). The strong players expend significantly higher efforts than the equilibrium in the first 15 periods of the experiment ( $p$-value $<0.05$ ), however, there is no significant difference in the last 15 periods $(p$-value $=0.73)$.
} 
a good indication of convergence towards the equilibrium prediction of symmetric efforts. At equilibrium, of course, the standard deviation should be zero.

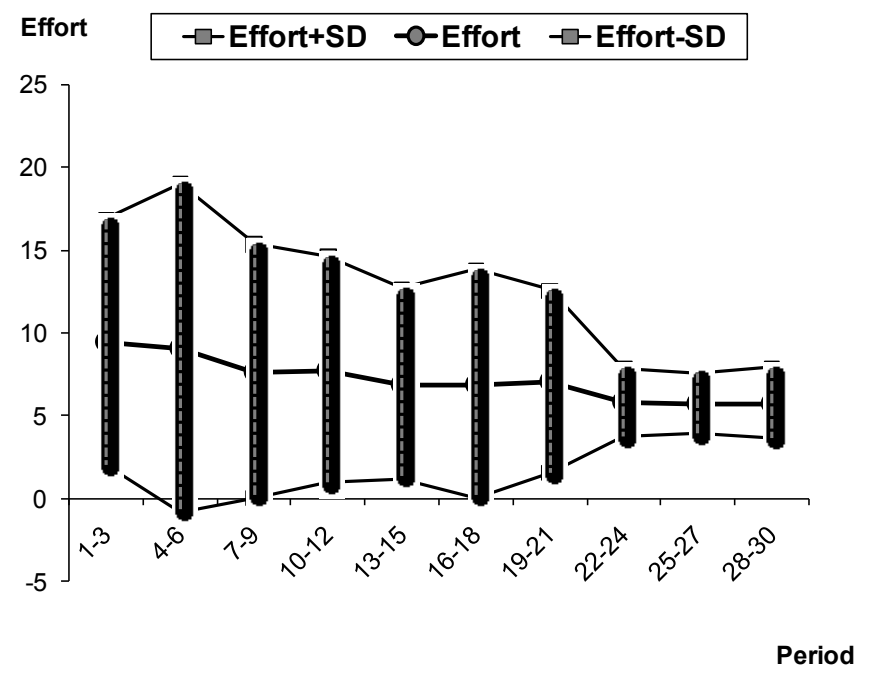

Figure 4.4.4 - Average Effort in the Weakest-Link Contest

Overall, the behavior we observe in the weakest-link contest is consistent with the Pareto dominant equilibrium. This finding contrasts with the early literature on coordination games with Pareto-ranked equilibria (Van Huyck et al., 1990, 1991; Cooper et al., 1990, 1992). The seminal studies by Van Huyck et al. (1990) and Cooper et al. (1990) document that coordination failure is a common phenomenon in the laboratory. A number of studies have tried to resolve the coordination failure through pre-play communication (Van Huyck et al., 1992), repetition and fixed-matching protocols (Clark and Sefton, 2001), and gradual increase in the group size (Weber, 2006). Our experiment points out that introduction of between-group competition may be a simple solution to the coordination failure problem. ${ }^{54}$

\footnotetext{
${ }^{54}$ Similar result is established by Bornstein et al. (2002), who find that competition between groups improves collective efficiency relative to the base line treatment of Van Huyck et al. (1990). The main
} 
The fairly strong correspondence to the equilibrium predictions in the best-shot and weakest-link contests (Results 2 and 3) suggests that over-contribution of efforts by strong and weak players in the perfect-substitutes contest (Result 1) is due not only to errors or misunderstanding of the contest but also to the result of "intentional" overbidding behavior. ${ }^{55}$ A rapidly developing literature in economics on social group identity may have an explanation for such behavior (Akerlof and Kranton, 2000, 2005; Chen and Li, 2008). By expending positive efforts in the perfect-substitutes contest players always contribute to the group performance, which is not necessarily true for the best-shot or weakest-link contest. Therefore, subjects participating in the perfect-substitutes contest may identify themselves as a group and be influenced by this group identification (Kugler et al., 2005). Obviously, the group identification shifts players' attention from selfinterested profit-maximizing behavior to altruistic group-maximizing behavior and thus may cause over-contribution of efforts. ${ }^{56}$

difference of our study is that all players in the losing group had to forfeit their efforts, whereas in Bornstein et al. they simply received zero payoffs.

${ }^{55}$ The QRE makes relatively similar predictions about the over-contribution of efforts in the perfectsubstitutes and best-shot contests (left and middle panels in Figure 4.1). However, the estimated level of error $(\lambda=1.22)$ in the best-shot contest is significantly different from the estimated level of error $(\lambda=2.42)$ in the perfect-substitutes contest based on the standard likelihood ratio test ( $p$-value $<0.01$ ).

${ }^{56}$ Players 1,2 , and 3 receive the total prize of $120=60+30+30$. Thus, if all players in group $G$ (group $B$ ) maximize their total group payoff, instead of maximizing individual payoffs, then the equilibrium group effort should be 30, instead of 15 (Table 4.4.1). This equilibrium effort is derived from a simple contest between two players for a prize of value 120 (Tullock, 1980). If the above argument is correct and social group identity promotes individual members to act as one, then the average group effort observed in the experiment is only $30 \%$ higher than the equilibrium group effort ( 40.5 versus 30$)$. The magnitude of such over-contribution is consistent with the findings of other experimental studies on contests between individual players (Anderson and Stafford, 2003; Sheremeta, 2009a,b). 


\section{B. Asymmetric Contests}

The asymmetric contests had two asymmetric groups competing against each other under three different contest rules. Table 4.4.2 summarizes the average individual and group efforts in all asymmetric contests. As in the symmetric case, weak players 2 and 3 in the asymmetric perfect-substitutes contest expend positive efforts, although the equilibrium predicts positive effort only for strong player 1 . This is consistent with the previous Result 1. In line with Result 2, most of the efforts in the asymmetric best-shot contest are made by strong players while weak players free-ride. Finally, in line with Result 3, strong and weak players in the asymmetric weakest-link contest learn to coordinate their efforts at the same level.

Table 4.4.2 - Average Effort and Probability of Winning in Asymmetric Contests

\begin{tabular}{|c|c|c|c|c|c|c|c|c|c|}
\hline \multirow[t]{2}{*}{ Treatment } & \multirow[t]{2}{*}{ Group } & \multicolumn{2}{|c|}{$\begin{array}{c}\text { Equilibrium } \\
\text { Effort of Player }\end{array}$} & \multicolumn{2}{|c|}{$\begin{array}{c}\text { Average Effort } \\
\text { of Player }\end{array}$} & \multicolumn{2}{|c|}{ Group Effort } & \multicolumn{2}{|c|}{$\begin{array}{l}\text { Probability of } \\
\text { Winning }\end{array}$} \\
\hline & & 1 & 2,3 & 1 & 2,3 & Total & $\overline{\text { Effective }}$ & Equilibrium & Actual \\
\hline \multirow{2}{*}{ Perfect-substitutes } & $G$ & 21.6 & 0 & $25.0(1.3)$ & $7.2(0.6)$ & 39.5 & 39.5 & 0.60 & 0.41 \\
\hline & $B$ & 14.4 & 0 & $19.1(1.1)$ & $12.0(0.6)$ & 43.1 & 43.1 & 0.40 & 0.59 \\
\hline \multirow{2}{*}{ Best-shot } & $G$ & 21.6 & 0 & $32.9(1.2)$ & $4.1(0.6)$ & 41.0 & 34.3 & 0.60 & 0.56 \\
\hline & $B$ & 14.4 & 0 & $19.4(1.5)$ & $5.9(0.6)$ & 31.2 & 24.5 & 0.40 & 0.44 \\
\hline \multirow{2}{*}{ Weakest-link } & $G$ & 3.3 & 3.3 & $7.5(0.4)$ & $5.6(0.2)$ & 18.8 & 4.0 & 0.33 & 0.42 \\
\hline & $B$ & 6.7 & 6.7 & $7.2(0.4)$ & $6.8(0.2)$ & 20.8 & 4.9 & 0.67 & 0.58 \\
\hline
\end{tabular}

Standard error of the mean in parentheses

The unique feature of contests between asymmetric groups is that, depending on the contest rule, either group $G$ or group $B$ has a higher probability of winning. For example, theory predicts that in the perfect-substitutes contest, group $G$ has a higher chance of winning. The data clearly rejects this prediction. We estimated a probit model where the dependent variable is winning and the independent variables are individual subject dummies, session dummies, and a dummy for group $G$. The group $G$ dummyvariable is negative and significant $(p$-value $<0.01)$. 
Result 4: Contrary to theoretical predictions, group $G$ wins significantly less in the perfect-substitutes contest than group $B$.

Although this result is not consistent with the equilibrium, it is in line with the unpredicted over-contribution of efforts by weak players (Result 1). Theory predicts that player $1 B$, whose valuation is 60 , should be discouraged by player $1 G$, whose valuation is 90. Given that the effective competition in equilibrium is only between strong players, group $G$ should have a higher probability of winning the contest. But Table 4.4.2 shows that, in the perfect-substitutes contest, player $1 B$ is not discouraged by player $1 G .^{57}$ Moreover, player $1 B$ receives significantly more support from weak players $2 B$ and $3 B$ than player $1 G$ receives from players $2 G$ and $3 G .{ }^{58}$ As a result, instead of winning the contest $40 \%$ of the time, group $B$ wins the contest $59 \%$ of the time.

In the best-shot and weakest-link contests the story is quite different. Consistent with theoretical predictions, group $G$ wins more often in the best-shot contest than group $B$. The estimation of a random effect probit model, where the dependent variable is winning and the independent variable is a dummy for group $G$, indicates significant difference $(p$-value $<0.01)$. Theory also predicts that group $G$ has a lower probability of winning the weakest-link contest. This prediction is supported by the data ( $p$-value $<$ $0.01)$.

\footnotetext{
${ }^{57}$ Note that although the equilibrium effort of player $1 B$ in the asymmetric perfect-substitutes contest (Table 4.4.2) is lower than in the symmetric perfect-substitutes contest (Table 4.4.2), the actual average efforts are almost identical, indicating no discouragement effect. This finding is consistent with experimental study of Anderson and Stafford (2003) who do not find evidence for a discouragement effect in a simple contest between heterogeneous individuals.

${ }^{58}$ Two pilot experiments employed a treatment in which there were 2 symmetric groups with 4 players in each group. The valuation for the dominant player 1 was 20 and the valuations for players 2,3 , and 4 were 16,12 , and 8 . In this contest, the low valuation players not only expended positive efforts but these efforts were proportional to players' valuations. This can explain why in the asymmetric perfect-substitutes contests players $2 B$ and $3 B$ expend higher efforts than players $2 G$ and $3 G$.
} 
Result 5: Consistent with theoretical predictions, group $G$ wins more often than group $B$ in the best-shot contest and less often in the weakest-link contest.

Why does group $G$ win the best-shot contest but lose the weakest-link contest? The outcome of the best-shot contest depends only on strong players. As previously established (Result 2), neither $1 G$ nor $1 B$ players receive any significant support from weak players in best-shot contests. Consequently, competition occurs between strong players only, with player $1 G$ having a higher valuation and thus a substantial advantage over player $1 B$. On the other hand, the outcome of the weakest-link contest depends only on the weakest player in each group. Since the weakest player in group $G$ has a lower valuation than in group $B$ (15 versus 30$)$, group $G$ has a lower probability of winning the contest. $^{59}$

The findings described in this section answer one of the questions that we posed in the introduction, namely, which firm will win the patent contest: the "Good Manager" firm with the better motivated manager or the "Bad Manager" firm with the better motivated workers? It turns out that the outcome of the competition depends upon the underlying rules. The firm with the better motivated manager is more likely to win the best-shot contest (Result 5), while the firm with the better motivated workers is more likely to win the weakest-link or perfect-substitutes contests (Results 4 and 5).

Another interpretation of our results relates to managerial compensation schemes. Let's say a CEO has a bonus pool which can be used to motivate a team of one manager and several workers. By wisely accounting for the type of underlying contest, the CEO

\footnotetext{
${ }^{59}$ Table 4.4.2 shows that in the weakest-link contest the strong player in group $\mathrm{G}$ expends significantly higher effort than weak players. One interpretation of this observation is that the strong player tries to coordinate with weak players at a substantially higher level than the equilibrium, because the prize valuation of the strong player is six times higher than the prize valuation of weak players.
} 
can increase the team's chance of success. For example, if the team is participating in the best-shot type of contest then CEO should allocate the largest bonus to the manager. However, if winning the contest requires considerable coordination (as in the weakestlink contest) or high level of joint effort (as in the perfect-substitutes contest) then it might not be optimal to allocate a very large bonus to the manager.

\section{A Comparison of Contest Rules}

This section shows how a contest designer (or an administrator) can meet a given objective by manipulating contest rules. In our case a designer has a choice between three contest rules: perfect-substitutes, best-shot, and weakest-link. ${ }^{60}$ The objective varies between contests (Tullock, 1988). In sports or social benefit programs the designer's objective is to maximize the total effort expended. In rent-seeking contests, the designer's objective may be to minimize the total effort expended, and thus to increase individual payoffs. For a patent race or innovation tournament the objective of the designer is to maximize the effort expended by the strongest contestant. Of course, the analysis in this section is subject to the specific parametric restrictions used in our experiment such as the group size and individual valuations. It is also assumed that the contest designer has a full control over the rule of the contest, which in many real life contests may not be the case.

\footnotetext{
${ }^{60}$ In developing countries like Nigeria, India, Pakistan, and Afghanistan, governments continuously target to eliminate polio - an acute viral infectious disease. To encourage this process, the government can use a contest: the region which performs the best in eradicating polio will receive a fund which can be distributed among the districts of the region. The winning region can be determined in three ways: (1) the region with the lowest number of total new polio patients in a year, (2) the region which has the lowest number of polio patients in a best district, (3) the region which has the lowest number of polio patients in a worst district. The first option corresponds to the perfect-substitutes, the second option is the best-shot, and the third option is the weakest-link.
} 
Nevertheless, we believe that the following analysis provides interesting insights that are worth reporting.

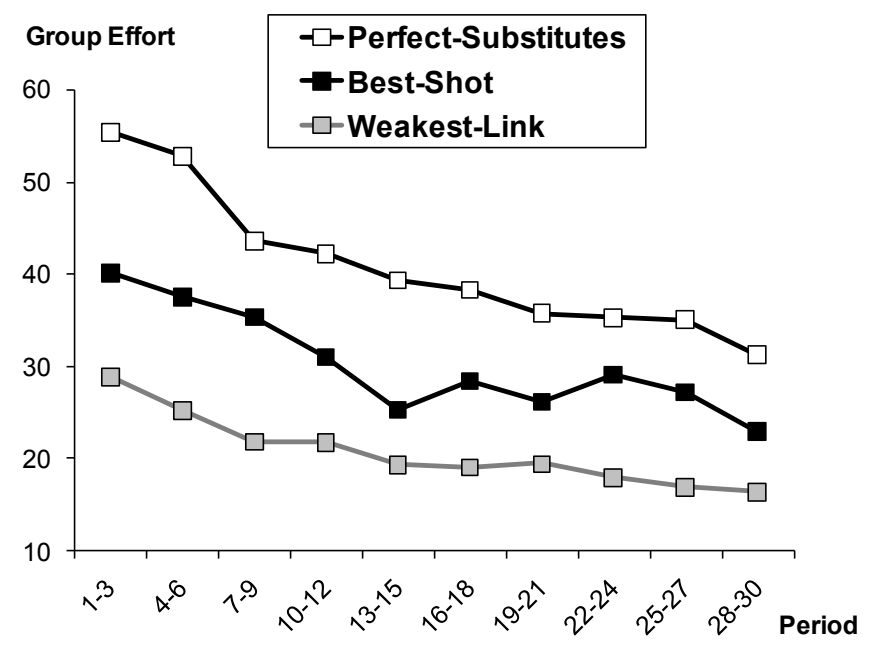

Figure 4.4.5 - Total Group Effort

Consider first what type of contest maximizes a group's total effort. Figure 4.4.5 shows the overall dynamics of a group's total effort in all contests. As players become more experienced, the average effort decreases in all contests. A simple regression of effort on the number of periods played shows a significant negative relationship. The declining trend resembles the findings from the public goods literature (Ledyard, 1995). It is also consistent with the experimental studies of contests between individual players (Millner and Pratt, 1989, 1991; Davis and Reilly, 1998; Sheremeta, 2009a,b). More importantly, perfect-substitutes contests generate the highest total effort among all contests, followed by best-shot contests. The lowest effort expended is in weakest-link contests. The differences are significant based on the estimation of random effect models, where the dependent variable is a group effort and the independent variables are a period trend and a treatment dummy-variable $(p$-value $<0.05)$. 
Result 6: Among all contests, perfect-substitutes contests generate the highest total effort expended, followed by best-shot and then weakest-link contests.

Another performance measure is the amount of free-riding in different contests. Usually, a free-riding behavior is defined as an effort of 0 . This definition is stronger than the one used by Isaac and Walker (1988), who defined players contributing less than one third of the endowment as "strong free-riders". Figure 4.4.6 shows the overall dynamics of free-riding (effort of 0 ) in each treatment of our experiment (at equilibrium, $67 \%$ of all players should free-ride in perfect-substitutes and best-shot contests and $0 \%$ in weakestlink contests). The graph highlights extreme variations in free-riding between contests with almost $60 \%$ free-riders in the best-shot contests, $30 \%$ - in the perfect-substitutes contests, and less than $1 \%$ - in the weakest-link contests.

Result 7: Most free-riding behavior occurs in the best-shot contests, followed by perfect-substitutes, and there is almost no free-riding in the weakest-link contests.

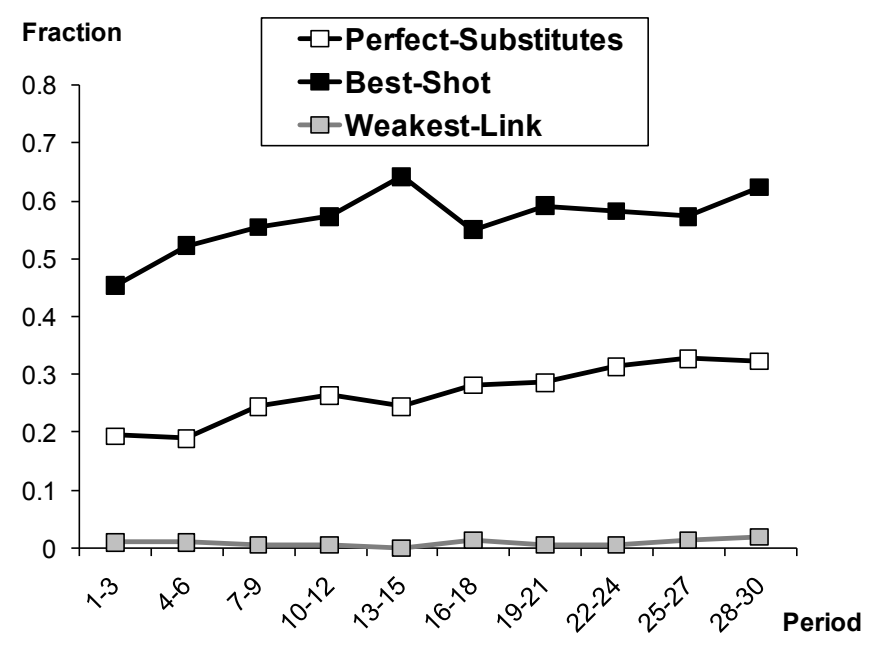

Figure 4.4.6 - Fraction of Free-Riders (Players Who Expend Effort of 0) 
The free-riding behavior observed in our experiment is consistent with the early conjectures of Harrison and Hirshleifer (1989). They predicted that free-riding behavior disappears under the weakest-link rule and is amplified under the best-shot rule. Disregarding a noticeable difference between public good games and contests, we find that the same ranking of free-riding behavior as in public good games also applies to contests. This information is important for a contest designer whose objective may be either to reduce or to amplify the free-riding behavior in the contest between groups.

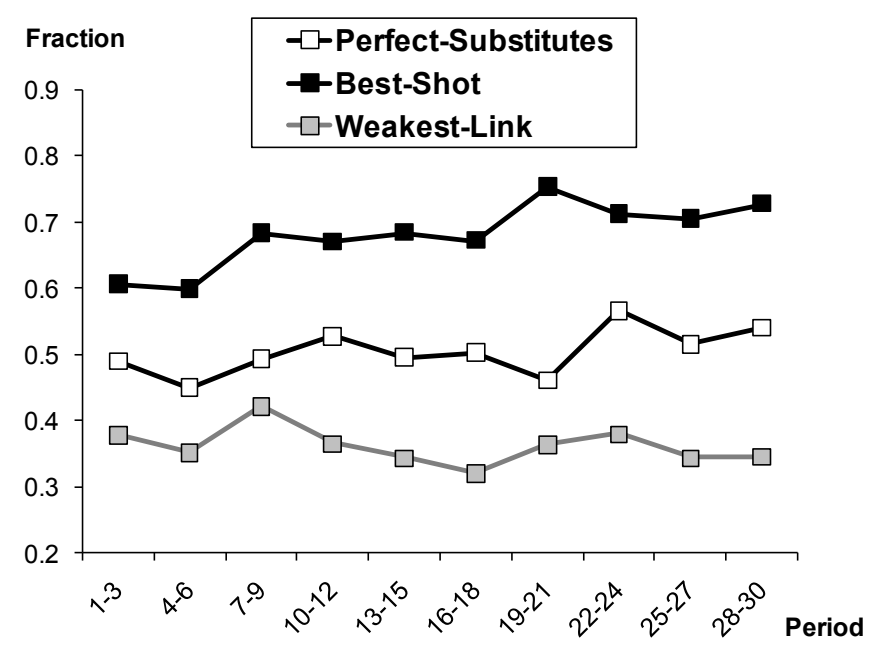

Figure 4.4.7 - Effort of Strong Player as a Fraction of Group Total Effort

In a patent race or innovation tournament, a contest designer may have an objective of getting strong players, who usually come up with much better ideas, to expend the highest efforts within their groups. This can be done by manipulating the contest rules. Figure 4.4 .7 shows that about $70 \%$ of total efforts in best-shot contests come from strong players, which decreases to $50 \%$ when moving to perfect-substitutes and to $40 \%$ in weakest-link contests. The differences are significant at the 0.01 level, based on the estimation of random effect models. 
Result 8: Strong players expend the highest relative efforts in best-shot contests, followed by perfect-substitutes and then weakest-link contests.

Results 6,7 , and 8 point us to the general conclusion that the advantage of one contest rule over another comes at a cost. For example, to reduce free-riding, a contest designer could choose the weakest-link contest (Result 7). However, by doing so the designer should anticipate the weakest-link contest to generate the lowest total effort expended (Result 6), as well as weak performance of strong players (Result 8).

\section{The Determinants of Effort}

This section provides a multivariate analysis in order to indentify the determinants of effort. To capture heterogeneity across subjects, we use random effect models with individual subject effects. The regressions are of the following form:

$$
\begin{aligned}
\text { effort }_{i t}= & \beta_{0}+\beta_{1} \text { risk }_{i}+\beta_{2} \text { win }_{i t-1}+\beta_{3} \text { group-lag }_{i t-1}+\beta_{4} \text { othergroup-lag }_{i t-1}+ \\
& +\beta_{5}(1 / t)+\beta_{6} \text { asymmetry }+\sum_{h=1}^{6} \beta_{7 h} S_{h}+u_{i}+\varepsilon_{i t}
\end{aligned}
$$

where effort ${ }_{i t}$ is player $i$ 's effort in a period $t, w_{i n} n_{i t-1}$ denotes whether player $i$ won in the previous period, group-lag $g_{i t-1}$ and othergroup-lag $g_{i t-1}$ denote own group effort and other group effort in a period $t-1$. To allow for time effects, all regressions include an inverse of a period trend $(1 / t)$. All regressions also include dummy-variables to capture contest asymmetry and session effects. The results of the estimation are presented in Table 4.4.3. Specifications (1) and (2) use the data from perfect-substitutes contests, specifications (3) and (4) use the data from best-shot contests, and specifications (5) and (6) use the data from weakest-link contests. 
The significant risk coefficient in specifications (1) and (2) implies that the more subjects choose risky lotteries, indicating a higher willingness to take risk, the higher their effort is in perfect-substitutes contests. ${ }^{61}$ This finding is consistent with the findings of other experimental studies on contests (Miller and Pratt, 1991; Sheremeta, 2009a). Note that the risk coefficient is not significant in specifications (3) through (6). This suggests that risk attitudes may affect individual behavior differently in best-shot and weakest-link contests than in perfect-substitutes contests.

Table 4.4.3 - Determinants of Effort (Random-Effect Models) ${ }^{62}$

\begin{tabular}{|c|c|c|c|c|c|c|}
\hline \multirow{3}{*}{ Dependent variable, effort } & $\overline{(1)}$ & $\overline{(2)}$ & \multirow{2}{*}{\multicolumn{2}{|c|}{$\frac{\text { (3) } \quad(4)}{\text { Best-Shot }}$}} & $\overline{(5)}$ & $\overline{(6)}$ \\
\hline & \multicolumn{2}{|c|}{ Perfect-Substitutes } & & & \multicolumn{2}{|c|}{ Weakest-Link } \\
\hline & Player 1 & Player 2-3 & \multicolumn{2}{|c|}{ Plaver 1 $\quad$ Plaver 2-3 } & Player 1 & Player 2-3 \\
\hline$\overline{\text { risk }}$ & $1.04^{*}$ & $0.66^{*}$ & 0.16 & -0.47 & -0.12 & -0.06 \\
\hline [number of risky options B] & $(0.53)$ & $(0.31)$ & $(0.48)$ & $(0.36)$ & $(0.12)$ & $(0.10)$ \\
\hline win-lag & -0.33 & -0.06 & -1.98 & 0.12 & 0.49 & 0.4 \\
\hline [ 1 if group won in period $t-1]$ & $(0.98)$ & $(0.50)$ & $(1.10)$ & $(0.44)$ & $(0.43)$ & $(0.21)$ \\
\hline group-lag & $0.19 * *$ & $0.10^{* *}$ & $0.10^{* *}$ & $0.04 * *$ & $0.33^{*}$ & $0.37^{* *}$ \\
\hline [group effort in period $t-1$ ] & $(0.02)$ & $(0.01)$ & $(0.03)$ & $(0.01)$ & $(0.13)$ & $(0.06)$ \\
\hline othergroup-lag & 0.03 & $0.03^{*}$ & $0.07^{*}$ & 0.03 & $0.26^{*}$ & $0.15^{*}$ \\
\hline [other group effort in period $t-1$ ] & $(0.02)$ & $(0.01)$ & $(0.03)$ & $(0.01)$ & $(0.12)$ & $(0.06)$ \\
\hline period-trend & $10.17 *$ & $11.33^{* *}$ & $18.49 * *$ & $11.77 * *$ & $8.50^{* *}$ & $7.15^{* *}$ \\
\hline [inverse of a period trend $1 / t$ ] & $(4.82)$ & $(2.45)$ & (5.19) & (2.04) & $(2.09)$ & $(1.06)$ \\
\hline asymmetry & $2.64 * *$ & $-1.33 * *$ & $9.52 * *$ & -0.37 & -0.09 & $-0.56 * *$ \\
\hline [ 1 if contest is asymmetric] & $(0.93)$ & $(0.47)$ & $(1.16)$ & $(0.45)$ & $(0.42)$ & $(0.21)$ \\
\hline Observations & 696 & 1392 & 696 & 1392 & 696 & 1392 \\
\hline
\end{tabular}

In all specifications of Table 4.4.3 the group-lag coefficient is positive and significant. This means that subjects are adjusting their efforts in period $t$ to reflect their

${ }^{61}$ As we described in Section 3.3, in our experiment we elicited a measure of risk attitudes from a series of lotteries. In these lotteries subjects were given a choice between a safe option A and a risky option B.

${ }^{62} \mathrm{We}$ also tried estimating alternative regression models. By interacting explanatory variables with asymmetry dummy-variable, we found that in the asymmetric perfect-substitutes and best-shot contests the othergroup-lag coefficient is significantly higher than in the symmetric contests. On the other hand, in the asymmetric weakest-link contest the othergroup-lag coefficient is significantly lower than in the symmetric weakest-link contest. One possible explanation for this is that the othergroup-lag coefficient is correlated with the total equilibrium effort (in the design of our experiment, asymmetry increases the total equilibrium effort in perfect-substitutes and best-shot contests while it decreases the total equilibrium effort in weakestlink contests). 
group effort in period $t-1 .^{63}$ Note that the group-lag coefficient in specifications (5) and (6) is the highest due to high coordination incentives in weakest-link contests. The significant othergroup-lag coefficient indicates that the efforts expended by subjects in one group also have an effect on the efforts of the rival group. The significant positive inverse of the period-trend in all regressions indicates that both strong and weak players decrease their efforts with the repetition of the game.

Overall, the coefficient asymmetry capturing group asymmetry has signs that are consistent with theoretical predictions. Theory predicts that by moving from symmetric to asymmetric perfect-substitutes and best-shot contests the strong player's effort should increase. This theoretical prediction is supported by positive and significant asymmetry coefficients in specifications (1) and (3). On the other hand, the behavior of weak players should not be affected by the asymmetry. This theoretical prediction is supported for the best-shot (specification 4) but not for the perfect-substitutes (specification 2). Theory also predicts that as we move from symmetric to asymmetric weakest-link contests, both strong and weak players should decrease their efforts. We find support for this prediction from estimation of specifications (5) and (6).

\subsection{Discussion and Conclusions}

This experiment shows that individual behavior in contests between symmetric and asymmetric groups depends upon a player's type and the rules that regulate the competition. In contests, where individual efforts are perfect substitutes, both strong and

\footnotetext{
${ }^{63}$ Croson et al. (2005) find that subjects in the linear public goods game attempt to match the average contributions of others, while in the weakest-link public goods game they attempt to match the minimum contribution of others.
} 
weak players significantly over-contribute their efforts. As a result, perfect-substitutes contests generate the highest level of group effort among all contests. In best-shot contests, where the performance of a group depends on the best performer within the group, most of the effort is expended by strong players while weak players free-ride. In weakest-link contests, where the group performance depends on the worst performer within the group, there is almost no free-riding and all players expend similar positive efforts.

What are the implications of our findings? First, our findings point out that introduction of between-group competition and asymmetry between players (as in the weakest-link and best-shot contests) may solve the coordination failure problem in games with Pareto-ranked equilibria (such as the minimum effort and best-shot public goods games). Second, our findings have direct implications for designing an optimal contest between groups. For example, if the designer of a contest wants to encourage the highest performance from the strongest players, he should employ a best-shot contest. In such a contest, as our results point out, most of the efforts within a group will be made by strong players. If the objective is to reduce free-riding, the contest designer should choose to use the weakest-link contest. It is important to emphasize, however, that choosing one contest over another comes at a cost. By choosing the best-shot contest, the designer should anticipate strong free-riding behavior from weak players. By choosing the weakest-link contest, the designer should anticipate little group effort as well as poor performance by strong players.

The results of our experiments can also help to explain some of the findings in the psychological literature on "burnout" - a phenomenon characterized by feelings of 
exhaustion from work. ${ }^{64}$ In particular, studies show that in Asian countries, such as Japan, the incidences of burnout are much higher than in the US (Golembiewski et al., 1996). One possible explanation is that the competition between US firms, which are more hierarchical with managers playing the major roles, resembles a best-shot contest, whereas the competition between Japanese firms, which are more horizontal with individual workers playing important roles (Aoki, 1990), resembles a perfect-substitutes contest. In our experiment, we find that perfect-substitutes contests generate much higher competition and thus could induce higher burnout rate than best-shot contests. To reduce incidences of burnout, most psychological studies suggest implementing individualcentered solutions, reasoning that "it is easier and cheaper to change people than organizations" (Maslach and Goldberg, 1998; Maslach we al., 2001). Our findings suggest this is not necessarily true. By organizing companies' work teams in specific ways, with specific rules, one can effectively control the competitive environment within a workplace and thus control the burnout rate within each team.

This study opens a new avenue for future research. First, it is important to further investigate how individual behavior changes when there are more than two groups in a contest or more than three players within each group. Second, it would be interesting to see how robust our findings are under alternative contest success functions and convex costs (Baik et al., 2001; Esteban and Ray, 2001). Another extension is to allow sequential contribution of efforts by weak players and then by strong players within each group.

\footnotetext{
${ }^{64}$ Two experimental studies by Amegashie et al. (2007) and Muller and Schotter (2009) implicitly address the issue of burnout in competitive economic environments.
} 
Such modification should not change the Nash equilibrium of the contest. ${ }^{65}$ However, behaviorally, sequential and simultaneous contests are very different. It is likely that the sequential design will lead subjects to behave more in the line with theoretical predictions (Harrison and Hishleifer, 1989). Future research should also consider other realistic extensions to the group-contest setting, including budget constraints, incomplete information, communication, and endogenous group formation.

${ }^{65}$ It will, however, provide a unique subgame perfect equilibrium in the best-shot and weakest-link contests. 


\subsection{References}

Abbink. K., Brandts, J., Herrmann, B., \& Orzen, H. (2009). Inter-Group Conflict and Intra-Group Punishment in an Experimental Contest Game. American Economic Review, forthcoming.

Akerlof, G.A., \& Kranton, R.E. (2000). Economics and Identity. Quarterly Journal of Economics, $115,715-753$.

Akerlof, G.A., \& Kranton, R.E. (2005). Identity and the Economics of Organizations. Journal of Economic Perspective, 19, 9-32.

Amegashie, J.A., Bram, C.C., \& Yang, S. (2007). Competitive burnout: Theory and experimental evidence. Games and Economic Behavior, 59, 213-239.

Anderson, L.R., \& Stafford, S.L. (2003). An experimental analysis of rent seeking under varying competitive conditions. Public Choice, 115, 199-216.

Aoki, M. (1990). Toward an Economic Model of the Japanese Firm. Journal of Economic Literature, 28, 1-27.

Baik, K.H. (1993). Effort Levels in Contests: The Public-Good Prize Case. Economics Letters, 41, 363-67.

Baik, K.H. (2008). Contests with group-specific public-good prizes. Social Choice and Welfare, 30, 103-117.

Baik, K.H., Kim, In-Gyu, \& Na, S. (2001). Bidding for a group-specific public-good prize. Journal of Public Economics, 82, 415-429.

Bernheim, B.D., B, Peleg., \& M.D., Whinston, (1987). Coalition-Proof Nash Equilibria I. Concepts. Journal of Economic Theory, 42, 1-12. 
Bliss, C., \& Nalebuff, B. (1984). Dragon-slaying and ballroom dancing: The private supply of a public good. Journal of Public Economics, 25, 1-12.

Bolton, G.E., \& Ockenfels, A. (2000). ERC - A Theory of Equity, Reciprocity, and Competition. American Economic Review, 90, 166-193.

Bornstein, G., Gneezy, U., \& Nagel, R. (2002). The effect of intergroup competition on group coordination: An experimental study. Games and Economic Behavior, 41, 125.

Cason, T.N., \& Mui, V.L. (2005). Uncertainty and resistance to reform in laboratory participation games. European Journal of Political Economy, 21, 708-737.

Cheikbossian, G. (2008). Heterogeneous groups and rent-seeking for public goods. European Journal of Political Economy, 24, 133-150.

Chen, Y., \& Li, S.X. (2008). Group Identity and Social Preferences, American Economic Review, forthcoming.

Clark, K., \& Sefton, M. (2001). Repetition and signalling: Experimental evidence from games with efficient equilibria. Economics Letters, 70, 357-362.

Cooper, R., De Jong, D., Forsythe, R., \& Ross, T. (1990). Selection criteria in coordination games: Some experimental results. American Economic Review, 80, 218-233.

Cooper, R., De Jong, D., Forsythe, R., \& Ross, T. (1992). Communication in coordination games. Quarterly Journal of Economics, 107, 739-771.

Crawford, V.P., Gneezy, U., \& Rottenstreich, Y. (2008). The Power of Focal Points Is Limited: Even Minute Payoff Asymmetry May Yield Large Coordination Failures, American Economic Review, 98, 1443-58. 
Croson, R., Fatas, E., \& Neugebauer, T. (2005). Reciprocity, Matching and Conditional Cooperation in Two Public Goods Games. Economics Letters, 87, 95-101.

Davis, D., \& Reilly, R. (1998). Do many cooks always spoil the stew? An experimental analysis of rent seeking and the role of a strategic buyer. Public Choice, 95, 89-115.

Diekmann, A. (1985). Volunteer's Dilemma. Journal of Conflict Resolution, 29, 605-610.

Diekmann, A. (1993). Cooperation in an Asymmetric Volunteer's Dilemma Game. Theory and Experimental Evidence. International Journal of Game Theory, 22, 75-85.

Engelmann, D., \& Strobel, M. (2004). Inequality Aversion, Efficiency, and Maximin Preferences in Simple Distribution Experiments. American Economic Review, 94, 857-869.

Ericsson, K.A., \& Charness, N. (1994). Expert performance: Its structure and acquisition. American Psychologist, 49, 725 - 747.

Esteban, J., \& Ray, D. (2001). Collective Action and Group Size Paradox. American Political Science Review, 95, 663-672.

Fehr, E., \& Schmidt, K.M. (1999). A Theory of Fairness, Competition, and Cooperation. Quarterly Journal of Economics, 114, 817-868.

Fischbacher, U. (2007). z-Tree: Zurich Toolbox for Ready-made Economic experiments. Experimental Economics, 10, 171-178.

Goeree, J., Holt, C., \& Palfrey, T. (2002). Quantal Response Equilibrium and Overbidding in Private-Value Auctions. Journal of Economic Theory, 247-272.

Golembiewski, R.T., Boudreau, R.A., Munzenrider, R.F., Luo, H. (1996). Global Burnout: A Worldwide Pandemic Explored by the Phase Model. Greenwich, CT: JAI Press. 
Gunnthorsdottir, A., \& Rapoport, A. (2006). Egalitarian vs. proportional profit-sharing rules in multi-level collective action problems. Organizational Behavior and Human Decision Processes, 101, 184-199.

Harrison, G. W., \& Hirshleifer, J. (1989). An Experimental Evaluation of Weakest Link/Best Shot Models of Public Goods. Journal of Political Economy, 97, 201-225.

Hirshleifer, J. (1983). From Weakest Link to Best-Shot: The Voluntary Provision of Public Goods. Public Choice, 41, 371-386

Holt, C.A., \& Laury, S.K. (2002). Risk Aversion and Incentive Effects. American Economic Review, 92, 1644-1655.

Isaac, R.M., \& Walker, J. (1988). Group Size Hypotheses of Public Goods Provision: The Voluntary Contribution Mechanism. Quarterly Journal of Economics, 103, 179-200.

Katz, E., \& Tokatlidu, J. (1996). Group competition for rents. European Journal of Political Economy, 12, 599-607.

Katz, E., Nitzan, S., \& Rosenberg, J. (1990). Rent-seeking for pure public goods. Public Choice, 65, 49-60.

Keser, C. (1996). Voluntary Contributions to a Public Good when Partial Contribution is a Dominant Strategy. Economics Letters, 50, 359-366.

Konrad, K.A. (2009). Strategy and Dynamics in Contests. Oxford University Press.

Kremer, M. (1993). The O-Ring Theory of Economic Development. Quarterly Journal of Economics, 108, 551- 575.

Kroll, S., Cherry, T., \& Shogren, J. (2007). The impact of endowment heterogeneity and origin on contributions in best-shot public good games. Experimental Economics, 10, 411-428. 
Kugler T., Rapoport A., \& Pazy A. (2005). Public good provision in inter-group conflicts: Effects of asymmetry and profit-sharing rule. Working Paper, University of Arizona.

Ledyard, J. (1995). Public goods: A survey of experimental research. In J. Kagel and A. Roth (Eds.), Handbook of Experimental Economics. Princeton: Princeton University Press, pp. 111-194.

Lee, D. (2009). Weakest-link contest with group-specific public good prizes, Working Paper. Virginia Tech.

Lee, S. (1995). Endogenous sharing rules in collective-group rent-seeking. Public Choice, $85,31-44$

Maslach, C., Schaufeli, W.B., Leiter, M.P. (2001). Job burnout. Annual Review of Psychology, 52, 397-422.

Maslach, C., Goldberg, J. (1998). Prevention of burnout: new perspectives. Applied and Preventive Psychology, 7, 63-74.

McKelvey, R., \& Palfrey, T. (1995). Quantal Response Equilibria for Normal Form Games. Games and Economic Behavior, 10, 6-38.

Millner E. L., \& Pratt, M. D. (1991). Risk aversion and rent seeking: An extension and some experimental evidence. Public Choice, 69, 91-92.

Millner, E.L., \& Pratt, M.D. (1989). An experimental investigation of efficient rentseeking. Public Choice, 62, 139-151.

Muller, W., \& Schotter, A. (2007). Workaholics and Drop Outs in Optimal Organizations. Working Papers, New York University. 
Munster, J. (2007). Simultaneous inter- and intra-group conflicts. Economic Theory, 32, $333-352$.

Nitzan, S. (1991). Collective rent dissipation. Economic Journal, 101, 1522-1534.

Nti, K. (1998). Effort and performance in group contests. European Journal of Political Economy, 14, 769-781.

Ochs, J. (1995). Coordination problems. In J. H. Kagel \& A. E. Roth (Eds.), Handbook of experimental economics. Princeton: Princeton University Press, pp. 195-251.

Olson, M. (1965). The Logic of Collective Action: Public Goods and the Theory of Groups, Harvard University Press, Cambridge, MA.

Palfrey, T. R. and Rosenthal, H. (1983). A Strategic Calculus of Voting. Public Choice, 41, 7-53.

Parco J., Rapoport A., \& Amaldoss W. (2005). Two-stage Contests with Budget Constraints: An Experimental Study. Journal of Mathematical Psychology, 49, 320338.

Potters, J.C., De Vries, C.G., \& Van Linden, F. (1998). An experimental examination of rational rent seeking. European Journal of Political Economy, 14, 783-800.

Rapoport, A., \& Bornstein, G. (1987). Intergroup competition for the provision of binary public goods. Psychological Review, 94, 291-299.

Rapoport, A., \& Bornstein, G. (1989). Solving Public Goods Problems in Competition between Equal and Unequal Size Groups. Journal of Conflict Resolution, 33, 460479.

Riaz, K., Shogren, J.F., \& Johnson, S.R. (1995). A general model of rent seeking for public goods. Public Choice, 82, 243-259. 
Schelling, T. C. (1960). The Strategy of Conflict. Cambridge, Massachusetts: Harvard University Press.

Schram, A., \& Sonnemans, J. (1996). Voter turnout as a participation game: an experimental investigation. International Journal of Game theory, 25, 385-406.

Sefton, M., \& Steinberg R. (1996). Reward Structures in Public Good Experiments. Journal of Public Economics, 61, 263-287.

Sheremeta, R.M. (2009a). Contest Design: An Experimental Investigation. Economic Inquiry, forthcoming.

Sheremeta. R.M. (2009b). Experimental Comparison of Multi-Stage and One-Stage Contests. Working Paper, Purdue University.

Tullock, G. (1980). Efficient Rent Seeking. In J.M. Buchanan, R.D. Tollison, G. Tullock, (Eds.), Toward a theory of the rent-seeking society. College Station, TX: Texas A\&M University Press, pp. 97-112.

Tullock, G. (1988). Rents and Rent-Seeking. In C.K. Rowley, R.D. Tollison, G. Tullock (Eds.), The Political Economy of Rent-Seeking, Boston, MA, Kluwer Academic, pp. $51-62$.

Van Huyck, J. B., Battalio, R. C., \& Beil, R. O. (1990). Tacit coordination games, strategic uncertainty, and coordination failure. American Economic Review, 80, 234248.

Van Huyck, J. B., Battalio, R. C., \& Beil, R. O. (1991). Strategic uncertainty, equilibrium selection, and coordination failure in average opinion games. Quarterly Journal of Economics, 106, 885-911. 
Van Huyck, J. B., Gillette, A., \& Battalio, R. C. (1992). Credible assignments in coordination games. Games and Economic Behavior, 4, 606-626.

Weber, R. (2006). Managing growth to achieve efficient coordination in large groups. American Economic Review, 96, 114-126. 


\subsection{Appendix}

\section{GENERAL INSTRUCTIONS}

This is an experiment in the economics of strategic decision making. Various research agencies have provided funds for this research. The instructions are simple. If you follow them closely and make appropriate decisions, you can earn an appreciable amount of money.

The experiment will proceed in three parts. Each part contains decision problems that require you to make a series of economic choices which determine your total earnings. The currency used in Part 1 of the experiment is U.S. Dollars. The currency used in Parts 2 and 3 of the experiment is francs. Francs will be converted to U.S. Dollars at a rate of $\_0$ francs to _ 1 dollar. At the end of today's experiment, you will be paid in private and in cash. 18 participants are in today's experiment.

It is very important that you remain silent and do not look at other people's work. If you have any questions, or need assistance of any kind, please raise your hand and an experimenter will come to you. If you talk, laugh, exclaim out loud, etc., you will be asked to leave and you will not be paid. We expect and appreciate your cooperation.

At this time we proceed to Part 1 of the experiment.

\section{INSTRUCTIONS FOR PART 1}

\section{YOUR DECISION}

In this part of the experiment you will be asked to make a series of choices in decision problems. How much you receive will depend partly on chance and partly on the choices you make. The decision problems are not designed to test you. What we want to 
know is what choices you would make in them. The only right answer is what you really would choose.

For each line in the table in the next page, please state whether you prefer option A or option B. Notice that there are a total of 15 lines in the table but just one line will be randomly selected for payment. You ignore which line will be paid when you make your choices. Hence you should pay attention to the choice you make in every line. After you have completed all your choices a token will be randomly drawn out of a bingo cage containing tokens numbered from 1 to 15 . The token number determines which line is going to be paid.

Your earnings for the selected line depend on which option you chose: If you chose option A in that line, you will receive $\$ 1$. If you chose option B in that line, you will receive either $\$ 3$ or $\$ 0$. To determine your earnings in the case you chose option B there will be second random draw. A token will be randomly drawn out of the bingo cage now containing twenty tokens numbered from 1 to 20 . The token number is then compared with the numbers in the line selected (see the table). If the token number shows up in the left column you earn $\$ 3$. If the token number shows up in the right column you earn $\$ 0$.

Are there any questions? 


\section{Participant ID}

\begin{tabular}{|c|c|c|c|c|}
\hline $\begin{array}{l}\text { Decis } \\
\text { ion } \\
\text { no. }\end{array}$ & $\begin{array}{l}\text { Optio } \\
\text { n A }\end{array}$ & & $\begin{array}{l}\text { Option } \\
\text { B }\end{array}$ & $\begin{array}{l}\text { Please } \\
\text { choose } \\
\text { A or B }\end{array}$ \\
\hline 1 & $\$ 1$ & $\$ 3$ never & $\begin{array}{l}\$ 0 \text { if } 1,2,3,4,5,6,7,8,9,10,11,12,13 \\
\quad 14,15,16,17,18,19,20\end{array}$ & \\
\hline 2 & $\$ 1$ & $\$ 3$ if 1 comes out & $\begin{array}{c}\$ 0 \text { if } 2,3,4,5,6,7,8,9,10,11,12,13 \\
\quad 14,15,16,17,18,19,20\end{array}$ & \\
\hline 3 & $\$ 1$ & $\$ 3$ if 1 or 2 comes out & $\begin{aligned} \$ 0 & \text { if } 3,4,5,6,7,8,9,10,11,12,13,14,15 \\
& 16,17,18,19,20\end{aligned}$ & \\
\hline 4 & $\$ 1$ & $\$ 3$ if 1,2 or 3 & $\begin{aligned} \$ 0 & \text { if } 4,5,6,7,8,9,10,11,12,13,14,15 \\
& 16,17,18,19,20\end{aligned}$ & \\
\hline 5 & $\$ 1$ & $\$ 3$ if $1,2,3,4$ & $\begin{aligned} \$ 0 & \text { if } 5,6,7,8,9,10,11,12,13,14,15 \\
& 16,17,18,19,20\end{aligned}$ & \\
\hline 6 & $\$ 1$ & $\$ 3$ if $1,2,3,4,5$ & $\begin{aligned} \$ 0 & \text { if } 6,7,8,9,10,11,12,13,14,15 \\
& 16,17,18,19,20\end{aligned}$ & \\
\hline 7 & $\$ 1$ & $\$ 3$ if $1,2,3,4,5,6$ & $\begin{aligned} \$ 0 & \text { if } 7,8,9,10,11,12,13,14,15 \\
& 16,17,18,19,20\end{aligned}$ & \\
\hline 8 & $\$ 1$ & $\$ 3$ if $1,2,3,4,5,6,7$ & $\begin{array}{l}\$ 0 \text { if } 8,9,10,11,12,13,14,15 \\
16,17,18,19,20\end{array}$ & \\
\hline 9 & $\$ 1$ & $\$ 3$ if $1,2,3,4,5,6,7,8$ & $\begin{array}{l}\$ 0 \text { if } 9,10,11,12,13,14,15 \\
\quad 16,17,18,19,20\end{array}$ & \\
\hline 10 & $\$ 1$ & $\$ 3$ if $1,2,3,4,5,6,7,8,9$ & $\begin{array}{ll}\$ 0 & \text { if } 10,11,12,13,14,15 \\
& 16,17,18,19,20\end{array}$ & \\
\hline 11 & $\$ 1$ & $\$ 3$ if $1,2,3,4,5,6,7,8,9,10$ & $\$ 0$ if $11,12,13,14,15,16,17,18,19,20$ & \\
\hline 12 & $\$ 1$ & $\$ 3$ if $1,2,3,4,5,6,7,8,9,10,11$ & $\$ 0$ if $12,13,14,15,16,17,18,19,20$ & \\
\hline 13 & $\$ 1$ & $\$ 3$ if $1,2,3,4,5,6,7,8,9,10,11,12$ & $\$ 0$ if $13,14,15,16,17,18,19,20$ & \\
\hline 14 & $\$ 1$ & $\begin{array}{l}\$ 3 \text { if } 1,2,3,4,5,6,7,8,9,10 \\
11,12,13\end{array}$ & $\$ 0$ if $14,15,16,17,18,19,20$ & \\
\hline 15 & $\$ 1$ & $\begin{array}{l}\$ 3 \text { if } 1,2,3,4,5,6,7,8,9,10 \\
11,12,13,14\end{array}$ & $\$ 0$ if $15,16,17,18,19,20$ & \\
\hline
\end{tabular}




\section{INSTRUCTIONS FOR PART 2}

\section{YOUR DECISION}

The second part of the experiment consists of 30 decision-making periods. At the beginning of each period, you will be randomly and anonymously placed into a group of 3 people (group A or B). Either group A or group B will receive the reward of 120 francs at the end of each period. In addition to your group assignment you will also be randomly assigned a specific type in the group (type 1, 2, or 3). Your type will determine how the reward is shared within the group. Each period your group as well as your type will be changed.

Each period you will be given an initial endowment of 60 francs and asked to decide how much to allocate to the group account or the individual account. You may allocate any integer number of francs between 0 and 60. An example of your decision screen is shown below. 


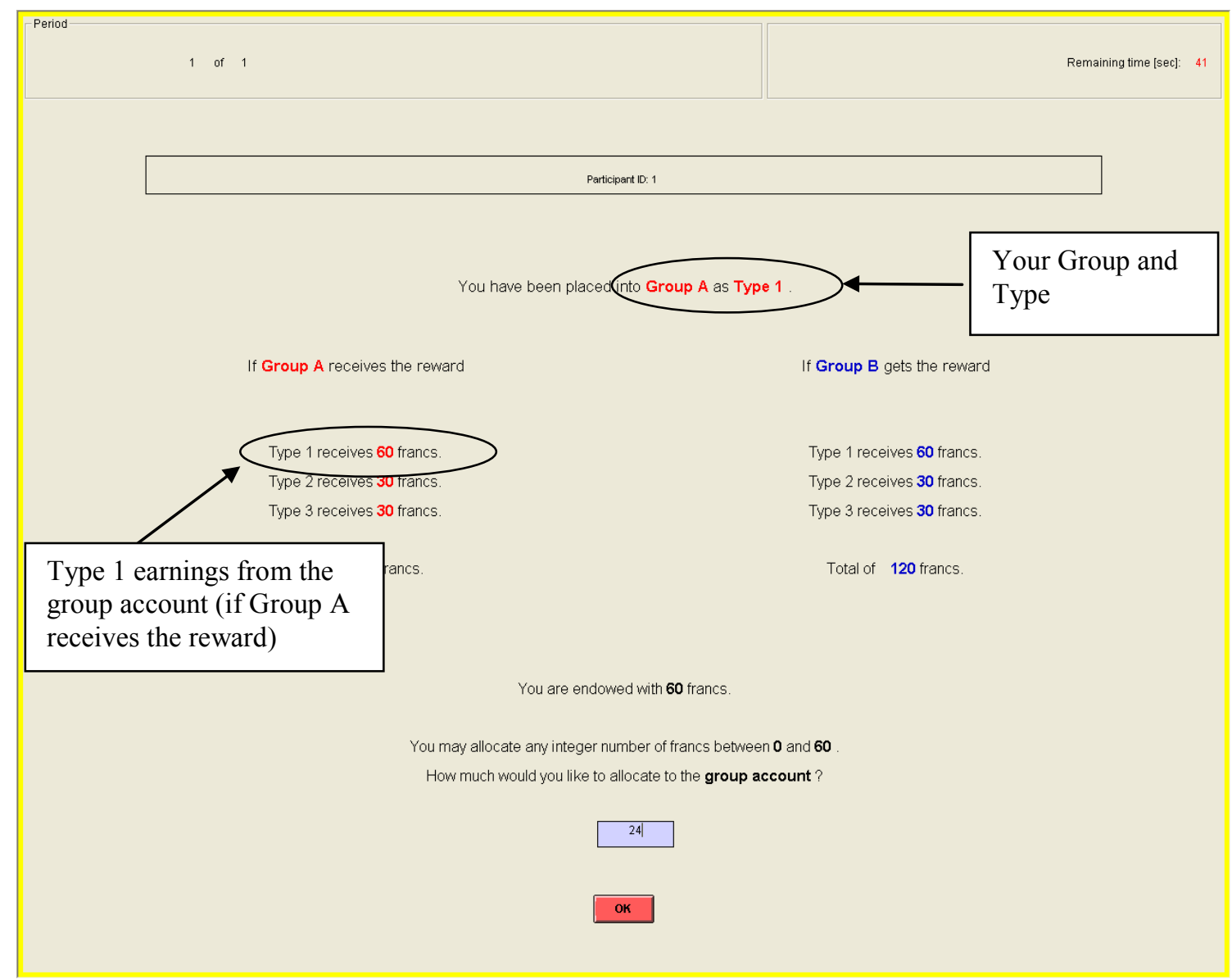

At the beginning of each period you will see which group and what type you are assigned to (as shown at the top of the screen). You will also see the composition of both group A and group B, thus you will know the types of participants in both groups (as shown on the right and left columns of the screen).

\section{YOUR EARNINGS}

After all participants have made their decisions, your earnings for the period are calculated. These earnings will be converted to cash and paid at the end of the experiment if the current period is one of the five periods that is randomly chosen for payment. 
1) Your period earnings are the sum of the earnings from your individual account and the earnings from your group account.

2) For each franc in your individual account, you will earn 1 franc in return. So, if you keep all 60 francs that you are endowed with to your individual account you will earn 60 francs. But you can also earn some francs from your group account.

3) By contributing to the group account you are increasing the chance of receiving the reward for your group. If the total number of francs in your group account exceeds the total number of francs in the other group account, your group has higher chance of receiving the reward. If your group receives the reward then in addition to the earnings from your individual account you receive the reward from your group account which is determined by your type. A group can never guarantee itself the reward. However, by increasing your contribution, you can increase your group's chance of receiving the reward.

4) The computer will assign the reward either to your group or to the other group, via a random draw. So, in each period, only one of the two groups can obtain the reward.

\section{Example 1. Random Draw}

This is a hypothetical example used to illustrate how the computer is making a random draw. Think of the random draw in the following way. For each franc in group A's account the computer puts 1 red token into a bingo cage and for each franc in group B's account the computer puts 1 blue token. Then the computer randomly draws one token out of the bingo cage. If the drawn token is red group A receives the reward, if the 
token is blue group B receives the reward. Assume that members of both group A and B have allocated their francs in the following way (as shown on the Table 1 below).

Table 1 - Allocation of francs by all types in group A and B

\begin{tabular}{|l|c|c|c|}
\hline $\begin{array}{c}\text { Group } \\
\text { A }\end{array}$ & $\begin{array}{c}\text { If Group } \\
\text { A } \\
\text { receives } \\
\text { reward }\end{array}$ & $\begin{array}{c}\text { Allocation } \\
\text { to the } \\
\text { individual } \\
\text { account }\end{array}$ & $\begin{array}{c}\text { Allocation } \\
\text { to the } \\
\text { group } \\
\text { account }\end{array}$ \\
\hline Type 1 & 60 & 40 & 20 \\
Type 2 & 30 & 45 & 15 \\
Type 3 & 30 & 50 & 10 \\
\hline Total & 120 & 135 & 45 \\
\hline
\end{tabular}

\begin{tabular}{|l|c|c|c|}
\hline $\begin{array}{c}\text { Group } \\
\text { B }\end{array}$ & $\begin{array}{c}\text { If Group } \\
\text { B } \\
\text { receives } \\
\text { reward }\end{array}$ & $\begin{array}{c}\text { Allocation } \\
\text { to the } \\
\text { individual } \\
\text { account }\end{array}$ & $\begin{array}{c}\text { Allocation } \\
\text { to the } \\
\text { group } \\
\text { account }\end{array}$ \\
\hline Type 1 & 60 & 50 & 10 \\
Type 2 & 30 & 60 & 0 \\
Type 3 & 30 & 55 & 5 \\
\hline Total & 120 & 165 & 15 \\
\hline
\end{tabular}

Group A members have allocated total of 45 francs to the group account while group B members only 15 francs. Thus, the computer will place 45 red tokens and 15 blue tokens into the bingo cage (60 tokens total). Then the compute will randomly draw one token out of the bingo cage. You can see that since group A has contributed more it has higher chance of receiving the reward (45 out of 60 times group A will receive the reward). Group B has lower chance of receiving the reward (15 out of 60 times group B will receive the reward).

5) After all contributions are made, the computer makes a random draw. Each member of the group that receives the reward will receive the reward according to his or her type. Not all types receive the same reward. For example, if you are type 1 in group A and your group received the reward, you earn 60 francs from group account. As mentioned earlier, at each period your group as well as your type will be changed. Sometimes you will be a member of group A, sometimes a member of group B. Sometimes you will be type 1, sometimes type 2 or 3 . 


\section{Example 2. Total Earnings}

This example illustrates the calculation of earnings. In Example 1, group A had 45 francs while group B had 15 francs in the group account. Let's say the computer made a random draw and group A received the reward. Thus, all the members of group A receive the reward according to their types from the group account plus they also receive earnings from the individual account. All members of group B receive earnings only from the individual account, since group B did not receive the reward. The calculation of the total earnings is shown in Table 2 below.

Table 2 - Calculation of earning for all types in group A and B

\begin{tabular}{|l|c|c|c|}
\hline $\begin{array}{c}\text { Group } \\
\text { A }\end{array}$ & $\begin{array}{c}\text { Earnings } \\
\text { from } \\
\text { group } \\
\text { account }\end{array}$ & $\begin{array}{c}\text { Earnings } \\
\text { from } \\
\text { individual } \\
\text { account }\end{array}$ & $\begin{array}{c}\text { Total } \\
\text { earnings }\end{array}$ \\
\hline Type 1 & 60 & 40 & $60+40=100$ \\
Type 2 & 30 & 45 & $30+45=75$ \\
Type 3 & 30 & 50 & $30+50=80$ \\
\hline Total & 120 & 135 & 255 \\
\hline
\end{tabular}

\begin{tabular}{|l|c|c|c|}
\hline $\begin{array}{c}\text { Group } \\
\text { B }\end{array}$ & $\begin{array}{c}\text { Earnings } \\
\text { from } \\
\text { group } \\
\text { account }\end{array}$ & $\begin{array}{c}\text { Earnings } \\
\text { from } \\
\text { individual } \\
\text { account }\end{array}$ & $\begin{array}{c}\text { Total } \\
\text { earnings }\end{array}$ \\
\hline Type 1 & 0 & 50 & 50 \\
Type 2 & 0 & 60 & 60 \\
Type 3 & 0 & 55 & 55 \\
\hline Total & 0 & 165 & 165 \\
\hline
\end{tabular}

At the end of each period, the total number of francs in the two groups' accounts, group which received the reward, earnings from individual and group accounts, and total earnings for the period are reported on the outcome screen as shown below. Please record your results for the period on your record sheet under the appropriate heading. 


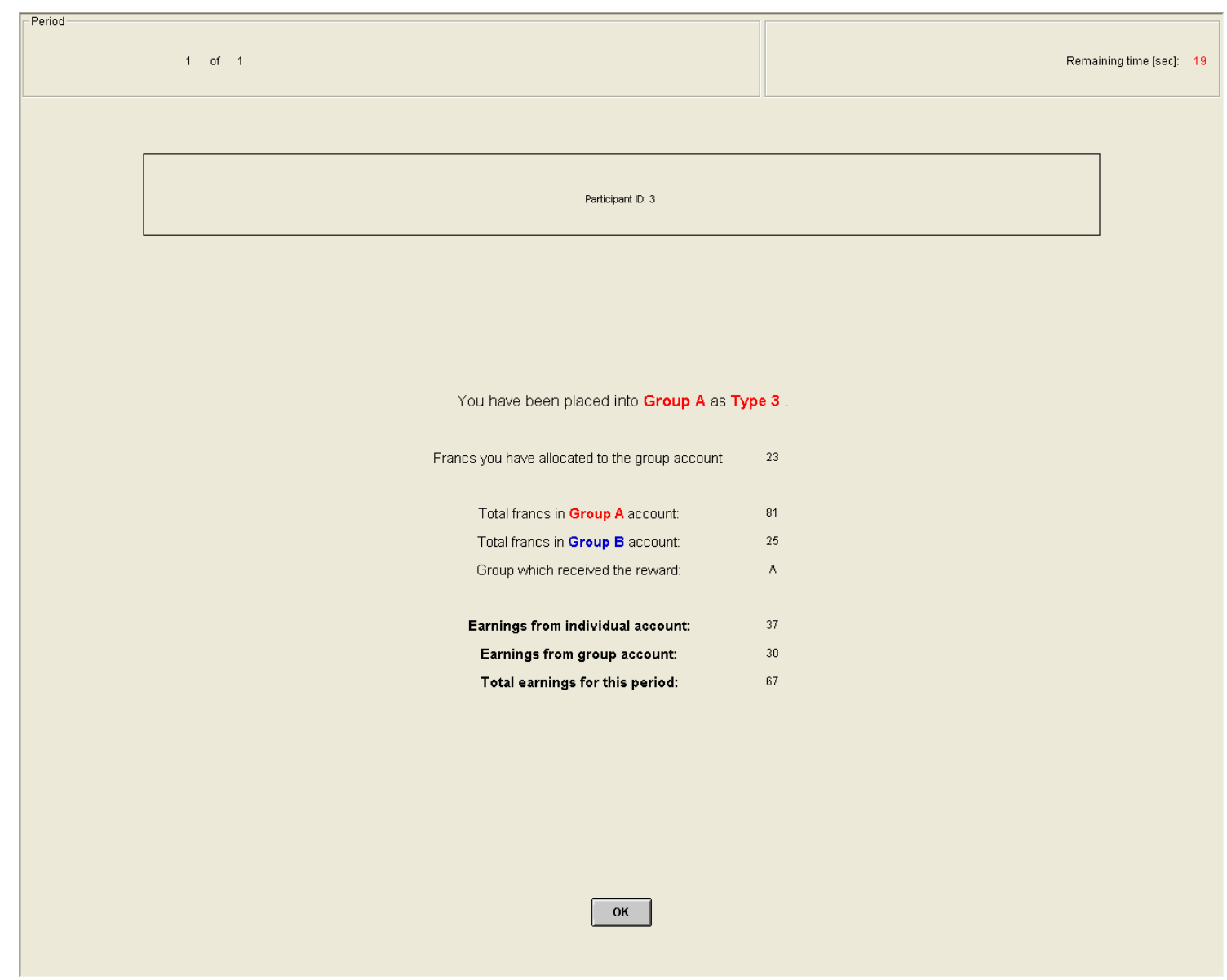

\section{IMPORTANT NOTES}

You will not be told which of the participants in this room are assigned to which group and to which type. At the beginning of each period your group as well as your type will be randomly changed. A group can never guarantee itself the reward. However, by increasing your contribution, you can increase your group's chance of receiving the reward.

At the end of the experiment we will randomly choose 5 of the 30 periods for actual payment in Part 2 using a bingo cage. You will sum the total earnings for these 5 periods and convert them to a U.S. dollar payment.

Are there any questions? 


\section{INSTRUCTIONS FOR PART 3}

The third part of the experiment consists of 30 decision-making periods. The rules for part 3 are exactly the same as the rules for part 2 . The only difference is that in part 3 the rewards for different types in group A and B are different than in part 2:

\begin{tabular}{|l|c|}
\hline \multicolumn{1}{|c|}{ Group A } & Reward \\
\hline Type 1 & 90 \\
Type 2 & 15 \\
Type 3 & 15 \\
\hline Total & 120 \\
\hline
\end{tabular}

\begin{tabular}{|l|c|}
\hline \multicolumn{1}{|c|}{ Group B } & Reward \\
\hline Type 1 & 60 \\
Type 2 & 30 \\
Type 3 & 30 \\
\hline Total & 120 \\
\hline
\end{tabular}

\section{IMPORTANT NOTES}

You will not be told which of the participants in this room are assigned to which group and to which type. At the beginning of each period your group as well as your type will be randomly changed. A group can never guarantee itself the reward. However, by increasing your contribution, you can increase your group's chance of receiving the reward.

At the end of the experiment we will randomly choose 5 of the 30 periods for actual payment in Part 3 using a bingo cage. You will sum the total earnings for these 5 periods and convert them to a U.S. dollar payment.

Are there any questions? 
VITA 
VITA

\title{
ROMAN M. SHEREMETA
}

\author{
ADDRESS \\ Department of Economics \\ Office: (765) 496-3508 \\ Krannert School of Management \\ Cell: (765) 418-7175 \\ Purdue University, KRAN 713 \\ Fax: (765) 494-9658 \\ 403 West State Street \\ West Lafayette, IN 47907-2056 \\ rshereme@purdue.edu \\ http://web.ics.purdue.edu/ rshereme
}

\section{EDUCATION}

Ph.D., Economics, Purdue University, Krannert School of Management

August 2009

M.S., Economics, Purdue University, Krannert School of Management

May 2006

L.B., Civil Law, Precarpathian National University, Ukraine

June 2004

B.A., Economics, National Technical University, Ukraine

June 2003

\section{TEACHING EXPERIENCE}

Principles of Economics, Microeconomics, Behavioral Economics, Game Theory

\section{ACADEMIC GRANTS}

National Science Foundation Doctoral Dissertation Grant, \$10,432

2008-2010

PGSG Travel Grant, Purdue University

Fall 2008

Purdue Research Foundation Research Grant, \$17,280

2007-2008

CIBER Travel Grant, Purdue University

Fall 2004

\section{ACHIEVEMENTS AND HONORS}

Associate Fellow of the Purdue University Teaching Academy

Dean's Office Doctoral Student Service Award

Purdue University Graduate Student Award for Outstanding Teaching

Robert W. Johnson Award for Distinguished Research Proposal

Center for Instructional Excellence Graduate Teacher Certificate

Krannert School of Management Award for Distinguished Teaching

Spring 2009

Fall 2008

Krannert School of Management Recognition for Teaching Excellence

Spring 2008

Spring 2008

Spring 2008

2006, 2007

2004, 2006 


\section{CHAPTERS IN BOOKS}

"Designing the Optimal Housing Market in Ivano-Frankivsk" (joint with Mykola Danylyuk), in I.G. Tkachyk (Ed.), Problems of Regional Economic Development (2007), (Ivano-Frankivsk, Ukraine: Precarpathian Press), pp. 197-207.

\section{WORKING PAPERS}

"A Generalized Tullock Contest and the Existence of Multiple Equilibria," with Subhasish Chowdhury.

"A Laboratory Study of a Multi-Level Trust Game with Communication," with Jingiing Zhang.

"An Experimental Investigation of Colonel Blotto Games," with Subhasish Chowdhury and Dan Kovenock.

"Can Groups Solve the Problem of Over-Bidding in Contests?" with Jingiing Zhang.

"Contest Design: An Experimental Investigation."

"Contests with Random Noise and a Shared Prize," with Tim Cason and William

Masters.

"Cooperation Spillovers in Coordination Games," with Tim Cason and Anya Savikhin.

"Endowment Effects in Contests," with Curtis R. Price.

"Entry into Winner-Take-All and Proportional-Prize Contests: An Experimental Study," with Tim Cason and William Masters.

"Expenditures and Information Disclosure in Two-Stage Political Contests."

"Experimental Comparison of Multi-Stage and One-Stage Contests."

"Perfect-Substitutes, Best-Shot, and Weakest-Link Contests between Groups."

"Reducing Efficiency through Communication in Competitive Coordination Games," with Tim Cason and Jingjing Zhang.

\section{CONFERENCES \& PRESENTATIONS}

International ESA Conference, Washington, D.C.

June, 2009

Midwest Economic Theory Conference, Iowa City, IA

May, 2009

MPSA Annual Conference, Chicago, IL

April 2009

International Industrial Organization Conference, Boston, MA

Economics Seminar, Maastricht University, Maastricht, Netherlands

April 2009

Economics Seminar, Copenhagen Business School, Copenhagen,

Denmark

Research Seminar, University of Michigan, Ann Arbor, MI

Economics Seminar, University of Arkansas, Fayetteville, AR

Research Seminar, University of Massachusetts, Amherst, MA

Economics Seminar, Chapman University, Orange, CA

North American ESA Conference, Tucson, AZ

Economics Workshop, Purdue University, West Lafayette, IN

Conference on Advances in the Theory of Contests and its

Applications, Venice International University, Venice, Italy

(Discussant)

International ESA Conference, California Institute of Technology,

Pasadena, CA

February 2009

February 2009

January 2009

January 2009

January 2009

January 2009

November 2008

September 2008

July 2008

June 2008 
Economics Workshop, Purdue University, West Lafayette, IN

April 2008

Economics Workshop, Purdue University, West Lafayette, IN

November 2007

Teaching and Learning with Technology 10th Annual Conference,

April 2007

Purdue University, West Lafayette, IN

International Foundation for Research in Experimental Economics

Summer 2006

Workshop in Experimental Economics, George Mason University,

Arlington, VA

PROFESSIONAL AFFILIATIONS AND ACTIVITIES

American Economic Association

Economic Science Association

Royal Economic Society

Vernon Smith Experimental Economics Laboratory

Referee for Economic Inquiry, Experimental Economics

VOLUNTEER SERVICE

President of Krannert Doctoral Student Association

$2008-2009$

Vice President of Krannert Doctoral Student Association

$2007-2008$

Peer Evaluator for New Graduate Student Teachers

$2007-2009$

Senator for Economics at Purdue Graduate Student Government

$2006-2007$

Member of the Graduate Student Libraries' Advisory Council

$2006-2009$

LANGUAGES

English (fluent), Ukrainian (native), Russian (native), German (basic)

COMPUTER SKILLS

Stata, E-Views, Gauss, Ox, z-Tree, Mathematica

REFERENCES

Tim Cason (Dissertation Chair)

Professor of Economics

Purdue University

Phone: (765) 494-1737

E-mail: cason@purdue.edu

Dan Kovenock

Henry B. Tippie Research

Professor of Economics

University of Iowa

Phone: (319) 335-1810

E-mail: dan-kovenock@uiowa.edu
Jason Abrevaya

Fred Hofheinz Regents

Professor in Economics

The University of Texas at Austin

Phone: (512) 475-8527

E-mail: abrevaya@eco.utexas.edu

Marco Casari

Associate Professor of Economics

University of Bologna, Italy

Phone: +39 (051) 209-8662

E-mail: marco.casari@unibo.it 